\title{
Paralelização da transformada de Hough
}

\author{
Christian Cesar Bones
}

Orientador: Prof. Dr. Odemir Martinez, Bruno

Dissertação apresentada ao Instituto de Ciências Matemáticas e de Computação - ICMC-USP, como parte dos requisitos para obtenção do título de Mestre em Ciência da Computação.

\section{"VERSÃO REVISADA APÓS A DEFESA"}

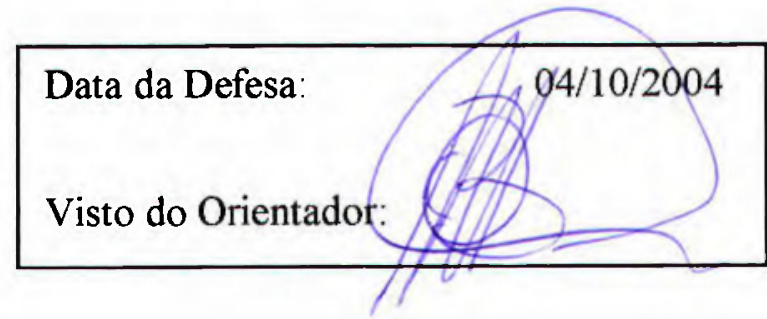

USP - São Carlos

Outubro/2004 


\section{Dedicatória}

Dedico este trabalho aos meus Pais, Ademar e Eli.

A minha eterna namorada Lia.

Aos meus irmãos queridos, Márcio e Paulo. 


\section{Agradecimentos}

Agradeço a Deus por todas as oportunidades de aprendizado e evolução.

Ao meu orientador o prof. Odemir, por toda a ajuda e por acreditar no meu potencial. Ao meu amigo Julio, pelas colaborações, pelas ajudas e pelas trocas de idéias.

Ao Cybernetic Vision Research Group do departamento de Física de São Carlos, por permitirem o uso de seus equipamentos.

Ao prof: Marcos Santana e a prof. Regina Santana, por todos os auxílios e por permitir/facilitar as trocas de idéias com os integrantes do seu grupo.

A todos os meus amigos que de alguma maneira contribuíram comigo.

A todos os funcionários do ICMC, pela presteza de seus trabalhos.

A minha cunhada, Maysa, pelo carinho.

A minha sogra por toda a ajuda e carinho.

Ao meu sogro, minha cunhada e família e ao meu cunhado e sua família, por todos os almoços e churrascos compartilhados.

Aos meus tios e tias por todo o carinho e apoio recebidos.

Ao $\mathrm{CNPq}$ pelo apoio financeiro. 


\section{Epígrafe}

"... Olhos abertos, o longe é perto, o que vale é o sonho..."

Trecho da música desgarrados - Sérgio Napp e Mário Barbará 


\section{SUMÁRIO}

Introdução ................................................................................................................................. 1

2 Computação Paralela e Computação Concorrente ……………………………...............3

2.1 Vantagens e desvantagens dos sistemas paralelos ............................ 4

2.2 Conceitos básicos de computação paralela ........................................... 5

2.2.1 Tipos de paralelismo ……....................................................

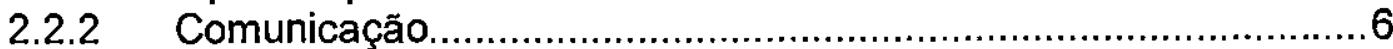

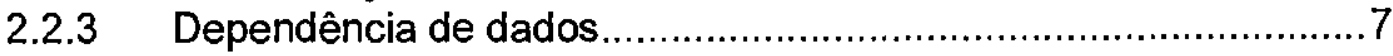

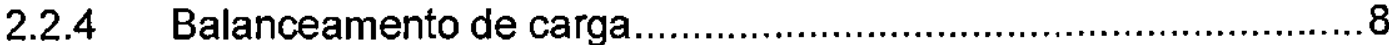

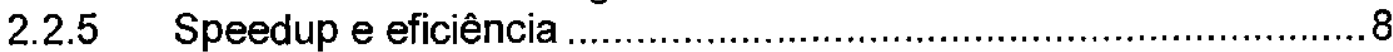

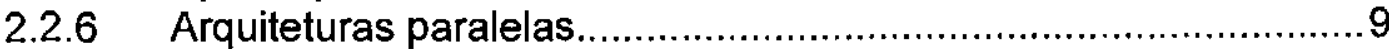

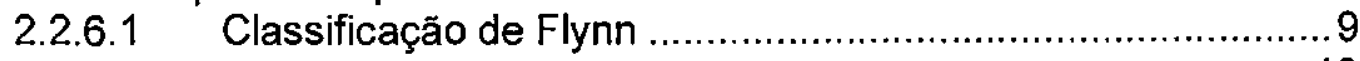

2.2.6.2 Classificação de Duncan ..................................................12

2.3 Computação distribuída ................................................................. 15

2.3.1 Desenvolvimento de programas paralelos .............................. 16

2.3.1.1 Linguagens de programação............................................16

2.3.1.2 Estratégias de paralelismo ............................................... 18

2.3.1.3 Mecanismos para exploração de paralelismo ......................20

2.4 Ferramentas de auxílio à programação paralela...................................22

2.4.1 Ferramentas de programação paralela em memória

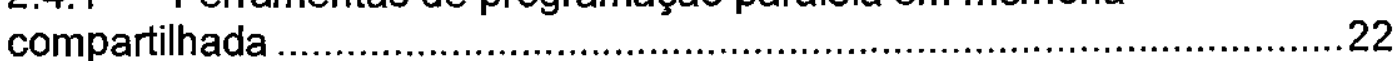

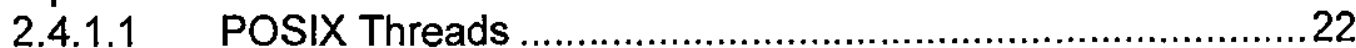

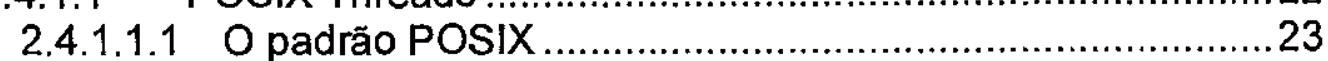

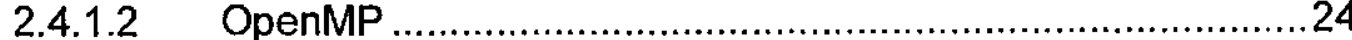

2.4.1.2.1 Compilador OpenMP...............................................24

2.4.1.2.2 Modelo de execução e programaçäo .................................24

2.4.2 Massage Passing Interface ...................................................25

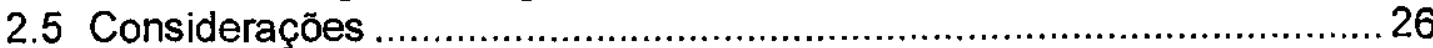

3 Transformada de Hough................................................................................................28

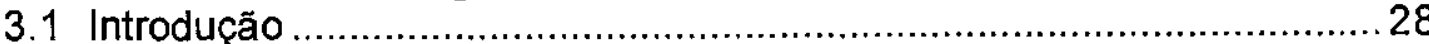

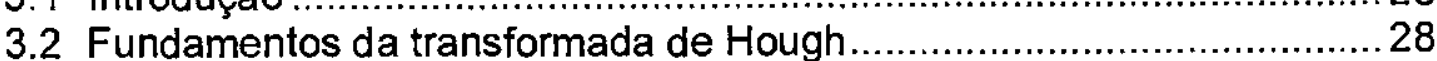

3.3 Transformada de Hough para retas ................................................... 30

3.3.1 Algoritmo da transformada de Hough para retas..........................35

3.4 Transformada de Hough para objetos circulares ...................................36

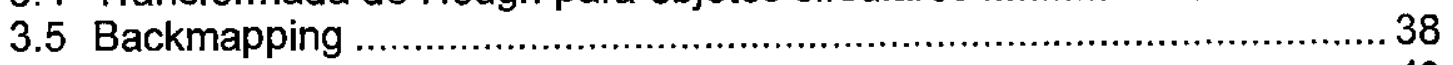

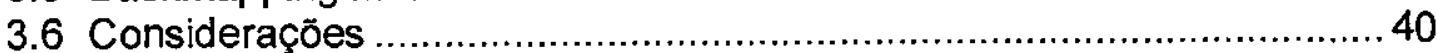




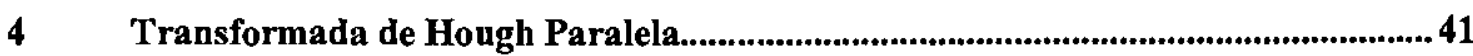

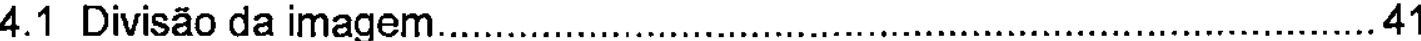

4.2 Distribuição do arranjo acumulador .........................................4 47

4.3 Broadcasting da imagem......................................................... 51

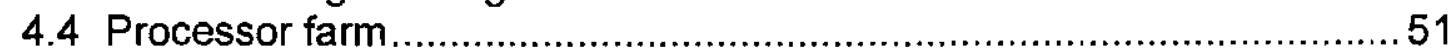

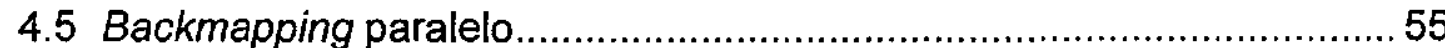

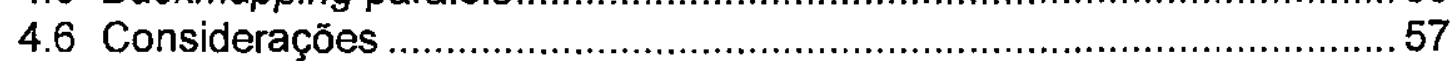

$5 \quad$ Implementaçôes e resultados .......................................................................................59

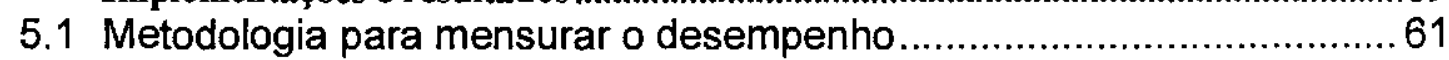

5.2 Experimentos para MIMD memória compartilhada .............................6. 62

5.2.1 Considerações sobre desempenho em MIMD compartilhada ......72

5.3 Experimentos MIMD memória distribuída. ...................................... 75

5.3.1 Considerações sobre os resultados MIMD com memória

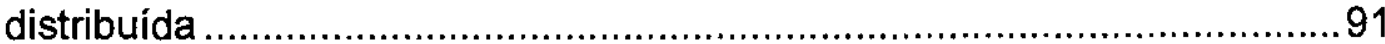

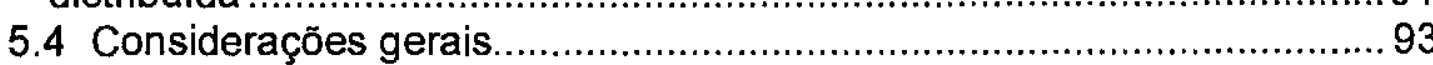

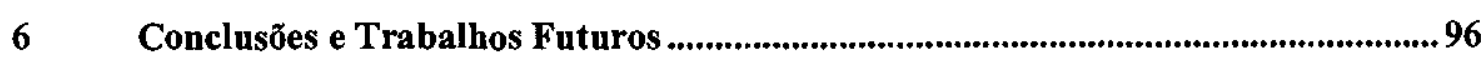

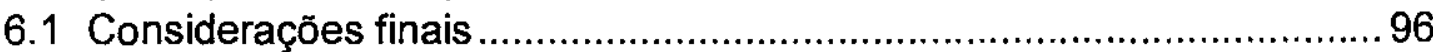

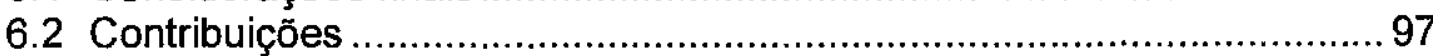

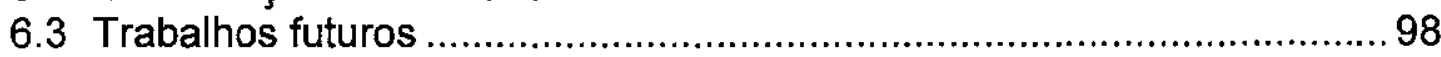

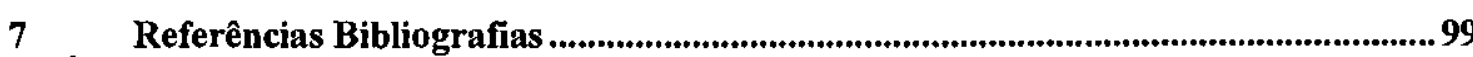

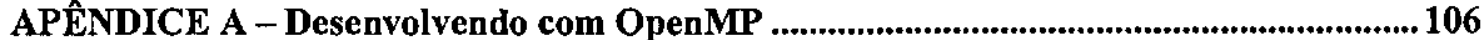

APENDICE B - Desenvolvendo com Pthreads...................................................................112

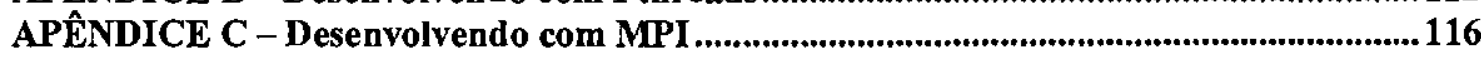




\section{Lista de Figuras}

Figura 2.1 Dependência de dados............................................................................................................7

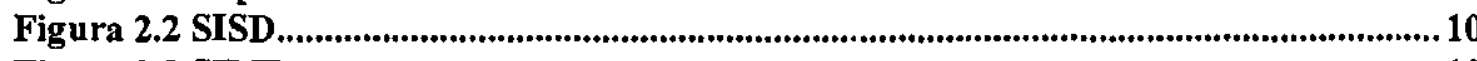

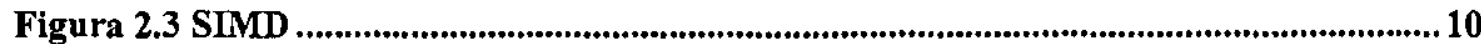

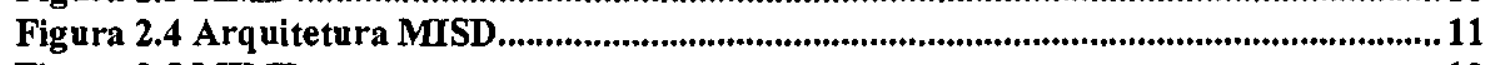

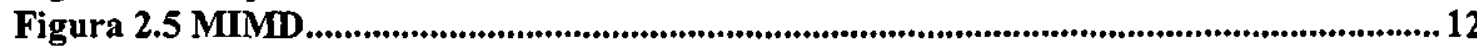

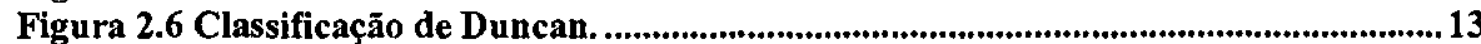

Figura 2.7 Arquitetura MIMD - (a) memória distribuída, (b) Memória compartilhada... 15

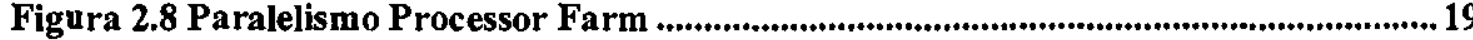

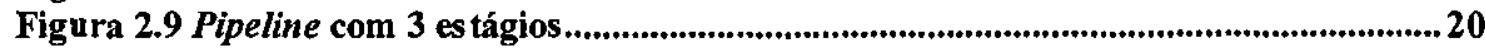

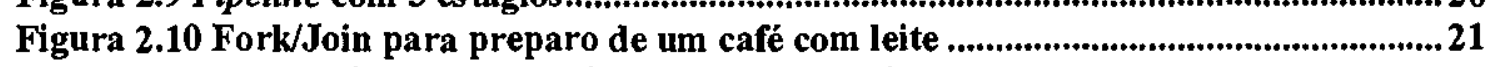

Figura 2.11 Modelo de exploração de paralelismo do OpenMP............................................25

Figura 3.1 (a) Espaço Imagem, (b) Espaço de parâmetros .....................................................29

Figura 3.2 Coordenadas Polares. ........................................................................................... 30

Figura 3.3 (a) pontos no espaço imagem, (b) mapeamento dos pontos no espaço $(\rho, \theta)$, (c) deteç̧ão das propriedades de colinearidade em (d) tem-se a propriedade de reflexão.

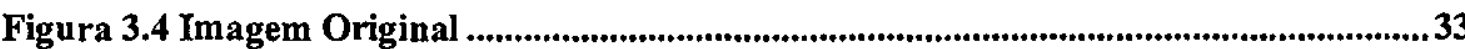

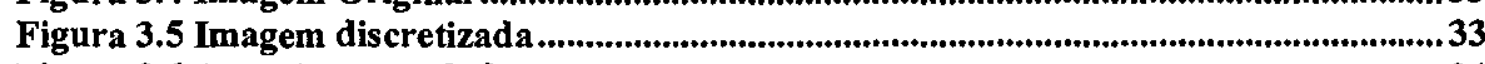

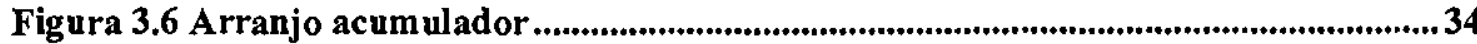

Figura 3.7 Transformada de Hough ..................................................................................35

Figura 3.8 Imagem de uma circunferência, ilustrando os pixels no plano x,y.....................37

Figura 3.9 espaço de parâmetros " $a$ " $e$ "b" para circunferências...........................................38

Figura 3.10 Hough com Backmapping ...................................................................................39

Figura 4.1 Divisão da imagem em 6 pedaços iguais............................................................4 42

Figura 4.2 Envio Estratégia de paralelismo para a transformada de Hough. As etapas (a), (b), (c), (d), (e) e (f) representam respectivamente: a imagem original, divisão da imagem e sua distribuição, processamento de cada fragmento da imagem, arranjos acumulador resultante do processamento de cada fragmento, somatório dos elementos dos arranjos acumulador e arranjo acumulador resultante. .......................42

Figura 4.3 Diagrama de estados da TH, estratégia divisão da imagem para as ferramentas OpenMP e Pthreads.

Figura 4.4. Diagrama de estados da TH, estratégia divisão da imagem com MPI................ 46 Figura 4.5 estratégia de paralelismo da distribuição do arranjo acumulador, onde em (a) tem-se a imagem original, em (b) é realizada a divisão do arranjo acumulador, em (c) é realizado o processamento para toda a imagem na porção do arranjo acumulador que couber ao escravo, em (d) é cada arranjo acumulador resultante, em (e) é realizada a união dos arranjos acumuladores e na imagem (f) é o arranjo acumulador total resultante.. 47

Figura 4.6. Diagrama de estados da TH, estratégia divisão do acumulador utilizando as ferramentas OpenMP e Pthreads.

Figura 4.7. Diagrama de estados da TH para a estratégia de divisão do acumulador utilizando MPI. 
Figura 4.8 Estratégia de paralelismo da distribuição do arranjo acumulador, onde em (a) tem-se a imagem original, em (b) é realizada a divisão do arranjo acumulador e o envio juntamente com a imagem a cada elemento de processamento escravo para ser realizado o processamento, em (c) é realizado o processamento para toda a imagem na porção do arranjo acumulador que couber ao escravo, em (d) é cada arranjo acumulador resultante, em (e) é realizada a união dos arranjos acumuladores e na imagem (f) é o arranjo acumulador total resultante.......................................................51

Figura 4.9. Diagrama de estados da TH para a estratégia processor farm combinado com a divisão do acumulador utilizando MPI.

Figura 4.10 Diagrama de estados da TH para a estratégia processor farm combinado com a divisão da imagem utilizando MPI........................................................................54

Figura 4.11 Diagrama de estados do backmapping para divisão da imagem com OpenMP.

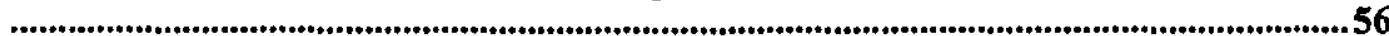

Figura 4.12 Diagrama de estados do backmapping para divisão da imagem com MPI......57

Figura 5.1 (a) retas horizontais, (b) retas mistas ........................................................................59

Figura 5.2 Imagem do canal da Piracema ...........................................................................60

Figura 5.3 conceito de broadcast.........................................................................................60

Figura 5.4 Estratégia de paralelismo da distribuição do arranjo acumulador com compactação da imagem para as implementações com MPI, onde em (a) tem-se a imagem original, em (b) é realizada a compactação da imagem e a divisão do arranjo acumulador e o envio a cada elemento de processamento escravo para ser realizado o processamento, em (c) é realizado o processamento para toda a imagem na porção do arranjo acumulador que couber ao escravo, em (d) têm-se cada arranjo acumulador resultante, sua compactação e o envio para o servidor, em (e) é realizada a união dos arranjos acumuladores e (f) é 0 arranjo acumulador total resultante.........................61

Figura 5.5 Speedup da implementação da TH com divisão do arranjo acumulador para retas horizontais.

Figura 5.6 Speedup da implementação da TH com divisão do arranjo acumulador para

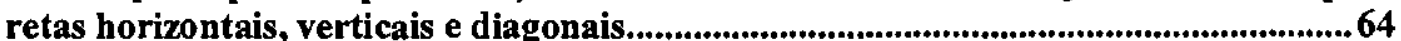

Figura 5.7 Speedup da implementação da TH com divisão do arranjo acumulador para uma imagem real....................................................................................................65

Figura 5.8 Speedup da implementação da TH com divisão da imagem para retas

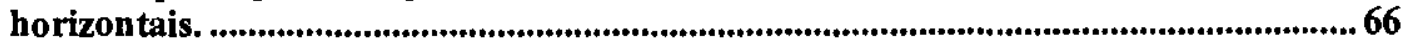

Figura 5.9 Speedup da implementação da TH com divisão da imagem para retas

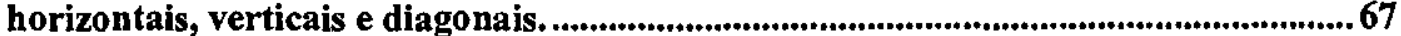

Figura 5.10 Speedup da implementação da TH com divisão da imagem para uma imagem real.

Figura 5.11 Speedup da implementaçăo da TH utilizando BackMapping para as imagens com retas horizontais.

Figura 5.12 Speedup da implementação da TH utilizando BackMapping para a imagem com retas mistas.

71

Figura 5.13 Speedup da implementação da TH utilizando Backmapping para a imagem do

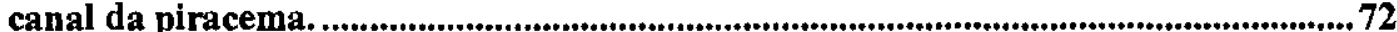

Figura 5.14 Comparativo entre as estratégia e ferramentas, para MIMD compartilhada, sobre a imagem real e de tamanho maior..............................................................73

Figura 5.15 Comparativo entre as estratégia e ferramentas, para MIMD compartilhada, sobre a imagem real e de tamanho intermediário.

Figura 5.16 Comparativo entre as estratégia e ferramentas, para MIMD compartilhada,

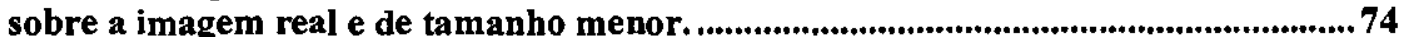

Figura 5.17 Speedup, obtido em cluster, da implementação da TH com divisão do arranjo acumulador para imagem horizontal.............................................................................75

Figura 5.18 Speedup, obtido em cluster, da implementação da TH com divisão da imagem para imagem horixontal.

Figura 5.19 Speedup, obtido em cluster, da implementação da TH com Backmapping para imagem horizontal. 
Figura 5.20 - Gráfico de processamento para seis (a) e (b) sete processadores.................... 78

Figura 5.21 Speedup, obtido em cluster, da implementação da TH com divisão do arranjo acumulador para imagem mista......................................................................................79

Figura 5.22 Speedup, obtido em cluster, da implementação da TH com divisão da imagem

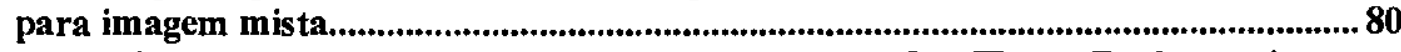

Figura 5.23 Speedup, obtido em cluster, da implementação da TH com Backmapping para imagem mista.

Figura 5.24 Speedup, obtido em cluster, da implementação da TH com divisão do arranjo acumulador para imagem do canal da piracema.............................................................82

Figura 5.25 Speedup, obtido em cluster, da implementação da TH com divisão da imagem para imagem do canal da piracema. ...................................................................................8 83

Figura 5.26 Speedup obtido em cluster da implementação da TH com Backmapping para imagem do canal da piracema. .............................................................................................8 84

Figura 5.27 Speedup obtido em cluster da implementação da TH com processor farm e divisão do arranjo acumulador para imagens com retas horizontais............................86

Figura 5.28 Speedup obtido em cluster da implementação da TH com processor farm e divisão do arranjo acumulador para imagens com retas mistas. ...................................8 87

Figura 5.29 Speedup obtido em cluster da implementação da TH com processor farm e divisão do arranjo acumulador para as imagens reais...................................................88

Figura 5.30 Speedup obtido em cluster da implementação da TH com processor farm e divisão da imagem para as imagens com retas horizontais............................................89

Figura 5.31 Speedup obtido em cluster da implementação da TH com processor farm e divisão da imagem para as imagens com retas mistas...................................................90

Figura 5.32 Speedup obtido em cluster da implementação da TH com processor farm e divisão da imagem para as imagens reais.

Figura 5.33 comparativo dos resultados, alcançados sobre a imagem real de tamanho maior, para todas as estratégias implementadas para a arquitetura MIMI

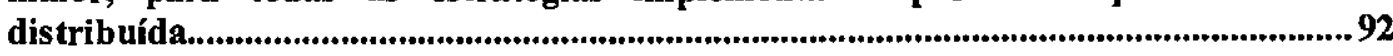

Figura 5.34 comparativo dos resultados, alcançados sobre a imagem real de tamanho maior, para todas as estratégias implementadas para a arquitetura MIMD distribuída.......................................................................................................................92 92

Figura 5.35 comparativo dos resultados, alcançados sobre a imagem real de tamanho maior, para todas as estratégias implementadas para a arquitetura MIMD distribuída. 


\section{Lista de Tabelas}

Tabela 3.1 Efeito da TH sobre uma linha reta 29

Tabela 5.1 Resultados obtidos para a imagem horizontal, com seus respectivos desvios padrões e utilizando a estratégia de divisão do acumulador..............................................63

Tabela 5.2 Resultados obtidos para as imagens com retas mistas e seus respectivos desvios padrões, utilizando a estratégia de divisão do acumulador. ............................................64

Tabela 5.3 Resultados obtidos para a imagem real, com seus respectivos desvios padrōes, utilizando a estratégia de divisão do acumulador.............................................................65

Tabela 5.4 Resultados obtidos para a imagem horizontal, com seus respectivos desvios padrões, utilizando a estratégia de divisão da imagem..................................................66

Tabela 5.5 Resultados obtidos para as imagens mistas, com seus respectivos desvios padrões, utilizando a estratégia de divisão da imagem....................................................67

Tabela 5.6 Resultados obtidos para a imagem real, com seus respectivos desvios padrōes, utilizando a estratégia de divisão da imagem.

Tabela 5.7 Resultados obtidos para a imagem horizontal, com seus respectivos desvios padrões, utilizando a estratégia backmapping.

Tabela 5.8 Resultados obtidos para a imagem mista, com seus respectivos desvios padrões, utilizando a estratégia backmapping.

Tabela 5.9 Resultados obtidos para a imagem real, com seus respectivos desvios padrões, utilizando a estratégia backmapping..

abela 5.10 Melhores resultados obtidos pela estratégia de divisão do acumulador processando sobre retas horizontais.............................................................................75

Tabela 5.11 Melhores resultados obtidos pela estratégia de divisão da imagem processando sobre retas horizontais.....................................................................................76

Tabela 5.12 Melhores resultados obtidos pela estratégia de backmapping processando

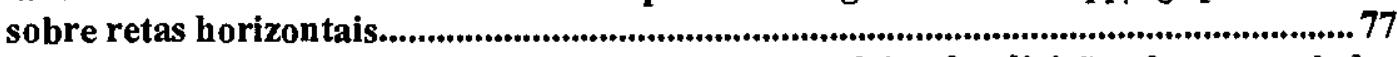

Tabela 5.13 Melhores resultados obtidos pela estratégia de divisão do acumulador processando sobre retas mistas.

.79

Tabela 5.14 Melhores resultad os obtidos pela estratégia de divisão da imagem processando sobre retas mistas...........................................................................................................80

Tabela 5.15 Melhores resultados obtidos pela estratégia backmapping processando sobre retas mistas.

.80

Tabela 5.16 Melhores resultados obtidos pela estratégia de divisão do acumulador processando sobre as imagens reais. ..................................................................................81

Tabela 5.17 Melhores resultados obtidos pela estratégia de divisão da imagem processando sobre a imagem real.......................................................................................................82

Tabela 5.18 Melhores resultados obtidos pela estratégia backmapping processando sobre as imagens reais.

Tabela 5.19 Melhores resultados obtidos pela estratégia processor farm em união com a estratégia de divisão do acumulador processando sobre retas horizontais. .................85

Tabela 5.20 Melhores resultados obtidos pela estratégia processor farm em união com a estratégia de divisão do acumulador processando sobre retas mistas. ...........................86 
Tabela 5.21 Melhores resultados obtidos pela estratégia processor farm em união com a estra tégia de divisão do acumulador processando sobre imagens reais.........................8 87

Tabela 5.22 Melhores resultados obtidos pela estratégia processor farm em união com a estratégia de divisão da imagem processando sobre retas horizontais. .......................... 88

Tabela 5.23 Melhores resultados obtidos pela estratégia processor farm em união com a estratégia de divisão da imagem processando sobre retas mistas...................................89

Tabela 5.24 Melhores resultados obtidos pela estratégia processor farm em união com a estratégia de divisão da imagem processando sobre as imagens reais. ..........................90 


\section{Resumo}

Este trabalho tem o objetivo de paralelizar a transformada de Hough, de modo a diminuir o tempo de execução. A transformada de Hough é um método que realiza o reconhecimento de curvas paramétricas em imagens, sendo sua mais conhecida utilização o reconhecimento de retas. Neste trabalho são consideradas algumas das estratégias de paralelização da transformada de Hough, encontradas na literatura. Estas estratégias são implementadas para as arquiteturas MIMD de memória distribuída e MIMD de memória compartilhada, utilizando as ferramentas de desenvolvimento de programas paralelos OpenMP, Pthreads e MPI. Deste modo, são analisados e comparados os algoritmos e estratégias de paralelismo da transformada de Hough sobre às arquiteturas MIMD compartilhada e MIMD distribuída. Através dos resultados e análises obtidos pelo trabalho, é possível, além de uma melhor compreensão da transformada de Hough paralela, definir as combinações entre estratégias, ferramentas e arquiteturas, que apresentam o menor tempo de execução. 


\begin{abstract}
This work has the objective of parallelizing the Hough transform, in order to reduce its execution time. Hough transform is a method that carries through the recognition of parametric curves in images, being the recognition of straight lines its most known use. This work considers some of the parallel Hough transform strategies found in literature. These strategies are implemented for MIMD architectures with distributed memory and MIMD with shared memory, using parallel programs development tools, such as OpenMP, Pthreads and MPI. In this way, the Hough transform parallelism algorithms and strategies are analyzed and compared over shared MIMD and distributed MIMD architectures. Through the results and analysis obtained from the work, it is possible, besides a better understanding of the parallel Hough transform, to define the combinations between strategies, tools and architectures, which present the smaller execution time.
\end{abstract}




\section{Introdução}

A transformada de Hough, cuja patente data de 1962, foi inicialmente utilizada em física para detectar a trajetória que partículas formavam em uma câmera de bolhas. Entretanto, a transformada de Hough somente tornou-se popular após a sua utilização computacional, sendo utilizada para detectar curvas parametrizadas em imagens. A transformada de Hough é, hoje em dia, mais empregada na deteç̧ão de retas em imagens. Todavia, a detecção de retas não é uma tarefa de fácil resolução, demandando um enorme esforço computacional para ser resolvida, inviabilizando o seu uso em sistemas que necessitem de respostas no menor tempo possível. Buscando melhorar o desempenho da transformada de Hough, alguns métodos foram propostos, como a transformada de Hough generalizada e a transformada de Hough rápida. Apesar desses métodos terem buscado melhorar o desempenho da transformada de Hough, ainda assim os seus desempenhos estão muito aquém dos desempenhos necessários para utilizar a transformada de Hough em sistemas de tempo real.

Buscando melhorar o desempenho de algoritmos morosos, como a da transformada de Hough, foi que surgiu a computação paralela. Procurando atender a uma demanda crescente de processamento, motivada pela evolução dos computadores, viabilizando implementações de aplicações que envolvem um intenso processamento e grandes volumes de dados. A computação paralela tem como principal característica à busca pela redução do tempo de processamento, de programas que costumam ser extremamente lentos e a ampliação do poder computacional das máquinas, através da divisão e distribuição da aplicação. Outra característica, intrínseca da computação paralela, consiste no desenvolvimento desse tipo de computação não ser trivial $\mathrm{e}$ demandar grande esforço e conhecimento específico, dos modelos de programação para arquiteturas paralelas. Restringindo, dessa maneira, o uso desse modelo de programação principalmente ao meio acadêmico e para fins de pesquisa.

Dessa maneira, o presente trabalho tem como objetivo principal a paralelização 
da transformada de Hough, para que o método consiga realizar a detecção de retas em um tempo de execução menor. Podendo, até mesmo, ser utilizado, em sistemas de tempo real. Além disso, será analisada qual a ferramenta de apoio à programação paralela e qual arquitetura, são mais adequadas para a utilização do método paralelizado. Foram consideradas as arquiteturas paralelas do tipo MIMD de memória compartilhada e MIMD com memória distribuída. $\mathrm{E}$ as ferramentas consideradas para implementar a paralelização do método foram o OpenMP (OpenMP, 2004) e o Pthreads (LAWRENCE, 2003) para a arquitetura de memória compartilhada e o MPI (LAWRENCE, 2003d) para a arquitetura de memória distribuída. Através da análise das combinações: arquiteturas de computadores, ferramentas de desenvolvimento de programas paralelos e estratégias de paralelização da transformada de Hough; será verificado qual dessas combinações apresentou o melhor desempenho, viabilizando o uso da transformada de Hough, inclusive em sistemas que necessitem de respostas quase que instantaneamente.

A presente dissertação foi dividida em capítulos que seguem uma ordem cronológica para o melhor entendimento do tema abordado. No capítulo 2 é realizada uma revisão da literatura sobre computação paralela, onde são descritos os conceitos, as características, as arquiteturas paralelas, os tipos de paralelismo existentes, as ferramentas e as formas de desenvolvimento de programas paralelos.

No capítulo 3 é feita uma revisão dos conceitos da transformada de Hough para retas, indicando um possível algoritmo para sua implementação. Há a descrição de algumas variações da transformada de Hough, como a transformada de Hough rápida e a transformada de Hough generalizada.

No capítulo 4 é feita a descrição de algumas das estratégias de paralelismo da transformada de Hough, encontradas na literatura. Bem como, os seus respectivos diagramas de estados, para o melhor entendimento de cada uma das estratégias.

Já no capítulo 5 são apresentados os resultados obtidos pelas diferentes estratégias de paralelismo implementadas, nas arquiteturas MIMD de memória compartilhada e MIMD de memória distribuída. Neste capítulo são, ainda, analisados os resultados obtidos por cada uma das implementações, além de indicar qual a melhor estratégia para os diferentes tipos de arquitetura.

Finalizando a dissertação, no capítulo 6, são apresentadas as conclusões, as contribuições do trabalho e as sugestões de trabalhos futuros. 


\section{Computação Paralela e Computação}

\section{Concorrente}

Freqüentemente, os softwares são desenvolvidos de forma serial, para serem executados em um único computador, com uma única Unidade de Processamento Central (UPC). Neste modelo, os softwares são um conjunto de instrução que são executadas uma após a outra. A computação paralela difere da computação serial pelo fato dos softwares serem escritos para executarem em um único computador, com diversas UPC, ou em diversos computadores, cada um contendo uma ou mais UPC (LAWRENCE, 2003c).

$\mathrm{Na}$ literatura encontram-se várias definições para a computação paralela, dentre as quais cabe citar a sugerida por Almasi e Gottlieb (ALMASI \& GOTTLIEB, 1994): "computação paralela constitui-se de uma coleção de elementos de processamento que se comunicam e cooperam entre si para resolver um problema de maneira mais rápida".

A computação paralela surge para atender a uma demanda crescente de processamento. Para tanto, têm surgido iniciativas desde os anos 40, tais como, arquiteturas paralelas que possuem vários elementos de processamento. Essas máquinas paralelas diferenciam-se por realizar uma quantidade cada vez maior de operações num período de tempo cada vez menor, atendendo às necessidades de processamento das aplicações científicas. Mas esses equipamentos são caros e demandam um grande investimento para adquiri-los.

Com base nesse cenário, surgiu, na década de 80 , a computação paralela realizada sobre sistemas distribuídos, tornando-se uma alternativa mais barata e versátil.

$\mathrm{Na}$ computação distribuída, um conjunto de computadores convencionais são conectados entre si, por uma rede de comunicação, formando uma máquina paralela virtual.

Baseado na concorrência de execução, são definidas três estratégias de 
programação (SANTANA et al, 1998):

- Programação seqüencial: uma tarefa só será executada após a execução de outra tarefa;

- Programação concorrente: uma tarefa poderá iniciar a sua execução, sem que as anteriores tenham necessariamente terminado o seu processamento (sistemas multitasking ou uniprocessadores);

- Programação paralela: caracteriza-se pela iniciação e execução das tarefas em paralelo (sistemas multiprocessadores).

Nas seções a seguir, serão tratadas algumas características específicas dos sistemas paralelos.

\subsection{Vantagens e desvantagens dos sistemas paralelos}

Os sistemas paralelos são utilizados com maior freqüência em aplicações que necessitam de grande desempenho computacional, como, por exemplo, a previsão de tempo, renderização de gráficos, reconhecimento de padrões e formas, simulações nucleares e cálculos matemáticos complexos, entre outros.

Algumas das vantagens da computação paralela em relação à computação seqüencial são:

- Alto desempenho para programas complexos;

- Soluções mais naturais para programas intrinsecamente paralelos;

- Maior tolerância à falhas;

- Modularidade (SOUZA, 1996);

- Uso simultâneo de recursos.

Algumas das desvantagens da utilização da computação paralela são:

- Maior dificuldade de programação;

- Intensa sobrecarga de comunicação;

- Maior complexidade gerada pela necessidade de um sincronismo entre os processos;

- Maior dificuldade de depuração, pois, não existe uma forma eficiente de acompanhar a alteração das variáveis durante a execução das diversas tarefas paralelas. 


\subsection{Conceitos básicos de computação paralela}

Para que haja um melhor entendimento dos conceitos existentes de computação paralela, é necessário um detalhamento desses conceitos, como tipos de paralelismo, unidades e medidas de desempenho, granulosidade, speedup e eficiência, linguagens e compiladores paralelos, que serão expostos nas subseções seguintes.

\subsubsection{Tipos de paralelismo}

Dentre as várias formas de se classificar o paralelismo, têm-se as que consideram o objeto a ser paralelizado (SANTOS, 2001) e, as que consideram os eventos a serem paralelizados (CAMPOS, 2001). Essas duas formas são tratadas a seguir:

Considerando o objeto a ser paralelizado:

- Paralelismo de dados - onde o processador executa as mesmas instruções sobre dados diferentes;

- Paralelismo funcional - onde o processador executa diferentes instruções que podem ou não operar sobre o mesmo conjunto de dados;

- Paralelismo de objetos - que utiliza o conceito de objetos distribuídos por uma rede, capazes de serem acessados por métodos em diferentes processadores, para uma determinada finalidade.

Considerando os eventos concorrentes, tem-se:

- Paralelismo lógico - vários processos são executados alternadamente em um único processador, de modo que apenas um está ativo em cada instante, este paralelismo é denominado programação concorrente;

- Paralelismo físico - neste tipo de paralelismo existem vários elementos de processamento e vários processos podem ser executados ao mesmo tempo, este paralelismo é denominado programação paralela. Podem existir três tipos de paralelismo fisico:

- Paralelismo temporal ou de operações sobrepostas (pipeline) determinada tarefa é subdividida em uma seqüência de subtarefas, cada uma é executada por estágios do pipeline;

- Paralelismo combinado - ocorre quando vários estágios do pipeline 
são executados em paralelo;

- Paralelismo espacial - este tipo de paralelismo pode ser síncrono ou assíncrono. No síncrono, existem várias unidades de processamento supervisionadas por uma unidade de controle, que envia as instruç̋̃es para serem processadas. No assíncrono, as tarefas são executadas paralelamente sem nenhum sincronismo. As tarefas executadas pelos processadores não serão as mesmas, assim como o momento de iniciar o processamento.

\subsubsection{Comunicação}

A comunicação entre tarefas depende do tipo de problema a ser resolvido, onde pode haver necessidade de comunicação ou a comunicação é somente utilizada para o controle das tarefas, possuindo, nesse caso, um mínimo de comunicação.

\section{Caso em que a comunicação é mínima}

Um problema pode ser decomposto e executado em paralelo sem a necessidade de compartilhar dados entre as tarefas. Um exemplo é a inversão de cores em uma imagem preto e branco, pode-se dividir a imagem entre diversas tarefas e cada uma realiza o seu trabalho sobre o pedaço da imagem que lhe couber, havendo, somente, um mínimo de comunicação, para que o computador mestre possa realizar o controle sobre a tarefa que esta sendo executada.

Existindo a necessidade de comunicação

Muitas aplicações paralelas não são tão fáceis de serem resolvidas e requerem o compartilhamento de dados entre as tarefas.

Quando se opta pelo desenvolvimento de um programa paralelo, alguns fatores devem ser considerados e entendidos, que são (LAWRENCE, 2003c):

- Custo de comunicação:

- Comunicação entre tarefas quase sempre implica em overhead;

- Ciclos e recursos de máquina que geralmente são utilizados para computação passam a serem utilizados para empacotar e transmitir dados;

- Freqüentemente, a comunicação requer algum tipo de sincronização entre as tarefas o que resulta em tarefas tendo que aguardar outras em vez de estar realizando computação; 
- Como as tarefas competem pela comunicação, pode levar a saturação da rede, comprometendo o desempenho da tarefa.

\section{- Latência versus largura de banda:}

- Latência é o tempo gasto para enviar uma mensagem de tamanho mínimo, geralmente contendo zero bytes, de um ponto A até um ponto $\mathrm{B}$;

- Largura de banda é a quantidade máxima de dados que pode trafegar na rede de uma só vez e é geralmente expressa em megabytes/segundo.

\section{- Comunicação síncrona versus assíncrona:}

- A comunicação síncrona é também chamada de bloqueante, pois uma tarefa $A$ que envia uma mensagem para uma tarefa $B$ deve aguardar até que a tarefa $\mathrm{B}$ tenha recebido integralmente a mensagem. Esta comunicação é utilizada entre tarefas que compartilham dados.

- Na comunicação assíncrona, também conhecida como não bloqueante, não é necessário que a tarefa que enviou a mensagem aguarde que a tarefa destinatária tenha recebido a mensagem para que então inicie outra atividade.

\subsubsection{Dependência de dados}

A dependência ocorre entre instruções do programa, quando a ordem de execução das instruções afeta o resultado do programa. Já a dependência de dados ocorre, quando uma tarefa necessita de uma posição de memória que outra tarefa irá atualizar (LAWRENCE, 2003c).

As dependências são muito importantes para a programação paralela, pois elas são um dos primeiros empecilhos para o desenvolvimento de aplicações paralelas. A Figura 2.1 exemplifica, num trecho de código, uma dependência de dados, onde o valor de $\mathrm{A}[\mathrm{i}]$ depende do valor de $\mathrm{A}[\mathrm{i}-1]$.

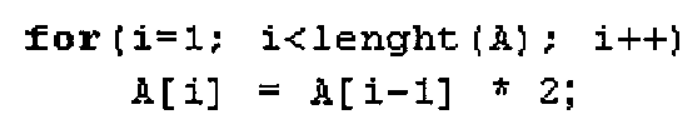

Figura 2.1 Dependência de dados 


\subsubsection{Balanceamento de carga}

O balanceamento de carga é utilizado para que um computador não fique sobrecarregado enquanto que outro não está realizando nenhuma atividade. Dessa maneira, o balanceamento de carga distribui as atividades sobre os computadores para que todos possam estar executando tarefas no máximo de tempo possível e não fiquem ociosos, contribuindo para a melhoria de desempenho da aplicação (LAWRENCE, 2003c).

\subsubsection{Speedup e eficiência}

Para aferir a qualidade dos algoritmos paralelos, são utilizadas duas medidas: o Speedup e a Eficiência. Essas medidas, procuram mostrar a vantagem na utilização da computação paralela se comparada à execução seqüencial (QUINN, 1994). O Speedup $(\mathrm{Sp})$ fornece o ganho de velocidade, quando se executa um determinado processo (paralelo) em $p$ processadores em relação à execução desse mesmo processo em sua versão seqüencial, sendo executado em um único processador. O cálculo do Speedup é realizado pela fórmula:

$$
\mathrm{Sp}=\mathrm{T} 1 / \mathrm{Tp} \quad(2-1)
$$

onde: Tl é o tempo de execução em um processador e TP é o tempo de execução em $p$ processadores.

A Eficiência (E) determina a taxa de utilização dos processadores e, assim, depende do Speedup alcançado, sendo calculado por:

$$
\mathbf{E}=\mathbf{S p} / \mathbf{p}
$$

onde $\mathrm{p}$ é o número de processadores.

$O$ ideal seria obter $S p=p$ e $E=1$. Mas esses valores não podem ser alcançados devido à lei de Amdahl's (ANNARATONE, 1992). Essa lei diz que todo o programa paralelo tem uma parte seqüencial, como por exemplo, a iniciação de variáveis. Se fé a fração inerentemente seqüencial de uma computação a ser resolvida por $p$ processadores, então o "speedup" S é limitado de acordo com a fórmula: 


$$
S \leq \frac{1}{f+\frac{1-f}{p}}
$$

Esta fórmula, diz que mesmo que se tenha diversos processadores capazes de atingir um speedup de 100 por cento para a parte paralela do algoritmo, mesmo assim, teríamos uma parte do código que é seqüencial e que influi diretamente no resultado. $\mathrm{O}$ speedup será maior para problemas que tenham uma pequena parte seqüencial e uma enorme porção paralela.

\subsubsection{Arquiteturas paralelas}

Devido a existência de inúmeras arquiteturas de computadores que apresentam características diferentes, houve a necessidade de organizar em grupos, para que sejam melhores estudadas, as diversas arquiteturas. Foram propostas algumas classificações que agrupam arquiteturas com características comuns permitindo, assim, uma melhor definição

As classificações mais usualmente encontradas, são a de Flynn (FLYNN, 1972) e de Duncan (DUNCAN, 1990). A classificação de Flynn, foi uma proposta inovadora no sentindo de agrupar diferentes arquiteturas de computadores. Posteriormente, Duncan propõe uma classificação, que buscou abranger uma maior quantidade de arquiteturas paralelas, incluindo as arquiteturas mais recentes.

\subsubsection{Classificaçāo de Flynn}

Flynn baseou sua classificação no fluxo de instruções e no fluxo de dados. Um fluxo de instruções equivale a uma seqüência de instruções executadas (em uma unidade de processamento) sobre um fluxo de dados aos quais essas instruções estão relacionadas (FLYNN, 1972).

A classificação proposta por Flynn é dividida em quatro categorias, como segue: a) SISD - Single Instruction Single Data Stream

Esta categoria compreende as arquiteturas que possuem um único fluxo de 
instruções e único fluxo de dados. Compreendendo as máquinas de von Neumann. A Figura 2.2 apresenta um modelo da categoria SISD.

IS

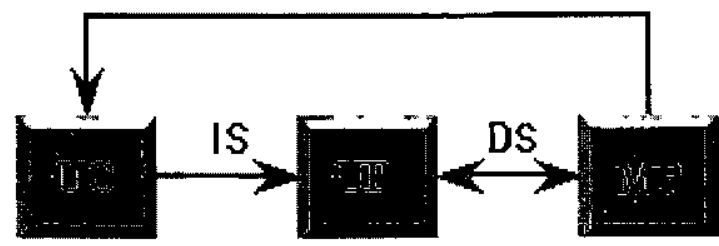

$$
\begin{array}{ll}
\text { UC - Unidade de Controle } & \text { IS - Istruçōes Sinqles } \\
\text { UP - Unidade de Processamento } & \text { DS - Dados Sinqles } \\
\text { MP - Merroria Principal } &
\end{array}
$$

Figura 2.2 SISD

\section{b) SIMD - Single Instruction Multiple Data Stream}

Nesta categoria estão representadas as arquiteturas que possuem fluxo único de instruções e múltiplo de dados. As arquiteturas pertencentes a esta categoria, são as que possuem várias unidades de processamentos e somente uma unidade de controle. Nessa arquitetura encontram-se os processadores de arranjo vetorial. A Figura 2.3 mostra um exemplo desta categoria.

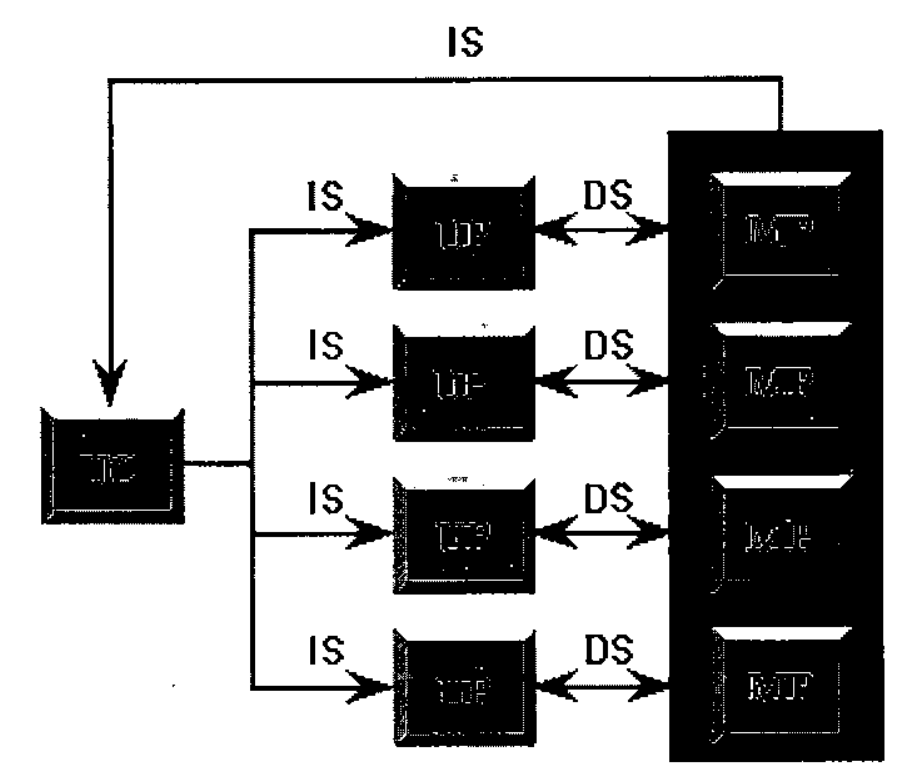

Figura 2.3 SIMD 


\section{c) MISD - Multiple Instruction Single Data Stream}

A categoria MISD representa as arquiteturas que possuem múltiplos fluxos de instruções e um único fluxo de dados. Não existem exemplos precisos de máquinas que pertencem a esta categoria. Entretanto, alguns autores consideram o pipeline como um representante dessa categoria. A Figura 2.4 ilustra esta arquitetura.

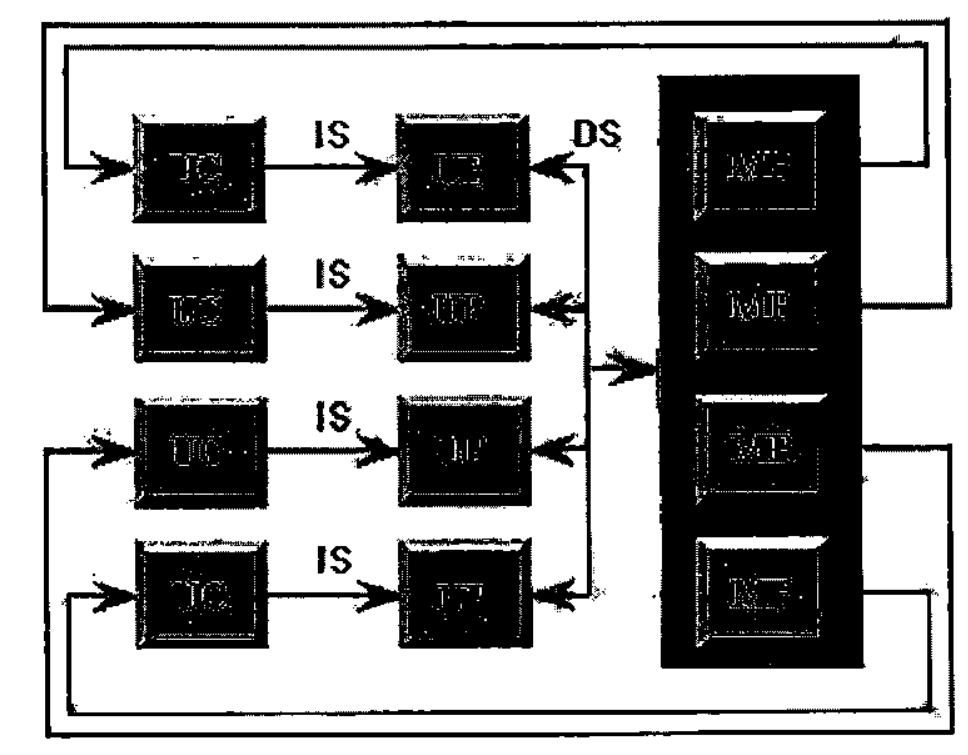

Figura 2.4 Arquitetura MISD

\section{d) MIMD - Multiple Instruction Multiple Data Stream}

Esta categoria representa as arquiteturas que possuem múltiplo fluxo de instruções e múltiplo fluxo de dados. Essa categoria envolve as arquiteturas que possuem várias unidades de processamento executando diferentes instruções, em diferentes conjuntos de dados, de maneira independente. Esta categoria engloba a maioria das arquiteturas paralelas recentes. A Figura 2.5 mostra a configuração desta arquitetura. 


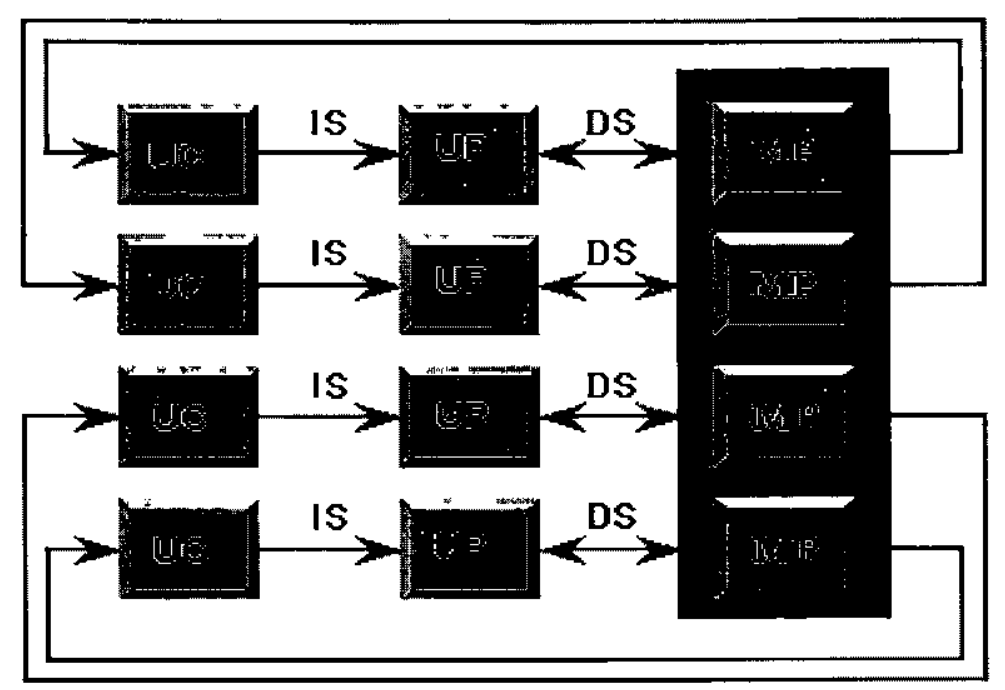

Figura 2.5 MIMD

\subsubsection{Classificação de Duncan}

Outra classificação existente é a classificação de Duncan, que surgiu para definir algumas arquiteturas que não estavam englobadas na classificação de Flynn.

Duncan excluiu de sua classificação as arquiteturas do tipo SISD e MISD. A exclusão da primeira foi por se tratar de uma arquitetura seqüencial e a segunda por não existir nenhuma arquitetura para essa abordagem (MOREIRA, 2000).

A classificação de Duncan acomoda as arquiteturas não compreendidas dentro da classificação de Flynn.

Duncan, divide as arquiteturas de computadores em dois grupos: arquiteturas Síncronas e Assíncronas. As arquiteturas Síncronas, são as que coordenam as operações paralelas sincronamente em todas as unidades de processamento, através de relógios globais. O outro grupo, é das arquiteturas Assíncronas, que possuem controle descentralizado do hardware. A classificação de Duncan com suas divisões pode ser vista na Figura 2.6.

\section{Arquiteturas síncronas}

- Processadores vetoriais - possuem um hardware específico, capaz de executar sequiências de instruções idênticas sobre vetores, de forma mais rápida do que uma seqüência de operaçðes escalares; 
- Arquiteturas SIMD - possui uma unidade de controle central, vários processadores e uma rede de interconexão entre os processadores e a memória. A unidade de controle difunde uma única instrução que irá atuar sobre múltiplos dados armazenados na memória local. Esta categoria, foi ainda subdivida por Duncan em Processadores Matriciais, criados para computação sobre matrizes e Memória Associativa, onde o acesso à memória é feito através de seu conteúdo e não através de endereçamento.

- Arquiteturas sistólicas - máquinas cujo objetivo é o equilibrio entre computações intensivas e a largura de banda de entrada/saída disponível. As arquiteturas sistólicas, possuem uma fila de processadores, onde a informação trafega por todos, antes de retornar a memória. Possui, também, um relógio global que sincroniza o fluxo de dados. Durante cada intervalo de tempo, esses processadores executam uma curta e constante seqüência de instruções.

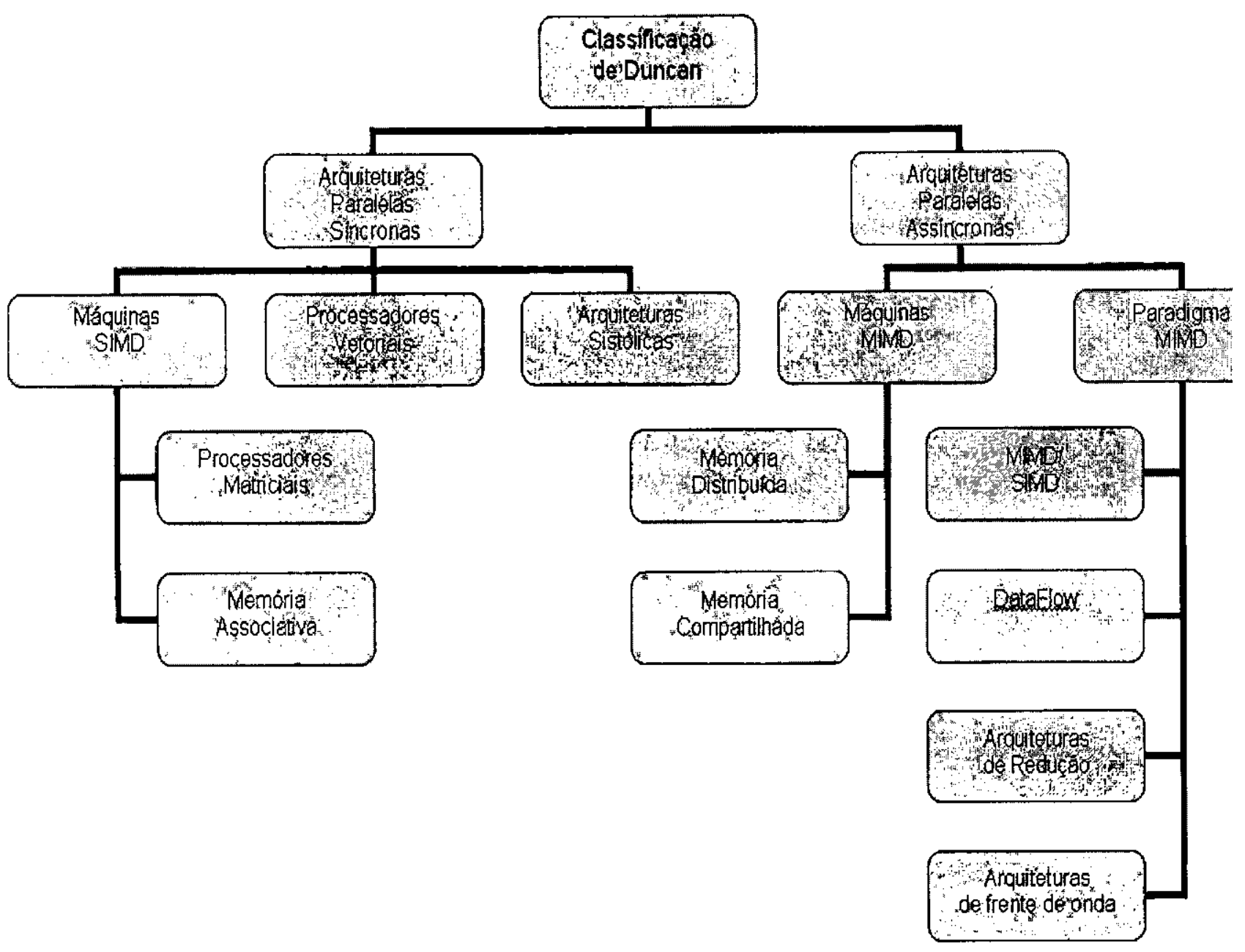

Figura 2.6 Classificação de Duncan. 


\section{Arquiteturas assíncronas}

- Arquiteturas MIMD - Possui a mesma característica de classificação de Flynn, ou seja, várias unidades de processamento atuando sobre vários fluxos de dados. Porém, são subdivididas conforme a organização da memória, que determina o sincronismo e a forma de comunicação entre as unidades de processamento, sendo arquiteturas fortemente acopladas ou fracamente acopladas, de memória compartilhada ou memória distribuída, respectivamente. A Figura 2.7 mostra um exemplo de memória distribuída e memória compartilhada;

- Arquiteturas MIMD com memória compartilhada - Possui memória com espaço de endereçamento único, onde todos os processadores podem ler ou escrever em todas as posições da memória.

- Arquitetura MIMD com memória distribuída - Possui várias memórias, uma para cada processador e que, somente pode ser endereçada pelo processador correspondente.

- Arquiteturas não convencionais MIMD - Na classe de arquiteturas não convencionais, Duncan acrescenta uma nova classe, para atender as arquiteturas que anteriormente não haviam sido classificadas. Estas arquiteturas, também conhecidas com Paradigmas arquiteturais baseados em MIMD, que possuem os princípios das arquiteturas MIMD de operação assíncrona e manipulação concorrente dos múltiplos fluxos de instruções e dados. As arquiteturas inclusas nessa nova categoria, são a híbrida MIMD/SIMD (como por exemplo, Non-von), máquinas de redução (Newcastle Reduction Machine), matrizes de frente de onda, são implementações assíncronas derivadas dos arranjos sistólicos, e fluxo de dados (MDM - Manchester Dataflow Machine) (BRUNO, 2000). 


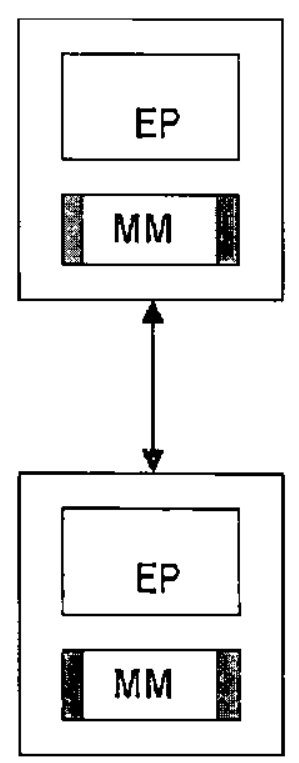

(a)

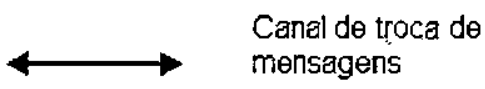
mensagens

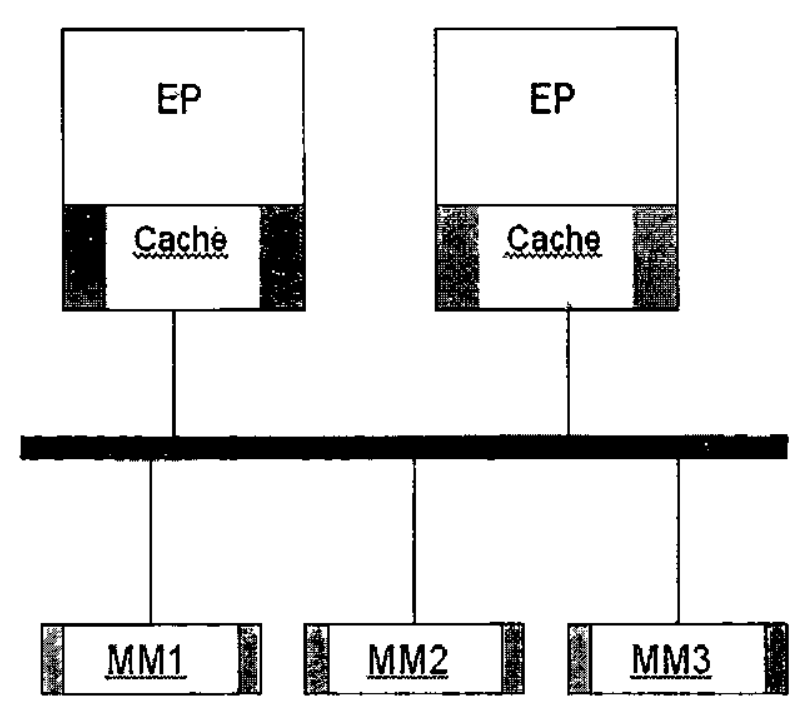

(b)

Barramento

\section{EP - Elemento de Processamento}

$\mathrm{MM}$ - Mémórià

Figura 2.7 Arquitetura MIMD - (a) memória distribuída, (b) Memória compartilhada

\subsection{Computação distribuída}

A Computação Distribuída é realizada sob sistemas distribuídos, enquadrando-se na classificação de Flynn, vista na subseção anterior, como uma computação que é realizada em uma arquitetura com memória distribuída, do tipo MIMD distribuída. Teve seu surgimento no final da década de 80 , sendo impulsionada, principalmente, pela proliferação das redes de computadores, que é base para os sistemas distribuídos.

A Computação Distribuída não necessita de hardware especial. Podendo utilizar computadores pessoais (ou não) conectados por uma rede de computadores qualquer, ficando todo o mecanismo de paralelização sob responsabilidade das camadas de software, sendo essa a nível de sistema operacional, através dos sistemas operacionais distribuídos (BRUNO, 2000), ou através de ferramentas de troca de mensagens como PVM, MPI, Socket e CVMP (BRUNO, 2000) que será apresentado na subseção $2.4 .3 \mathrm{e}$ com o qual esse trabalho pretende colaborar.

Os Sistemas Distribuídos se tornaram arquiteturas paralelas populares devido à simplicidade, ao baixo custo e ao aumento da velocidade de comunicação das redes de 
computadores (ALMASI \& GOTTLIEB, 1994).

Os sistemas distribuídos, podem possuir uma característica homogênea, em que todos os elementos de processamento são idênticos, ou podem ser heterogêneos, como ocorre em algumas máquinas de arquitetura MIMD.

Os sistemas distribuídos podem, também, possuir um número variável de elementos de processamento, permitindo a sua utilização em sistemas tolerantes a falha, pois, quando um elemento de processamento falhar, outro pode assumir o seu lugar. Para caracterizar um aglomerado de computadores como Sistema Distribuído (Computação Distribuída), basta que hajam mecanismos de integração e comunicação entre as máquinas e que, através desses mecanismos seja possível, ao sistema distribuído, realizar uma tarefa comum, ou diferentes partes de uma mesma tarefa. Existem diversas maneiras para transformar um sistema para um sistema paralelo, permitindo que tal sistema seja utilizado como distribuído. Algumas dessas maneiras para explorar o paralelismo, transformando um sistema para paralelo, bem como as estratégias e linguagens que podem ser utilizadas, são apresentados na subseção 2.3.1.

\subsubsection{Desenvolvimento de programas paralelos}

Existem várias maneiras de desenvolver um programa paralelo. Para Quinn (QUINN, 1994) existem pelo menos três maneiras de se desenvolver um algoritmo paralelo para solucionar um determinado problema. São elas:

- Buscando a exploração de qualquer paralelismo inerente que exista em um programa seqüencial - essa abordagem é muito utilizada, embora em alguns casos não seja óbvio transformar um algoritmo seqüencial em paralelo;

- Desenvolvendo um novo algoritmo paralelo - em algumas situações é melhor desenvolver um algoritmo paralelo do início, pois possibilitará melhor desempenho;

- Utilizando um algoritmo paralelo que resolva um problema similar como base - exige-se menor trabalho do programador em relação à construção completa do algoritmo, possibilitando bom desempenho.

\subsubsection{Linguagens de programaçāo}


Quando o programador opta pelo desenvolvimento de programas paralelos, deve considerar que o desenvolvimento implica basicamente em decompor o algoritmo e/ou os dados, distribuir as tarefas e os dados entre os vários processadores para que eles trabalhem simultaneamente e coordenar os processos em execução e a comunicação entre os processadores (CAMPOS, 2001).

Para auxiliar no desenvolvimento de um programa paralelo o programador possui algumas alternativas, que são o paralelismo automático, extensões paralelas para linguagens imperativas, bibliotecas de paralelismo e linguagens não imperativas paralelas (BRUNO, 2000).

$\mathrm{Na}$ paralelização automática, um compilador de paralelização analisa e transforma um programa seqüencial em um programa paralelo. Nesta abordagem, o programador não necessita interferir no desenvolvimento do programa paralelo, não precisa aprender uma nova linguagem, nem técnicas e estratégias de desenvolvimento de programas paralelos. Esta tática apresenta, para a maioria dos casos, um ganho de desempenho modesto (SANTANA et al, 1998).

Outra alternativa é a extensão paralela para linguagens imperativas. Esta abordagem exige um esforço maior por parte do programador, comparado com a paralelização automática, pois este, deverá aprender sobre computação paralela e sobre o funcionamento das ferramentas adicionais. Este método elimina a necessidade de aprender uma nova linguagem ou de modificar completamente o programa original, podendo reutilizar muitas de suas bibliotecas e programas. Assim, o programador pode utilizar a linguagem com a qual está familiarizado e através do acréscimo de comandos e estruturas específicas para funções paralelas, ser capaz de explorar o paralelismo. Esta estratégia é muito utilizada atualmente, embora mantenha vínculo com a programação de von Neumann, sendo muito criticada por isso. Esta abordagem resulta em um desempenho melhor, dependendo da estratégia de paralelismo adotada pelo programador, pois este deverá conhecer muito bem a semântica de paralelismo, bem como a estrutura da plataforma paralela (CAMPOS, 2001). Alguns exemplos desse gênero são HPF (High Performance Fortran) e $C^{*}$ (C paralelos), entre outras.

Existe também a utilização de bibliotecas de funções e procedimentos focadas no desenvolvimento paralelo. Nesta abordagem, as bibliotecas são utilizadas em linguagens de programação seqüencial, permitindo o desenvolvimento de aplicações paralelas.

A última opção, refere-se às linguagens não imperativas. Nesse modelo, o 
programador deve aprender uma nova linguagem desvencilhando-se do modelo tradicional de computação de von Neumann. Esta abordagem, é a que necessita de um maior esforço por parte do programador, pois deverá reescrever todo o seu código para essa nova linguagem. Esta abordagem, apresenta formas mais naturais para a ativação $e$ coordenação de processos e, com implementação mais eficiente e flexibilidade maior na exploração de paralelismo.

Linguagens desse gênero podem ser classificadas como baseadas em predicados lógicos, como o Prolog ou podem ser classificadas como linguagens funcionais, como o Sisal, que é baseada na arquitetura DataFlow (BRUNO, 2000).

A escolha de uma ferramenta, para programação paralela, deve ser feita de acordo com os objetivos do programador. Compiladores paralelizadores oferecem desempenho modesto, mas em contrapartida oferecem sobrecarga nula sobre o programador. As linguagens não imperativas apresentam ótimo desempenho, mas existe a necessidade do programador aprender um novo modo de programação, bem como uma nova linguagem. Num modo intermediário, estão as extensões paralelas para as linguagens imperativas, oferecendo bom desempenho com pouca sobrecarga sobre $o$ programador.

\subsubsection{Estratégias de paralelismo}

Considerando a exploração de paralelismo baseada em processos, podem-se encontrar três modelos padrões de paralelismo, o que influenciará na decisão da estratégia a ser adotada, dependendo do tipo de plataforma onde será executado o programa paralelo. Os modelos são: paralelismo geométrico, pipeline e processor farm.

\section{Paralelismo Geométrico}

Também conhecido como paralelismo de resultados ou paralelismo de dados (Data Parallelism), caracteriza-se pela divisão do conjunto de dados a serem trabalhados igualmente entre todos os processadores. Dessa maneira, cada processador executa uma cópia do programa completo, porém em um subconjunto de dados. Este é considerado o modo mais fácil de desenvolvimento de algoritmos paralelos e é freqüentemente utilizado em computadores massivamente paralelos (CAMPOS, 2001).

\section{Paralelismo Processor Farm}

O conceito de paralelismo Processor Farm é muito similar ao conceito mestre/escravo. No conceito Processor Farm existe o supervisor que similar ao mestre, delega trabalho aos trabalhadores, que são os escravos. Sempre que um trabalhador 
conclui sua tarefa, este avisa ao supervisor que imediatamente delega outro trabalho, da lista de trabalhos aguardando para ser executados, ao trabalhador. Este modelo também é conhecido como paralelismo pela pauta, visto que é definido um conjunto de tarefas (pauta) e a partir daí são distribuídas às tarefas pelo processador mestre (SANTANA $e t$ $a l, 1998)$. A Figura 2.8 apresenta esse tipo de paralelismo.

O estilo "processor farm" possui várias vantagens, como por exemplo, a facilidade de ampliação do sistema, consegue-se isto, através do aumento de trabalhadores, facilidade de programação, balanceamento de carga mais natural, visto que as tarefas vão sendo submetidas aos processadores de acordo com a disponibilidade. Dentre as desvantagens, podem ser citados a sobrecarga de comunicação e a possibilidade de gargalo no processador mestre.

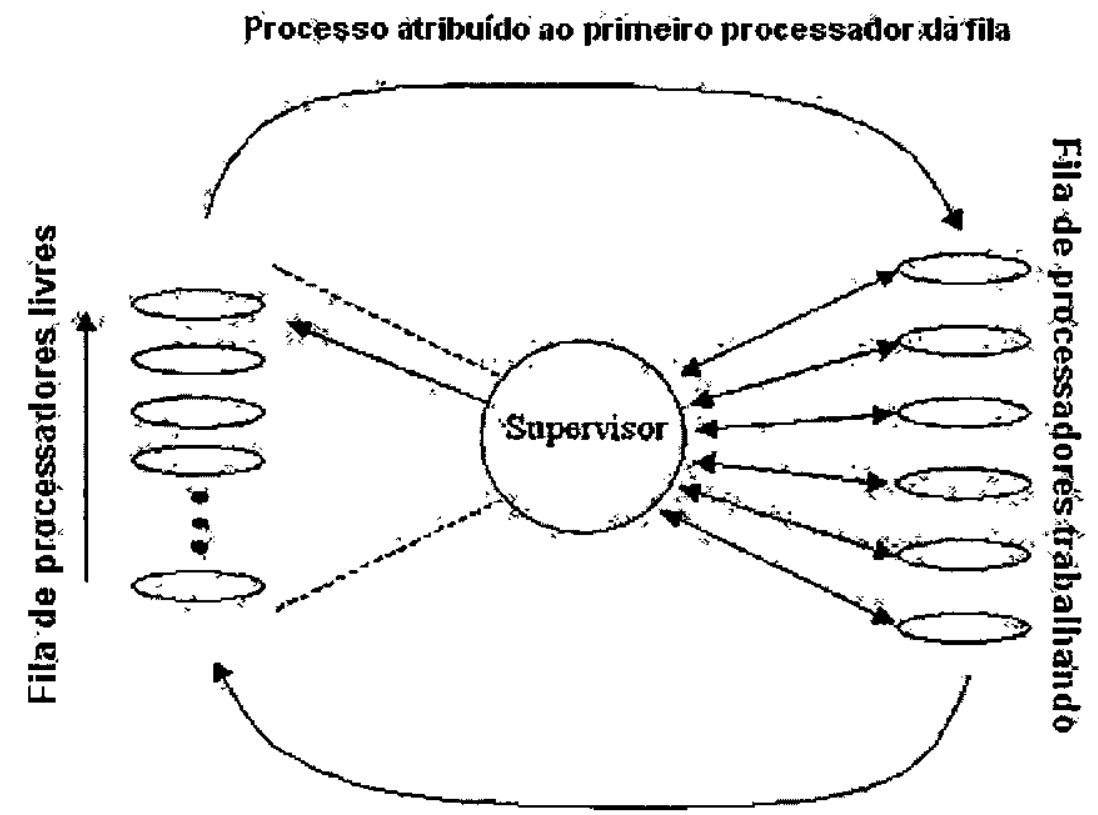

Procesşador concluiu à execuçăo dó processo

Figura 2.8 Paralelismo Processor Farm

\section{Paralelismo Pipeline}

Caracteriza-se pela divisão de uma aplicação em várias tarefas específicas. Estas tarefas são distribuídas aos vários processadores de modo pipeline. Quando apenas uma tarefa atravessa o pipeline não há paralelismo. Este estilo, é utilizado em casos em que ocorre dependência de dados entre os estágios (SANTANA et al, 1998). O paralelismo Pipeline é muito semelhante a uma linha de produção de uma indústria, onde existem 
várias etapas para a elaboração de uma tarefa. A Figura 2.9 ilustra uma pipe com três estágios, o primeiro estágio é à busca da instrução, o segundo é a decodificação da instrução e o terceiro é a execução da instrução. Em cada estágio, após o terceiro ciclo, há uma instrução diferente que está sendo processada.

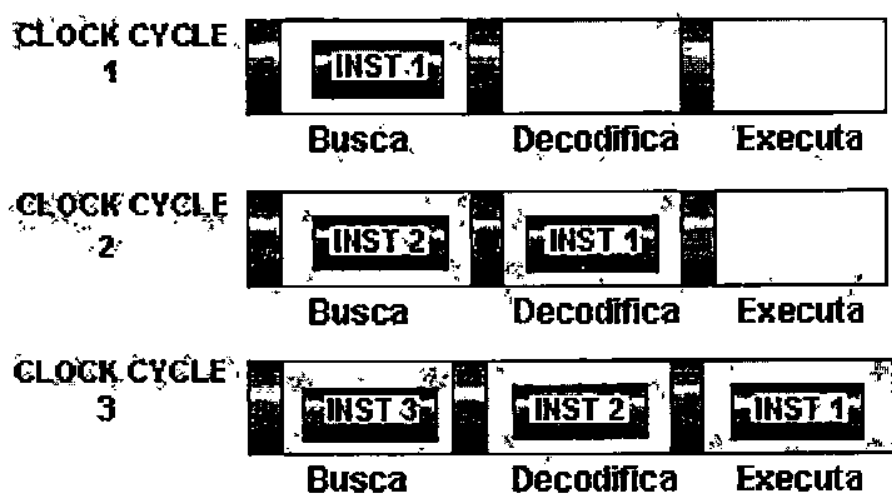

Figura 2.9 Pipeline com 3 estágios

\subsubsection{Mecanismos para exploração de paralelismo}

Nesta seção, descrevem-se alguns mecanismos para iniciar e controlar a execução de processos em paralelo utilizando dois dos conceitos apresentados na subseção 2.3.1.1. Serão descritas as formas de obter paralelismo a partir de extensões de linguagens convencionais e posteriormente, serão apresentadas algumas bibliotecas de paralelismo.

Para transformar um algoritmo seqüencial em paralelo, algumas tarefas são realizadas, mas primeiro deve-se ter a certeza que o algoritmo em sua forma seqüencial está funcionando corretamente, pois, existe uma enorme dificuldade de implementação e depuração de programas paralelos (BRUNO, 2000). Em termos gerais, a base para paralelização de um algoritmo seqüencial segue a execução das seguintes tarefas (SANTANA et al, 1998), (BRUNO, 2000) e (CAMPOS, 2001):

- Definir quais conjuntos de sub-tarefas podem ser executadas paralelamente (dependência de dados);

- Quando e como ativar e encerrar a execução dessas tarefas;

- Coordenar e especificar a interação entre essas tarefas, enquanto estiverem executando.

A dependência de dados ocorre, quando um comando ou operação depende do 
resultado do processamento de outra operação. Após verificar a dependência de dados, deve-se decidir quando e como ativar e encerrar a execução de tarefas paralelas. Existem algumas primitivas básicas, tanto em bibliotecas de extensão paralela quanto em linguagens de programação paralela. Algumas delas são as Co-rotinas efork/join.

\section{Co-rotinas}

Co-rotinas ou sub-rotinas possuem um modo de transferência de controle não hierárquico. Uma sub-rotina comum, ativada através de uma chamada call sub-rotina, ao executar um comando return, retorna o controle ao módulo de programa que a ativou e termina a sua execução. Além disso, toda vez que esta é ativada, será executada desde o seu início. Sub-rotinas são como procedimentos, mas que possuem uma forma adicional de passagem de controle: a primitiva resume (BRUNO, 2000).

\section{Fork/Join}

Nas co-rotinas o chaveamento dos processos é explícito. Ao executar um resume a rotina é interrompida e o controle é passado para a rotina chamada.

Fork dispara um segundo processo, sem interromper o primeiro. O chaveamento entre os processos é controlado pelo sistema operacional. O processo que faz o fork é chamado normalmente de pai e o processo filho é aquele disparado pela chamada. Para garantir uma sincronização é usado o join, que suspende o processo pai até que o filho termine (CAMPOS, 2001). A Figura 2.10 mostra um exemplo de uso das primitivas fork/join para a execução de uma tarefa cotidiana, como o preparo de um café com leite.

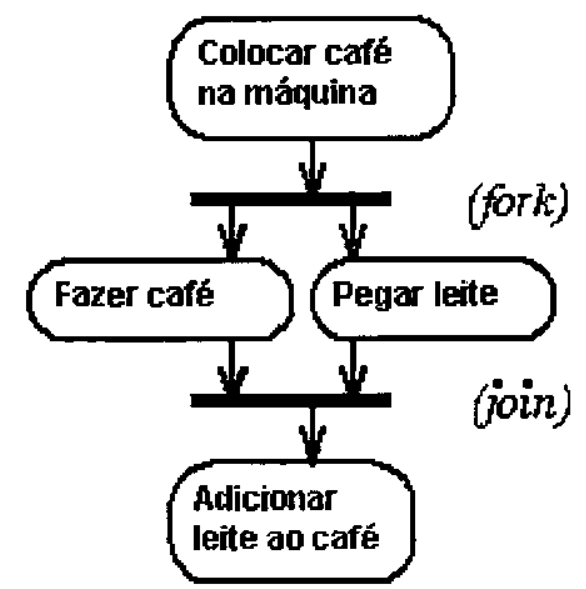

Figura 2.10 Fork/Join para preparo de um café com leite

\section{ParBegin/ParEnd}

Outra primitiva para explorar o paralelismo são as primitivas ParBegin/ParEnd, 
oferecendo a construção de um código mais elegante, mas por outro lado à exploração do paralelismo não é tão flexível quanto fork/join.

ParBegin/ParEnd, especificam explicitamente uma seqüência de segmentos de programa que serão executados concorrentemente (BRUNO, 2000).

\subsection{Ferramentas de auxílio à programação paralela}

Nesta seção, são descritas algumas ferramentas que colaboram com o desenvolvimento de programas paralelos. Estas ferramentas auxiliam a programação

paralela tanto em arquiteturas MIMD de memória compartilhada, quanto em arquiteturas MIMD de memória distribuída.

\subsubsection{Ferramentas de programação paralela em memória compartilhada}

Para se entender o conceito/funcionamento do POSIX Threads e do OpenMP, que serão descritos nas subseções seguintes, é necessário que primeiro se entenda o conceito de um thread. Um thread é definido como um stream independente de instruções, com um fluxo seqüencial único de controle dentro de um programa. A thread utiliza os recursos alocados para o processo e permanece executando enquanto 0 processo que a criou permanecer executando, ou termina sua execução com uma ordem explícita de término (MOREIRA, 2004) e (LAWRENCE, 2003).

Múltiplas threads podem ser executadas ao mesmo tempo, compartilhando recursos e sendo executadas concorrentemente com outras threads. E, podem também, executar ao mesmo tempo uma mesma função, mas com diferentes dados.

Por permitir esses tipos de execuçães, é que a programação com threads tornouse largamente utilizada no desenvolvimento de aplicações que necessitem de múltiplos fluxos de execuções e, também, no desenvolvimento de aplicações paralelas em ambientes de memória compartilhada.

O POSIX Threads e o OpenMP são Aplication Program Interface (API) que contribuem com o desenvolvimento de aplicações paralelas em memória compartilhada, utilizando como base para o desenvolvimento das aplicações as threads descritas nos parágrafos anteriores desta mesma subseção.

\subsubsection{POSIX Threads}


O POSIX Thread (IEEE, 2004), (LAWRENCE, 2003) e (TORELLI \& MALLARA, 2003), ou Pthreads é uma API para a linguagem $\mathrm{C} / \mathrm{C}++$ que auxilia o desenvolvimento de aplicações paralelas em ambientes de memória compartilha. O Pthreads utiliza o conceito de múltiplas threads, permitindo que aplicações paralelas sejam criadas para executarem concorrentemente, ou que uma aplicação seja dividida para que cada porção processe um conjunto de dados diferente.

\subsection{O padrão POSIX}

Diversos fabricantes de hardware implementaram suas versões de threads. O problema destas diversas implementações, é que cada uma difere substancialmente da outra, dificultado o desenvolvimento e a portabilidade das aplicações. Devido a estes problemas, a IEEE resolveu padronizar a interface de programação para o ambiente UNIX. Desta iniciativa, surgiu em 1988 o padrão IEEE 1003.n e parte do ISO/IEC 9945, que passou a ser chamado de POSIX.1. Em 1995, o padrão IEEE 1003.c foi incorporado ao padrão POSIX.1. Com esta incorporação o padrão POSIX.1 passa também a definir interfaces de programação que permitem a construção de aplicações multi-threads e desde então, o padrão passou a se chamar POSIX Threads ou Pthreads (LAWRENCE, 2003) e (TORELLI \& MALARA, 2003).

Pthreads define um conjunto de chamadas de procedimentos e tipos para a linguagem de programação $\mathrm{C} / \mathrm{C}++$. Esse conjunto é implementado através do pthread.h e da biblioteca threads, embora esta biblioteca possa fazer parte de uma outra biblioteca, tal como a libc.

Algumas das motivações para usar o Pthreads (LAWRENCE, 2003):

- Potenciais ganhos de desempenho do programa;

- Custo de criação e gerenciamento dos processos é maior que o custo de criação e gerenciamento de threads pelo sistema operacional;

- Todas as threads dentro do processo compartilham o mesmo espaço de endereçamento de memória; $\mathrm{e}$

- A comunicação inter-threads é mais eficiente que a comunicação interprocessos e em muitos casos mais fácil de ser utilizada;

No apêndice $B$, é explicado com mais detalhes algumas funções e rotinas utilizadas pela API Phtreads e que contribuem e facilitam o desenvolvimento de programas paralelos com essa API. 


\subsubsection{OpenMP}

O OpenMP (LAWRENCE, 2003b), (NATIONAL, 2004), (OpenMP, 2004) e (SILVA, 2004), assim como o Pthreads, é uma API utilizada para o desenvolvimento de programas paralelos em ambientes MIMD com memória compartilhada. O OpenMP é uma especificação que define um conjunto de diretivas de compilação, variáveis de ambiente e biblioteca de rotinas.

A meta que a especificação do OpenMP buscou atingir, é permitir que os programas desenvolvidos com essa API sejam portáveis para as diferentes arquiteturas de memória compartilhada. O OpenMP pode ser utilizado em conjunto com as linguagens $\mathrm{C}$ e $\mathrm{C}++$, assim como o Pthreads e, também para o Fortran.

\subsection{Compilador OpenMP}

Para compilar os programas, desenvolvidos com o OpenMP, cada fabricante procurou desenvolver o seu próprio compilador, agregando características e otimizações para a sua própria arquitetura. O compilador OpenMP, utilizado nos experimentos (Capítulo 5), foi desenvolvido pela Intel@ e chama-se icpc (INTEL®, 2004).

O compilador icpc procura melhorar o desempenho do software para a arquitetura Intel $\otimes$, possuindo otimizações para a arquitetura MIMD de memória compartilhada. $\mathrm{O}$ icpc possui algumas características como (INTEL $(2004)$ ):

- Isenta o programador de ter que tratar detalhes de baixo nível como o gerenciamento do espaço de compartilhamento da memória, o compartilhamento de dados, e a sincronização e escalonamento das threads.

- Melhora os benefícios do compartilhamento de memória e dos sistemas multi-processadores.

\subsection{Modelo de execução e programação}

Para prover o paralelismo das aplicaçбes o OpenMP utiliza o mecanismo de exploração de paralelismo Fork/Join, apresentado neste capitulo na subseção 2.3.1.3 e demonstrado na Figura 2.13 a seguir. 


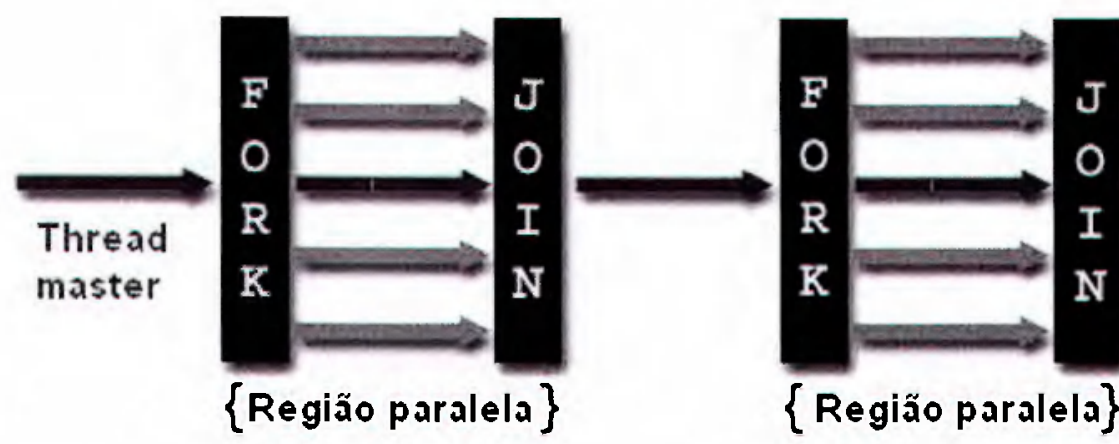

Figura 2.11 Modelo de exploração de paralelismo do OpenMP

Todos os programas OpenMP iniciam a execução com um thread master, que executam seqüencialmente até encontrar a primeira região paralela. Então, a thread master cria um conjunto de threads que irão realizar a sua execução em paralelo. Quando o conjunto de thread finaliza a sua execução paralela, elas são então sincronizadas e terminadas, voltando à execução para a thread master.

O OpenMP é um modelo de programação explícito, permitindo que o programador tenha controle total sobre a paralelização. $\dot{E}$ suportada pelo OpenMP a programação multi-thread, onde uma thread principal é iniciada e a partir dela se pode criar diversas outras threads.

Alguns exemplos de desenvolvimento com o OpenMP podem ser observados no apêndice A, bem como algumas diretivas dessa API.

\subsubsection{Massage Passing Interface}

Message Passing Interface (MPI) (GROPP \& LUSK, 2004), (LAWRENCE, 2003d), (LAWRENCE, 2003e), (MPI, 2003), (NATIONAL, 2003), (PACHECO, 1997) e (PACS, 2004), diferentemente do OpenMP e do Pthreads, é uma API para a comunicação em ambientes de máquinas MIMD de memória distribuída. O MPI é uma biblioteca de sub-rotinas de comunicação, desenvolvidas em linguagem $\mathrm{C}$ e que são utilizadas no desenvolvimento de programas para serem executados em mais de um processador, simultaneamente (Programas Paralelos). Pode ser utilizado nas linguagens FORTRAN, C ou CH. O MPI é uma biblioteca de sub-rotinas padronizada, cada fabricante de computadores é responsável por desenvolver e otimizar uma biblioteca MPI para o seu ambiente paralelo de processamento (PACHECO, 1997). É um padrão para software de programação paralela em multicomputadores, ou seja, em ambientes 
que possuem a memória distribuída.

Ao contrário do que muitas pessoas podem pensar, o MPI não é uma implementação, mas sim uma especificação padrão. Uma especificação descreve o que deve ser feito, mas não descreve como fazê-lo. O órgão responsável pela definição da sintaxe e da semântica do padrão MPI é o MPI Fórum (MPI, 2003). Os principais objetivos desse comitê são, a padronização para a maioria dos fabricantes de hardware e plataformas portáveis. Ficando a cargo dos desenvolvedores a implementação das especificações MPI definidas pelo fórum.

O MPI Forum definiu diversas características do MPI (MPI, 2003). Dentre elas estão:

- Facilidade - definir uma interface semelhante as já existentes, como a PVM, acrescentando algumas extensões que permitam maior flexibilidade;

- Eficiência - desenvolvido para executar com eficiência em um ambiente heterogêneo;

- Portabilidade - compatível para sistemas de memória distribuída;

- Transparência - permite a portabilidade para sistemas e implementações heterogêneas, não necessitando de mudanças significativas;

- Segurança - fornece uma interface de comunicação segura. Isentando do usuário a preocupação com falhas de comunicação;

- Escalabilidade - Permite vários níveis de escalabilidade, podendo, por exemplo, uma aplicação criar subgrupos de processos.

No apêndice $C$, são apresentadas algumas funções e rotinas que contribuem e auxiliam o desenvolvimento de programas paralelos com a API do MPI.

\subsection{Considerações}

Para se desenvolver um programa paralelo, deve-se pensar em diversas questões como o tipo de arquitetura em que o programa irá executar, qual a melhor forma de dividir o programa seqüencial, o que pode ser executado em paralelo e onde poderão estar os gargalos de comunicação. Após a escolha da arquitetura e identificado os pontos que poderão se tornar paralelos, tem-se que escolher qual a melhor ferramenta para desenvolver o programa. Daí o programador deve escolher qual ferramenta se enquadra melhor nas suas necessidade e qual ferramenta que ele possui maior afinidade. 
Quando o programa paralelo estiver desenvolvido, então o programador deverá mensurar o desempenho para realmente saber se o desempenho superou a versão seqüencial e em caso negativo, verificar se será melhor permanecer com a versão seqüencial ou desenvolver o programa novamente.

Diante de tantas questões é que a programação paralela não se torna trivial e por isso é desenvolvida por poucos. 


\section{Transformada de Hough}

\subsection{Introdução}

$\mathrm{Na}$ área de processamento de imagens, atualmente, existem diversas pesquisas que necessitam extrair dados de uma imagem. Alguns dos dados extraídos a partir de uma imagem são os reconhecimentos de retas, círculos e elipses. A detecção dessas características requer, em sua maioria, grande poder de processamento, e por esse motivo, necessita de atenção especial. Esse foi um dos motivos que determinaram o desenvolvimento desse trabalho, que procura auxiliar a área de processamento de imagens com a execução da deteç̧ão de retas através da Transformada de Hough Paralela, que será vista em mais detalhes no restante do capítulo.

$\mathrm{O}$ reconhecimento de padrões complexos em uma imagem pode ser obtido pelo método desenvolvido por Hough em 1962, que objetivava reconhecer padrões de uma fotografia(HOUGH, 1962), é um método bastante utilizado atualmente para o reconhecimento de padrões em imagens(PEREIRA, 1995). A idéia básica da técnica inventada por Hough, era de encontrar curvas que podem ser parametrizadas, tais como segmentos de retas, polinômios, círculos, elipses e etc., em um espaço de parâmetros (arranjo acumulador).

Dentre os diversos padrões que podem ser reconhecidos a partir da transformada de Hough, o mais difundido e utilizado é o segmento de reta (provavelmente devido à importância dessa modalidade em visão e processamento de imagens), sendo diversas vezes reconhecida como uma técnica de deteç̧ão de retas, técnica essa que será abordada em mais detalhes na seção 3.3 .

\subsection{Fundamentos da transformada de Hough}

A Transformada de Hough (HT), foi inicialmente proposta como um método para deteç̧ão de padrões complexos em imagens binárias, patente que foi concedida a 
P.V.C Hough (HOUGH, 1962) em 1962, como o nome de "Method and Means for Recongnizing Complex Patterns". Pela proposta de Hough a linha é mapeada usando os parâmetros de inclinação-interseç̧ão. A Figura 3.1 (a) ilustra uma linha reta que conecta uma seqüência de pontos expressos pela seguinte equação:

$$
y=m \cdot x+c
$$

onde $\boldsymbol{m}$ representa a inclinação e $\boldsymbol{c}$ a intersecção.

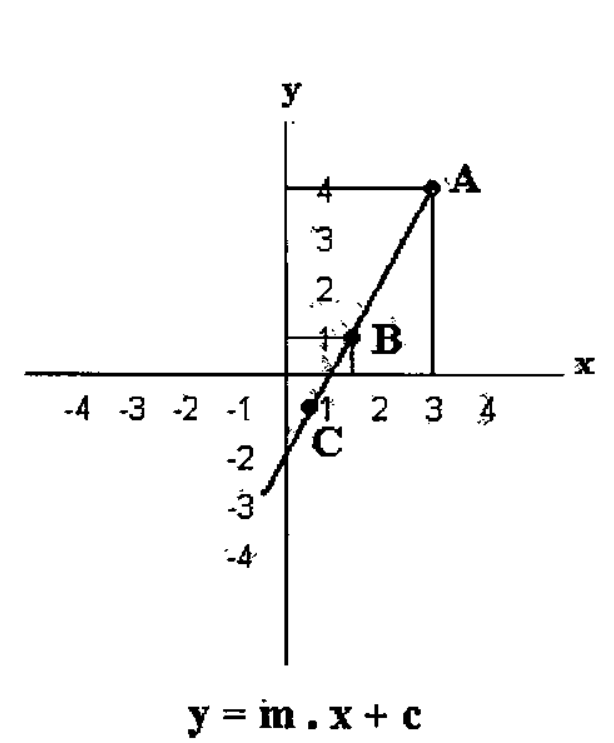

(a)

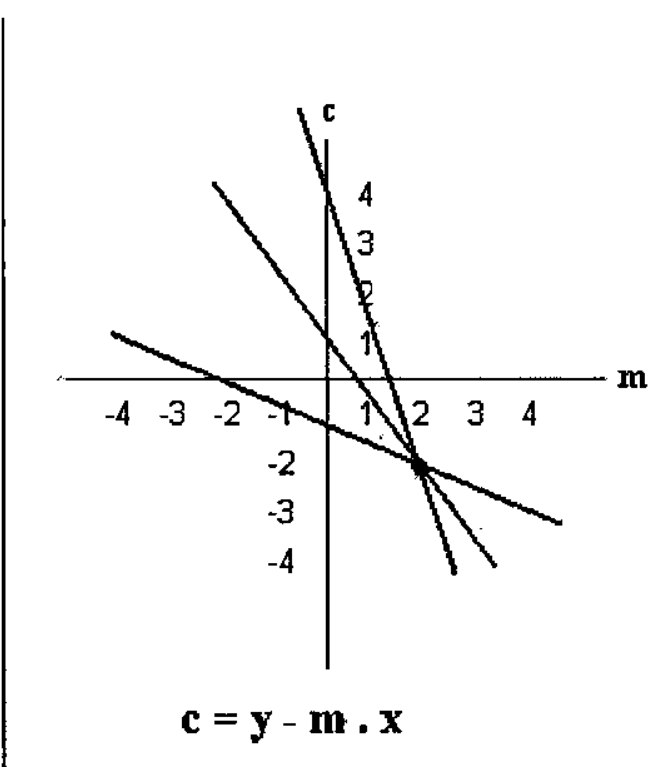

(b)

Figura 3.1 (a) Espaço Imagem, (b) Espaço de parâmetros

Considerando-se três pontos, A, B e C, conforme indica a Figura 3.1 (a), pertencentes à mesma reta, onde cada ponto do espaço imagem é transformado em uma equação de reta. A tabela a seguir ilustra as equações.

Tabela 3.1 Efeito da TH sobre uma linha reta

\begin{tabular}{|c|c|c|c|c|}
\hline & $\mathrm{x}$ & $\mathrm{Y}$ & $\mathrm{y}=\mathrm{m} \cdot \mathrm{x}+\mathrm{c}$ & $\mathrm{c}=-\mathrm{x} \cdot \mathrm{m}+\mathrm{y}$ \\
\hline $\mathrm{A}$ & 3 & 4 & $4=\mathrm{m} \cdot 3+\mathrm{c}$ & $\mathrm{C}=-3 \cdot \mathrm{m}+4$ \\
\hline $\mathrm{B}$ & 1,5 & 1 & $1=\mathrm{m} \cdot 1,5+\mathrm{c}$ & $\mathrm{C}=-1,5 \cdot \mathrm{m}+1$ \\
\hline $\mathrm{C}$ & 0,5 & -1 & $-1=\mathrm{m} \cdot 0,5+\mathrm{c}$ & $\mathrm{C}=-0,5 \cdot \mathrm{m}+-1$ \\
\hline
\end{tabular}

Essas retas então, são traçadas no espaço de parâmetros, definindo, assim, o ponto de intersecção, conforme indica a Figura 3.1 (b). Entretanto, tanto a inclinação como a intersecção são ilimitadas e essa parametrização tem a desvantagem de ser 
sensível à escolha do eixo de coordenadas no plano da Figura. $\mathrm{O}$ que dificulta a aplicação da técnica (CHUTATAPE \& GUO, 1999), (SILVA, 1996) e (MARTINEZ, 2002).

Uma solução para esse problema foi proposta por Duda e Hart (DUDA \& HART, 1972), onde eles utilizaram coordenadas polares para definir uma reta, trabalhando com os parâmetros Ângulo-Raio ao invés de Inclinação-Intersecção. O método de Duda e Hart (DUDA \& HART, 1972), envolve o mapeamento de retas do espaço imagem, para conjuntos de pontos num espaço de parâmetros Ângulo-Raio. Esse método será descrito em detalhes na seção seguinte.

\subsection{Transformada de Hough para retas}

O método desenvolvido por Hough constituía em detectar pontos colineares ou quase colineares numa imagem. Para saber se os pontos são colineares, deve-se calcular o coeficiente das retas que passam pelo ponto. Em um dado ponto da imagem podem passar infinitas retas. E uma reta pode ser definida por dois parâmetros, utilizando-se coordenadas polares (DUDA \& HART, 1972) $(\rho, \theta)$ onde $\rho$ indica a distância mínima da reta a origem do plano cartesiano e, $\theta$ indica o coeficiente angular que o segmento de reta $\rho$ faz com o eixo " $x$ " das ordenadas. Conforme indica a Figura 3.2

Os pontos que caem sobre essa reta podem ser representados por:

$$
\rho=\mathrm{x}^{*} \cos \theta+\mathrm{y} * \operatorname{sen} \theta \quad(3.2)
$$

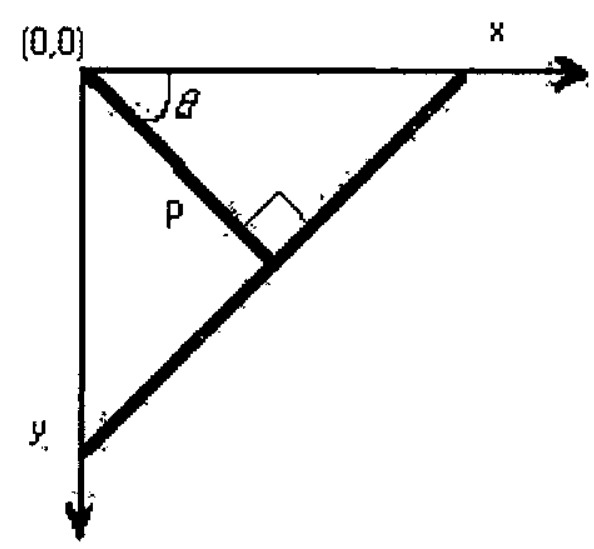

Figura 3.2 Coordenadas Polares. 
Os novos parâmetros utilizados para representar o espaço são definidos agora por $\rho$ e $\theta$ Logo, o problema de detectar pontos colineares pode ser convertido no problema de se encontrar curvas concorrentes (BRUNO, 2000), (MARTINEZ, 2002), (SILVA, 1996) e (PEREIRA, 1995).

Segundo Duda e Hart (DUDA \& HART, 1972) as propriedades para se transformar pontos em curvas são:

- Um ponto no plano da Figura, ou plano imagem corresponde a uma curva senoidal no plano de parâmetros;

- Um ponto no plano de parâmetros corresponde a uma reta no plano da Figura;

- Pontos pertencentes à mesma linha reta no plano imagem correspondem a curvas através de um ponto no plano de parâmetros;

- Pontos pertencentes à mesma curva no plano de parâmetros correspondem a linhas através do mesmo ponto no plano imagem.

$\mathrm{Na}$ Figura $3.3 \mathrm{em}$ (a) temos a ilustração dos pontos no espaço imagem, em (b) tem-se o mapeamento dos pontos no espaço $(\rho, \theta)$, na ilustração (c) tem-se a detecção das propriedades de colinearidade, onde o ponto " $\mathrm{A}$ " denota a intersecção entre as curvas correspondentes aos pontos 1,3 e 5 no plano $x-y$ e similarmente o ponto " $B$ " corresponde aos pontos colineares 2, 3 e 4 e em (d) tem-se a propriedade de reflexão, onde " $\mathrm{A}$ ", " $\mathrm{B}$ " $\mathrm{e}$ "C" se repetem quando a senóide inicia um novo ciclo, entretanto, com sinal negativo. 


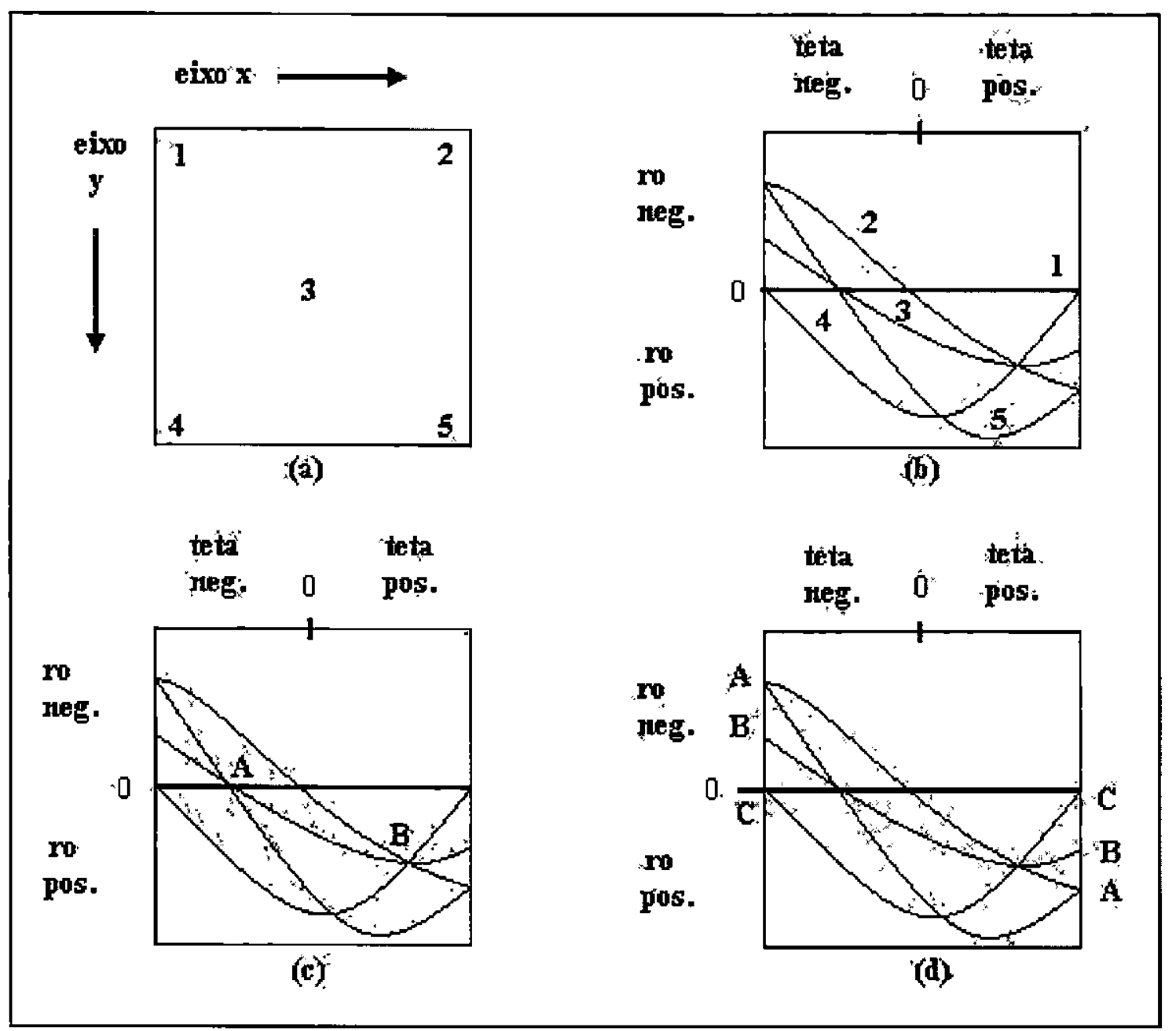

Figura 3.3 (a) pontos no espaço imagem, (b) mapeamento dos pontos no espaço $(\rho, \theta),(c)$ detecção das propriedades de colinearidade e em (d) tem-se a propriedade de reflexão

Essa transformada é aplicada a uma imagem contendo as bordas detectadas da cena a ser analisada. Para cada ponto $(x, y)$ da imagem uma senóide é traçada para o espaço paramétrico. Ao final do processamento, os pontos onde houver a maior intersecção de senóides, indicarão quais são os parâmetros que correspondem à reta, ou a outra forma especificada (círculo, elipse). A Figura 3.4 abaixo mostra a imagem original e a Figura 3.5 mostra a imagem já discretizada. 


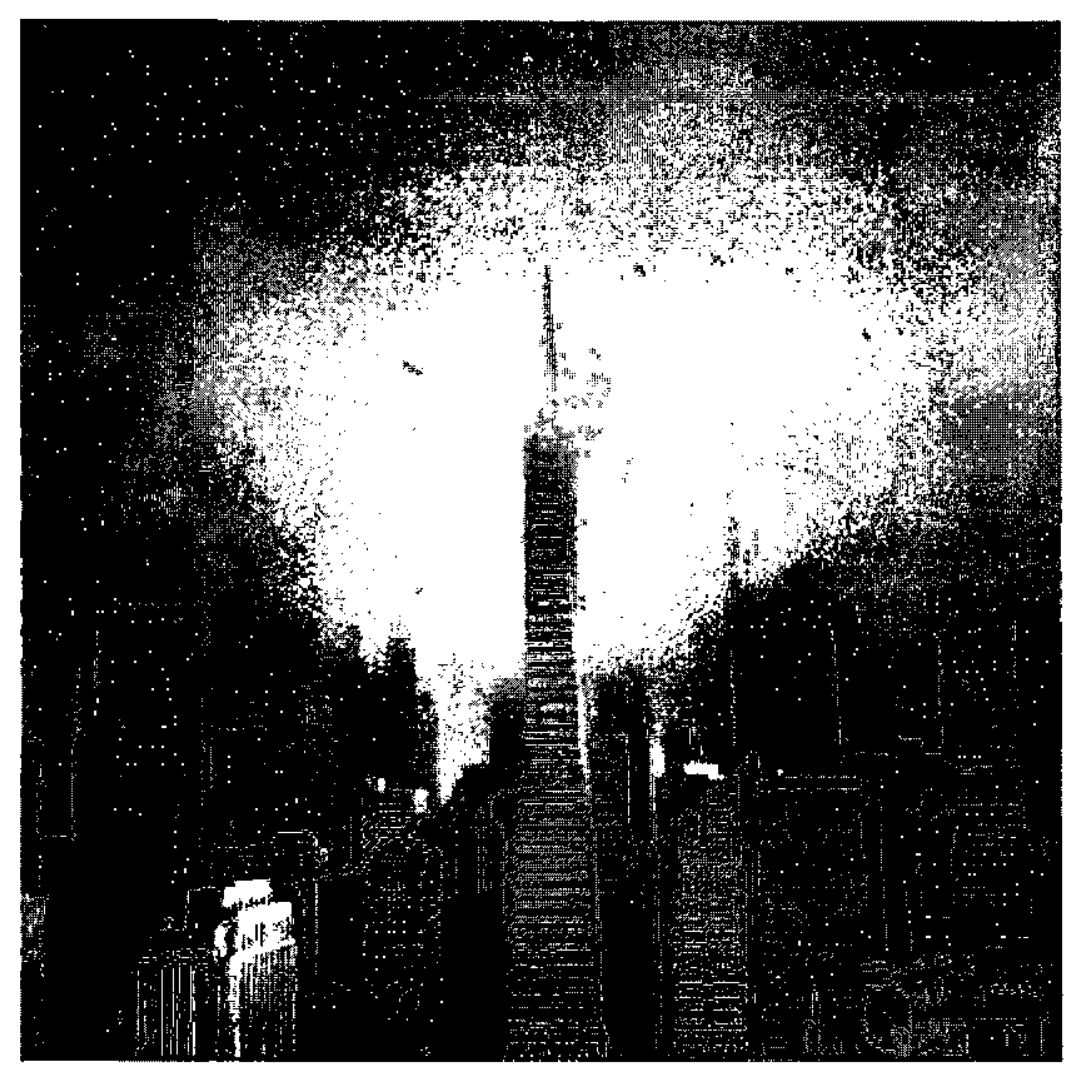

Figura 3.4 Imagem Original

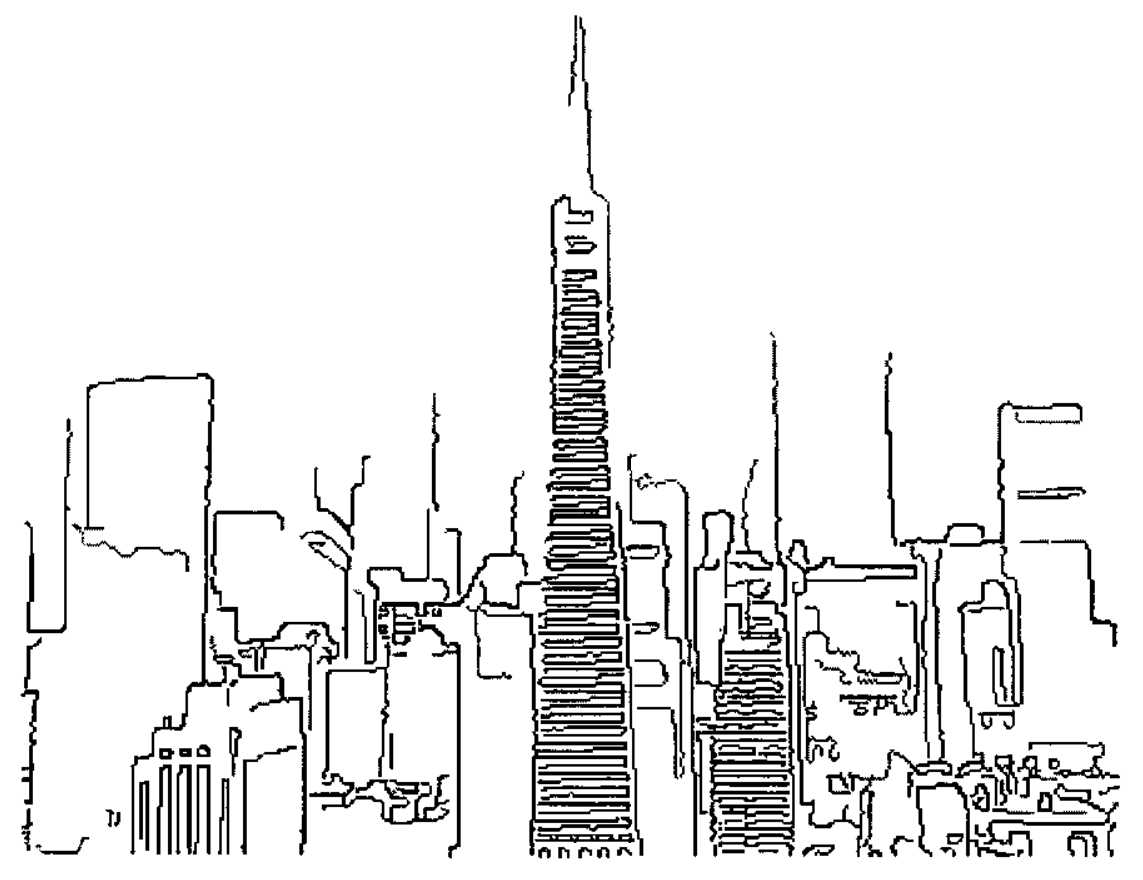

Figura 3.5 Imagem discretizada 
De posse das propriedades, é feito o mapeamento das curvas no arranjo acumulador. A construção do arranjo acumulador bidimensional é definida dentro de um erro aceitável, em $(\rho, \theta)$ formando uma grade. Esta grade pode ser limitada no intervalo $0 \leq \theta<180$ e $-\mathrm{R} \leq \rho<\mathrm{R}$, onde $\mathrm{R}$ é o tamanho da célula, desde que pontos fora desse retângulo correspondam a linhas no plano da imagem que não cruzem a célula. Com a limitação de $\theta$, toda linha no plano $x-y$ corresponde a um único ponto no plano $(\rho, \theta)$. Com a equação 3.2 , a cada ponto $(x, y)$ do espaço imagem, a curva correspondente é colocada no arranjo incrementando-se de uma unidade o contador em cada célula ao longo da curva (DUDA \& HART, 1972), (MARTINEZ, 2002) e (SILVA, 1996). A Figura 3.6 mostra um arranjo acumulador.

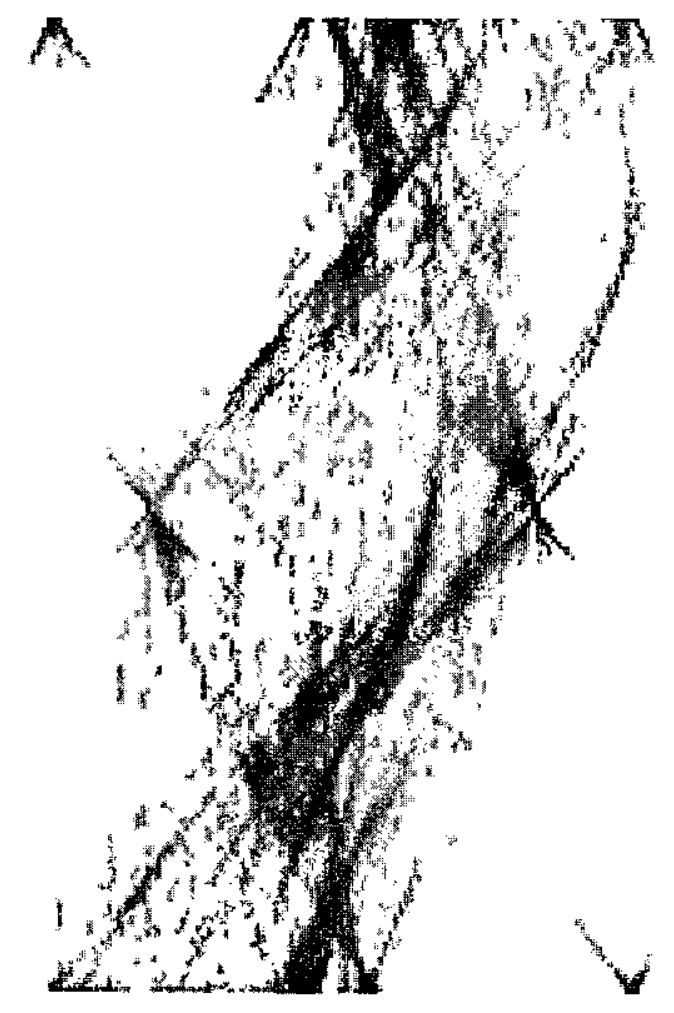

Figura 3.6 Arranjo acumulador

A análise do arranjo, após os cálculos da equação 3.2 , revelam células que possuem números elevados de contagens. Esses valores de contagem representam, para cada célula, dentro de um erro de quantização, a quantidade de pontos coincidentes de uma reta. Então, o método da HT requer que sejam identificados os pontos que possuem máximos locais. Muitas vezes, ocorrem vários picos altos próximos uns dos outros no arranjo (MARTINEZ, 2002), (SILVA, 1996), (PEREIRA, 1995). Com isso, existe a necessidade de utilizar um "threshold", para filtrar a quantidade de erros e 
aproximações e assim poder identificar realmente os parâmetros da imagem, ou utilizar alguma outra técnica para identificação desses máximos locais, uma dessas técnicas é a "backmapping" (BRUNO, 2000), que é apresentada na seção 3.5. Na subseção seguinte será visto um algoritmo da HT para retas.

\subsubsection{Algoritmo da transformada de Hough para retas}

$\mathrm{O}$ algoritmo requer um acumulador de dimensão igual a quantidade de parâmetros da família da curva a ser reconhecida, neste caso uma reta com dois parâmetros $(\rho, \theta)$ portanto, é necessária uma matriz de duas dimensões, onde $\rho$ indicará a altura do espaço paramétrico que pode ser definida como a raiz quadrada da soma da altura da imagem ao quadrado e da largura da imagem ao quadrado. E $\theta$ a largura do espaço paramétrico, indicando o ângulo, que pode variar de zero a $180^{\circ}$.

Para cada ponto da imagem $(\mathrm{x}, \mathrm{y})$ calcula-se a senóide. O cálculo da senóide é feito variando o ângulo de zero a $180^{\circ}$ e para cada valor encontrado de $\rho$ com seu respectivo ângulo $\theta$ incrementa-se a matriz acumuladora na posição correspondente. $\mathrm{A}$ Figura 3.7 ilustra o algoritmo da $\mathrm{TH}$.

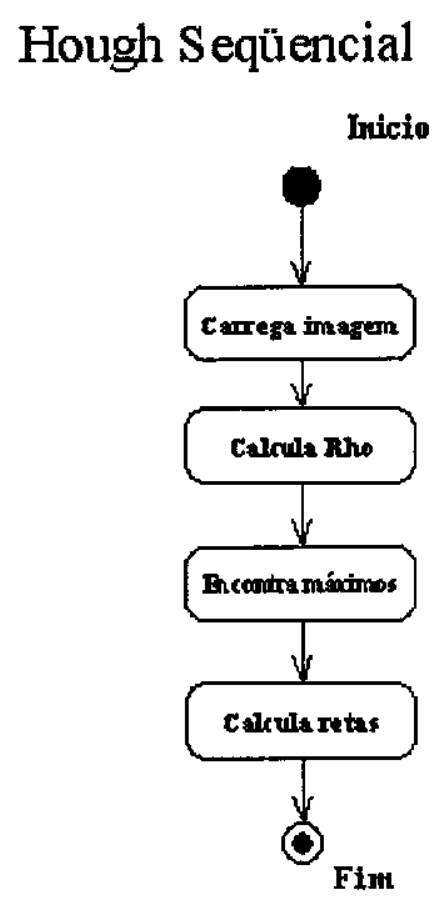

Figura 3.7 Transformada de Hough

Depois de geradas as senóides de todos os pontos, verifica-se na matriz acumuladora onde houve a maior intersecção de senóides, esse ponto indica um ponto da reta, faz-se 
isso para todos os pontos que estão acima de um limiar, abaixo disso pode ser considerado como ruído

Em seguida, é feita a conversão dos pontos restantes no espaço paramétrico, para retas no plano cartesiano (indicado na Figura 3.7 pelo estado cálculo das retas). $\mathrm{O}$ cálculo é feito isolando-se o x ou o y da equação (1):

$$
\mathbf{x}=\left(\rho-y^{*} \operatorname{sen} \theta\right) / \cos \theta
$$

ou

$$
y=\left(\rho-x^{*} \cos \theta\right) / \operatorname{sen} \theta
$$

O ângulo indicará qual das fórmulas utilizar, se o ângulo estiver próximo a $90^{\circ}$, indica que a reta está quase vertical, ou seja, se a reta está vertical ao eixo "x", então se usa a fórmula (3.4), senão utiliza-se a fórmula (3.3). Variando o $x$ ou $y$ até a largura ou altura da imagem original.

\subsection{Transformada de Hough para objetos circulares}

Duda e Hart (DUDA \& HART, 1972) sugeriram que a transformada de Hough para retas fosse adaptada para reconhecer objetos circulares em imagens. Pode-se ter uma circunferência dada por uma equação paramétrica e a transformada de Hough pode ser aplicada. A equação de uma circunferência é dada por:

$$
(x-a)^{2}+(y-b)^{2}=c^{2}
$$

Onde "a" e "b" são coordenadas do centro da circunferência e "c" o seu raio de curvatura.

Tomando todos os pixels do plano imagem e aplicando a equação abaixo:

$$
\left(x_{i}-a\right)^{2}+\left(y_{i}-b\right)^{2}=c^{2}
$$

Tem-se que cada pixel do plano imagem provocará uma circunferência no espaço de parâmetros. A partir da transformação do espaço imagem, através da transformada de Hough circular, é gerado um espaço onde os pontos da imagem correspondem a circunferências no espaço de parâmetros. Os pontos $(a, b)$ são assim, 
armazenados no arranjo acumulador. $O$ cruzamento das circunferências traçadas no espaço de parâmetros $(a, b)$ define as coordenadas do centro de uma circunferência e o valor acumulado nesta célula define quantos pixels pertencem à circunferência (DUDA \& HART, 1972), (BENTES, 1997) e (MARTINEZ, 2002).

Desta forma, dada uma imagem com cinco pixels, como apresentada na Figura 3.8 e querendo saber se existe pixels que possam compor a imagem de uma circunferência no raio $=1 / \sqrt{2}$. Monta-se um arranjo acumulador com o espaço de parâmetros, conforme ilustra a Figura 3.9.

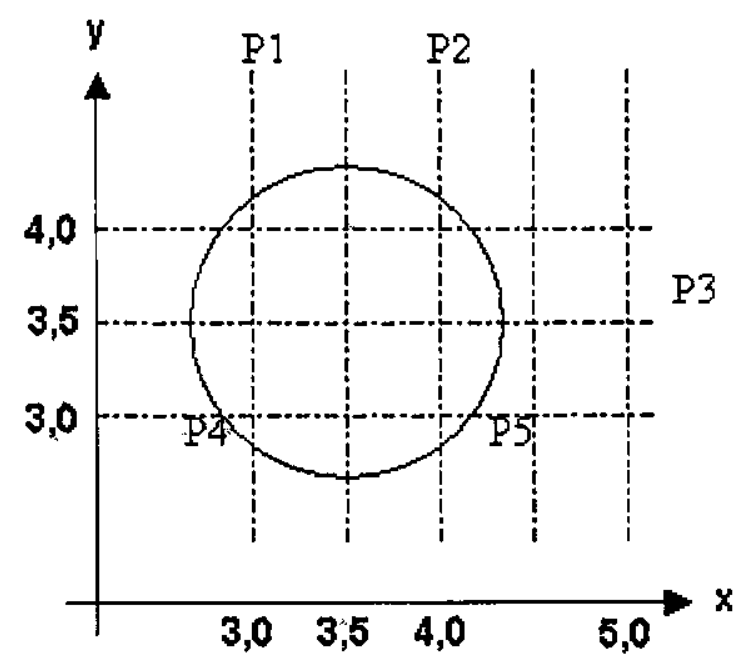

Figura 3.8 Imagem de uma circunferência, ilustrando os pixels no plano $x, y$.

Como foi realizado no caso de detecção de retas, define-se um arranjo acumulador, onde serão armazenadas as circunferências traçadas com centro nos pixels da imagem (plano cartesiano). 


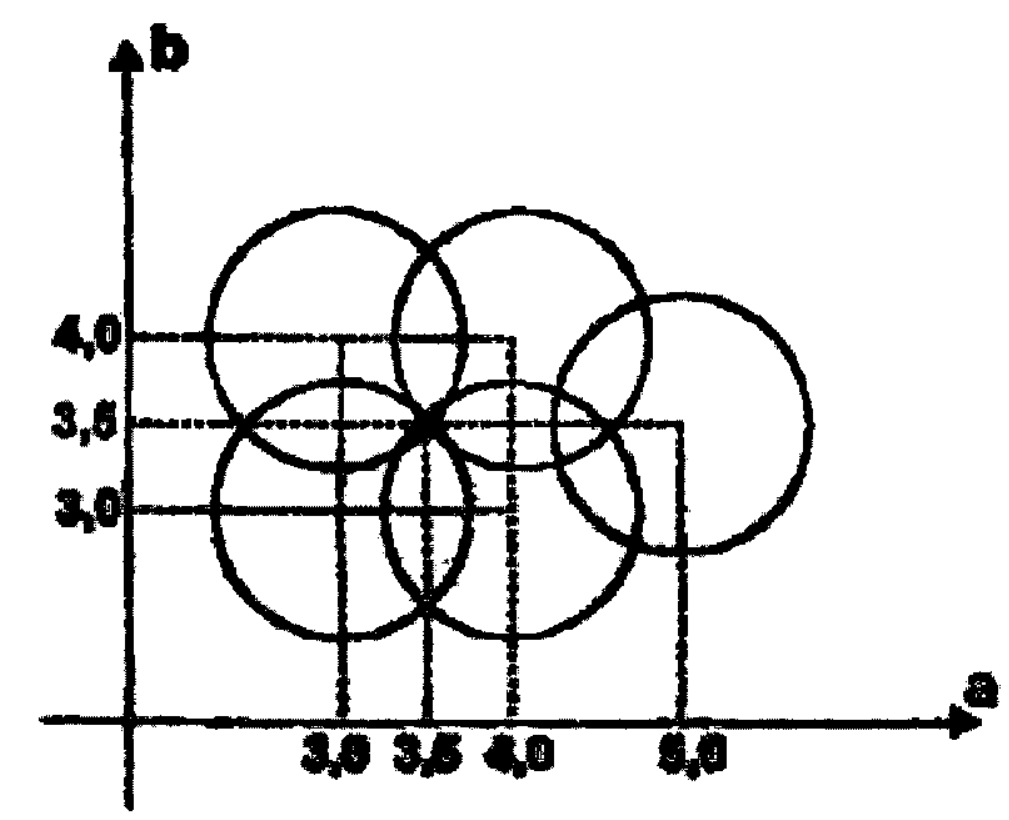

Figura 3.9 espaço de parâmetros "a" e "b" para circunferências.

Mais detalhes da transformada de Hough para objetos circulares, podem ser encontrados em (DUDA \& HART, 1972), (BENTES, 1997) e (MARTINEZ, 2002).

\subsection{Backmapping}

Na transformada de Hough, um dos grandes problemas existentes é o de encontrar os picos no arranjo acumulador. A grande dificuldade reside na característica local de cada pico, sendo este um problema que ainda se encontra em pesquisa para ser solucionado por completo (BRUNO, 2000).

Devido às limitações no processo de localização dos picos locais, como resultado da transformada podem ser apresentadas diversas curvas inexistentes, provocadas pela interferência de pontos colineares entre diferentes curvas, entre segmentos com poucos pixels e até mesmo o ruído presente na imagem (BRUNO, 2000).

Para a solução deste problema, foi introduzida uma etapa a mais na transformada de Hough, por Gerig e Klein (GERIG \& KLEIN, 1986), chamado de backmapping. O método de backmapping cria um novo arranjo acumulador, onde a transformada é novamente calculada para cada ponto da imagem. Para este novo espaço, somente são computadas as células que correspondem aos valores máximos de cada uma das senóides do arranjo original. Desta forma, essa abordagem corresponde a um reforço 
aplicado à transformada de Hough (BRUNO, 2000), na tentativa de encontrar os picos locais e reduzir os picos causados pelos pontos colineares de curvas distintas, pelos ruídos, pela interferência entre objetos e segmentos com poucos pontos. Na Figura 3.10 é ilustrado o diagrama de estados da TH com Backmapping.

\section{Hough Seqüencial BackMapping}

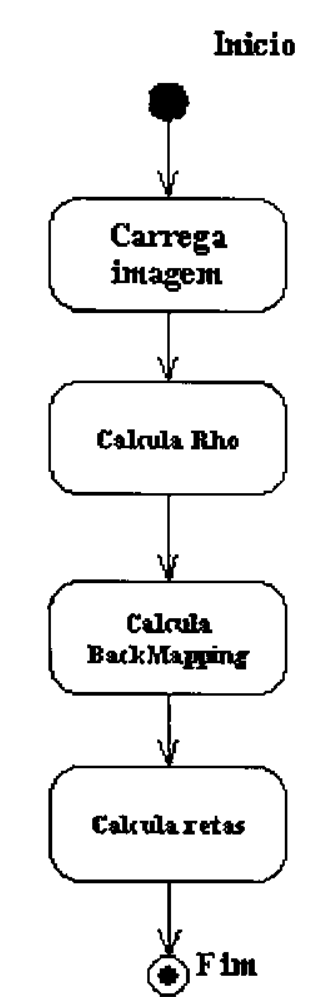

Figura 3.10 Hough com Backmapping

Note que, para o diagrama de estados do Hough normal (Figura 3.7), apenas um estado muda, em vez de encontrar os máximos locais definindo um limiar, realiza-se novamente o cálculo do rho $(\rho)$ só que para identificar os máximos de cada curva, isso é, o Backmapping.

O problema que surge realizando novamente o cálculo do rho é o incremento substancial da quantidade de computação envolvida, pois, como ocorre quando se realiza o primeiro cálculo do rho, no Backmapping deve-se realizar novamente o cálculo de cada senóide para encontrar os máximos, isto significa que, para ponto da imagem original tem-se que calcular o rho variando o theta $(\theta)$ de 0 a 180 graus, quase dobrando a computação envolvida. 


\subsection{Considerações}

Como pode ser visto, o entendimento da transformada de Hough é relativamente fácil. Mas a facilidade de entendimento não se traduz em facilidade de computação, pois a quantidade de computação envolvida na identificação das retas é grande. Demandando grande poder computacional para ser resolvida.

Além da quantidade de computação, há, também, o problema de identificação dos máximos locais, podendo gerar ruído se utilizada à identificação por limiar. Para solucionar este problema, pode-se utilizar a técnica do backmapping, que constitui em um novo cálculo do $(\rho)$, mas esse método quase dobra os cálculos envolvidos. Devido a esses fatores é que a transformada de Hough torna-se onerosa. E para tentar minimizar esse custo computacional é que foram desenvolvidas algumas estratégias de paralelização da transformada de Hough, que serão vistos no próximo capítulo. 


\section{Transformada de Hough Paralela}

A transformada de Hough seqüencial é muito morosa, haja visto que para cada coordenada da imagem, em que exista um ponto, devem-se fazer os cálculos de $\rho$ variando o $\theta$ de 0 a 180 graus, exigindo grande poder computacional e uma grande repetição de tarefas. Observando esses problemas, surgiu a idéia de transformar o método de Hough seqüencial em um método que seja executado em paralelo. Algumas estratégias para paralelizar a Transformada de Hough seqüencial são expostas nas subseções a seguir.

\subsection{Divisão da imagem}

Uma das alternativas utilizadas para paralelizar a transformada de Hough foi a divisão da imagem em pedaços (BRUNO, 2000), (KRISHNASWAMY \& BANERJEE, 1997) e (LI et al, 1991). Um computador central, chamado de mestre, é o responsável por dividir a imagem em tamanhos iguais e enviar os pedaços da imagem para os processadores ou computadores escravos, para ser processado. O escravo irá calcular os valores de $r h o(\rho)$ variando os valores de theta $(\theta)$ de 0 a 180 graus, para o pedaço da imagem que foi a ele designado.

Após calculados os valores de $\rho$ e incrementado o arranjo acumulador na posição correspondente, é passado para o processo mestre somente $o$ arranjo acumulador, para que ele faça a junção de todos os arranjos acumuladores, vindos dos escravos.

A Figura 4.1 a seguir, mostra a divisão da imagem e a Figura 4.2 mostra o envio dos pedaços da imagem aos computadores escravos. 


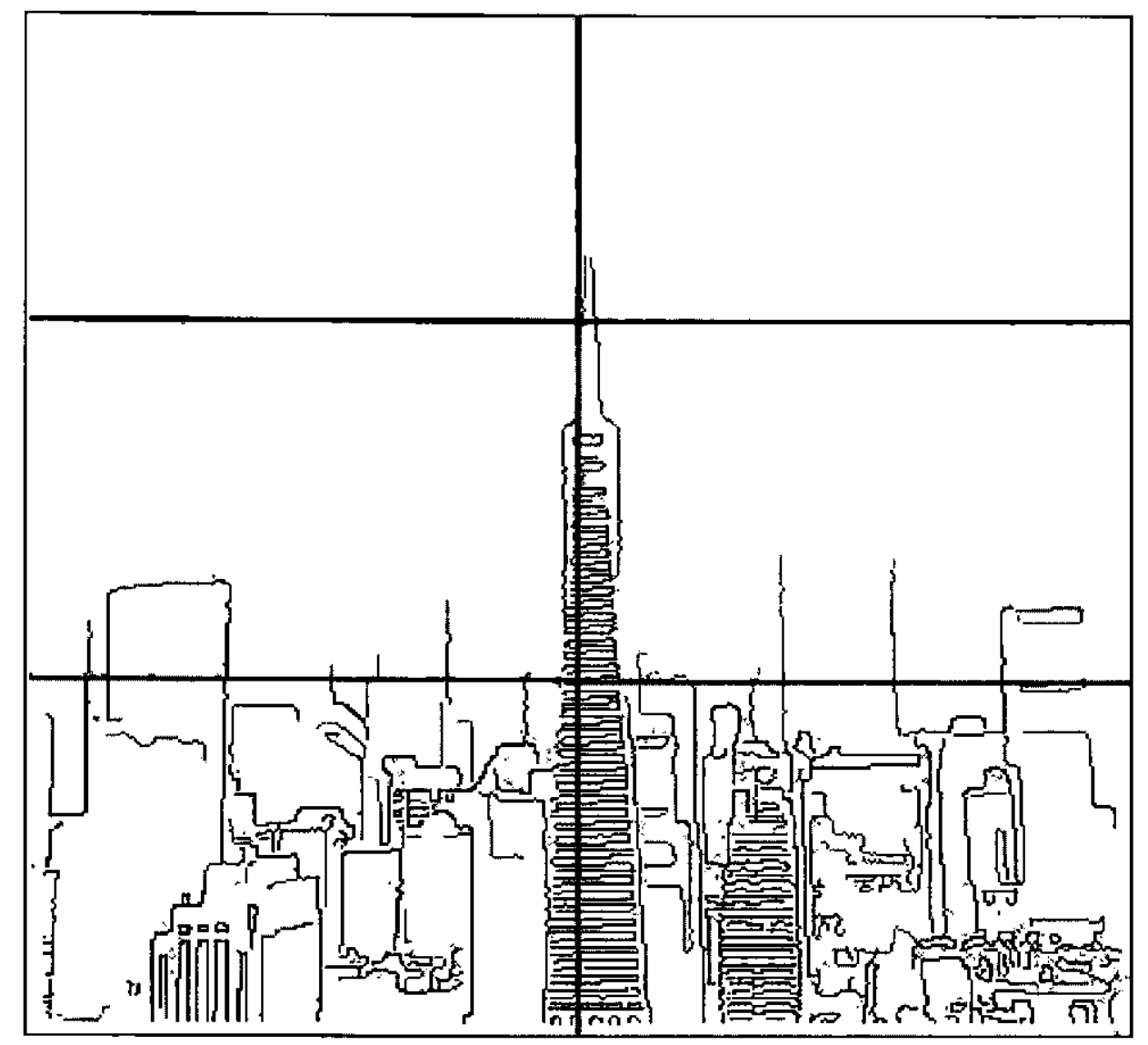

Figura 4.1 Divisão da imagem em 6 pedaços iguais

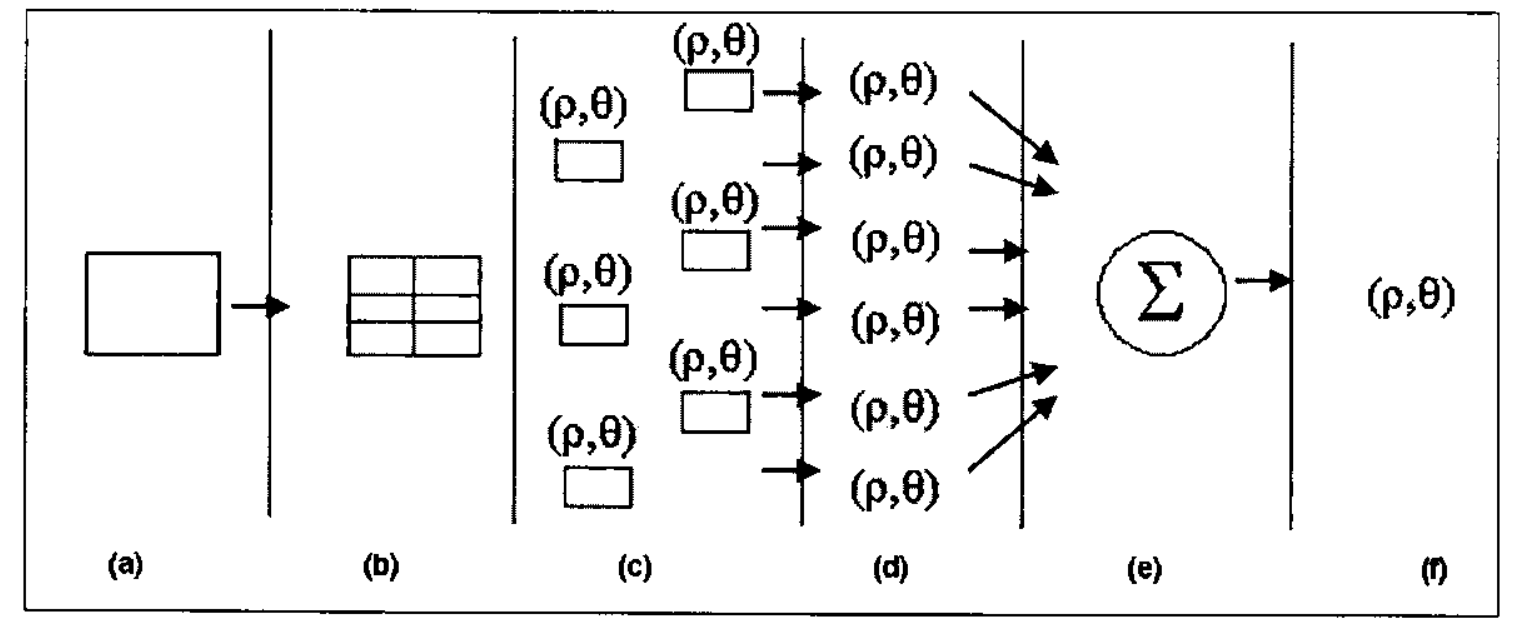

Figura 4.2 Envio Estratégia de paralelismo para a transformada de Hough. As etapas (a), (b), (c), (d), (e) e (f) representam respectivamente: a imagem original, divisão da imagem e sua distribuição, processamento de cada fragmento da imagem, arranjos acumulador resultante do processamento de cada fragmento, somatório dos elementos dos arranjos acumulador e arranjo acumulador resultante.

A estratégia de divisão da imagem foi paralelizada com três ferramentas de 
apoio a programação paralela. As ferramentas utilizadas foram o OpenMP (LAWRENCE, 2003b), (NATIONAL, 2004), (OpenMP, 2004) e (SILVA, 2004) e o Pthreads (IEEE, 2004), (LAWRENCE, 2003) e (TORELLI \& MALLARA, 2003) para arquiteturas MIMD com memória compartilhada e o MPI (GROPP \& LUSK, 2004), (LAWRENCE, 2003d), (LAWRENCE, 2003e), (MPI, 2003), (NATIONAL, 2003), (PACHECO, 1997) e (PACS, 2004) para arquiteturas MIMD de memória distribuída Estas três ferramentas,podem ser observadas com detalhes no capítulo 2, nas subseções 2.4.1.1, 2.4.1.2 e 2.4.2 respectivamente.

Na Figura 4.3, é demonstrado o diagrama de estados para as ferramentas OpenMP e Pthreads. 


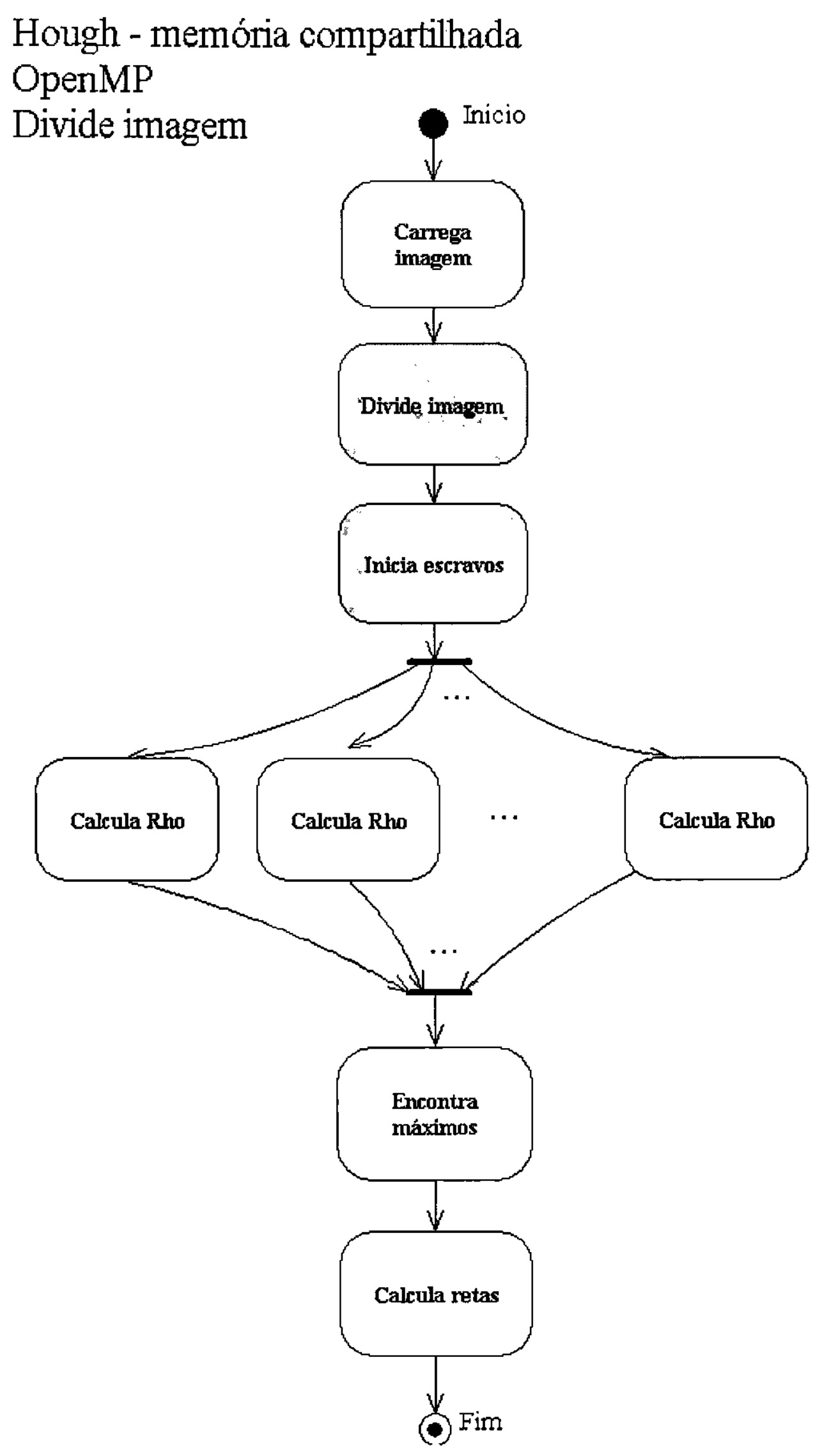

Figura 4.3 Diagrama de estados da $\mathrm{TH}$, estratégia divisão da imagem para as ferramentas OpenMP e Pthreads. 
O diagrama de estados para as ferramentas OpenMP e Pthreads é o mesmo, isso se dá pelo fato de as duas ferramentas serem utilizadas para o auxílio à programação paralela em arquiteturas MIMD de memória compartilhada e possuírem a mesma filosofia para a construção de programas paralelos.

$\mathrm{Na}$ Figura 4.4, é ilustrado um diagrama de estados da TH para a estratégia de divisão da imagem para arquiteturas MIMD de memória distribuída, utilizando a ferramenta, de auxílio à programação paralela por troca de mensagens, MPI. 


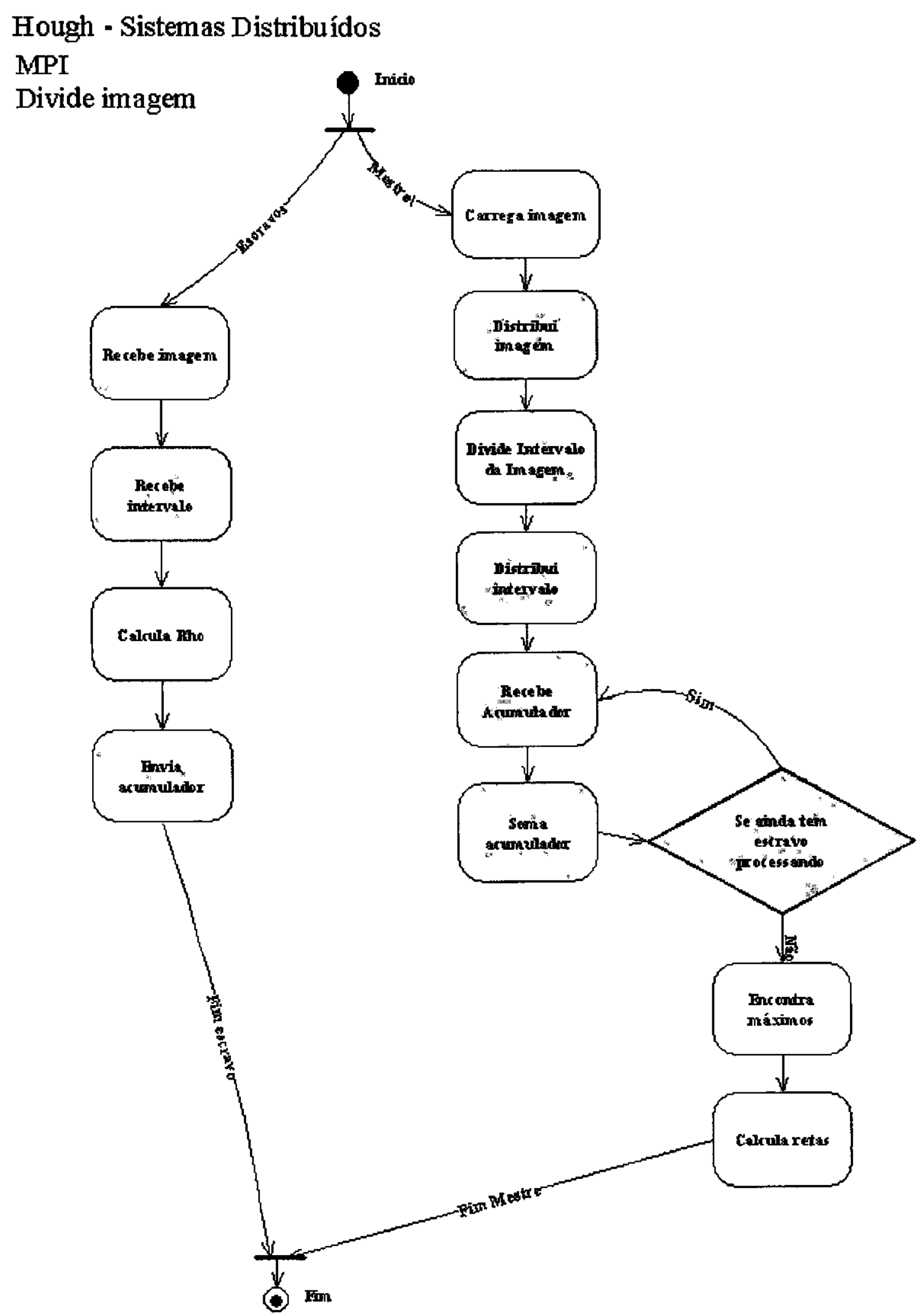

Figura 4.4. Diagrama de estados da TH, estratégia divisão da imagem com MPI.

Nota-se, que a quantidade de estados existentes para realizar as transformadas de Hough paralela em relação a seqüencial é maior. Isto se dá pela necessidade de controlar os processos escravos, dividir e distribuir a imagem. A paralelização da 
transformada de Hough é feita no cálculo do rho $(\rho)$ e a partir deste estado no diagrama seqüencial, são criados todos os estados que estão pintados indicados nos diagramas 4.3 e 4.4 .

\subsection{Distribuição do arranjo acumulador}

Neste método, em vez dos escravos receberem pedaços da imagem, eles receberam toda a imagem. $O$ que será dividido em partes iguais para os escravos é o arranjo acumulador (BRUNO, 2000), (JIN \& YANG, 1992) e (HOPWOOD et al, 1996) no eixo do ângulo theta $(\theta)$, ou seja, será dividido o ângulo para realização dos cálculos, de acordo com a quantidade de escravos.

Por exemplo, se existirem 4 escravos o ângulo será divido em 4 partes, cabendo ao primeiro escravo calcular sobre toda a imagem o ângulo $\theta$ que irá variar de zero a 44 graus. $O$ segundo escravo também calculará para toda a imagem mas o ângulo $\theta$ irá variar de 45 a 89 graus, e assim subseqüentemente até completar 180 graus.

A Figura 4.5 ilustra a estratégia de paralelização dividindo o arranjo acumulador e o distribuindo para ser processado pelos escravos. A imagem não é alterada, ela é distribuída a todos os escravos para ser processada. Os escravos realizarão o processamento em toda a imagem, mas na porção do arranjo acumulador que lhes couber.

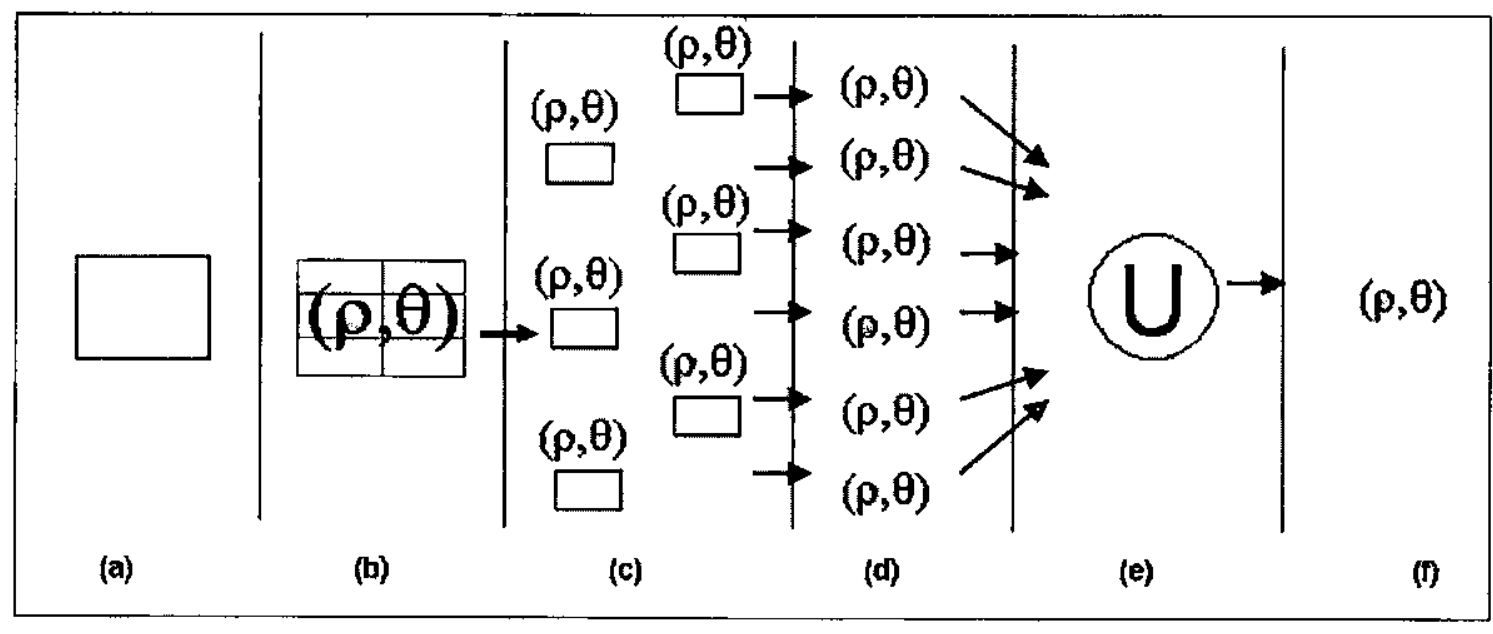

Figura 4.5 estratégia de paralelismo da distribuição do arranjo acumulador, onde em (a) tem-se a imagem original, em (b) é realizada a divisão do arranjo acumulador, em (c) é realizado o processamento para toda a imagem na porção do arranjo acumulador que couber ao escravo, em (d) é cada arranjo acumulador resultante, em (e) é realizada a união dos arranjos acumuladores e 
na imagem ( $f$ ) é o arranjo acumulador total resultante.

A paralelização da TH para a estratégia do arranjo acumulador foi realizada com as mesmas ferramentas da estratégia anterior (divisão da imagem), OpenMP (LAWRENCE, 2003b), (NATIONAL, 2004), (OpenMP, 2004) e (SILVA, 2004), Pthreads (IEEE, 2004), (LAWRENCE, 2003) e (TORELLI \& MALLARA, 2003) e MPI (GROPP \& LUSK, 2004), (LAWRENCE, 2003d), (LAWRENCE, 2003e), (MPI, 2003), (NATIONAL, 2003), (PACHECO, 1997) e (PACS, 2004). Esta estratégia de programação é muito similar a anterior, como pode ser observado nos diagramas nas Figuras 4.6 e 4.7, o que difere é que é enviado para os escravos o intervalo do theta $(\theta)$ que cada um irá processar.

Na Figura 4.6 é ilustrado o diagrama de estados para as ferramentas OpenMP e Pthreads. Os estados escuros são os estados que tiveram que ser criados em relação à versão seqüencial. 


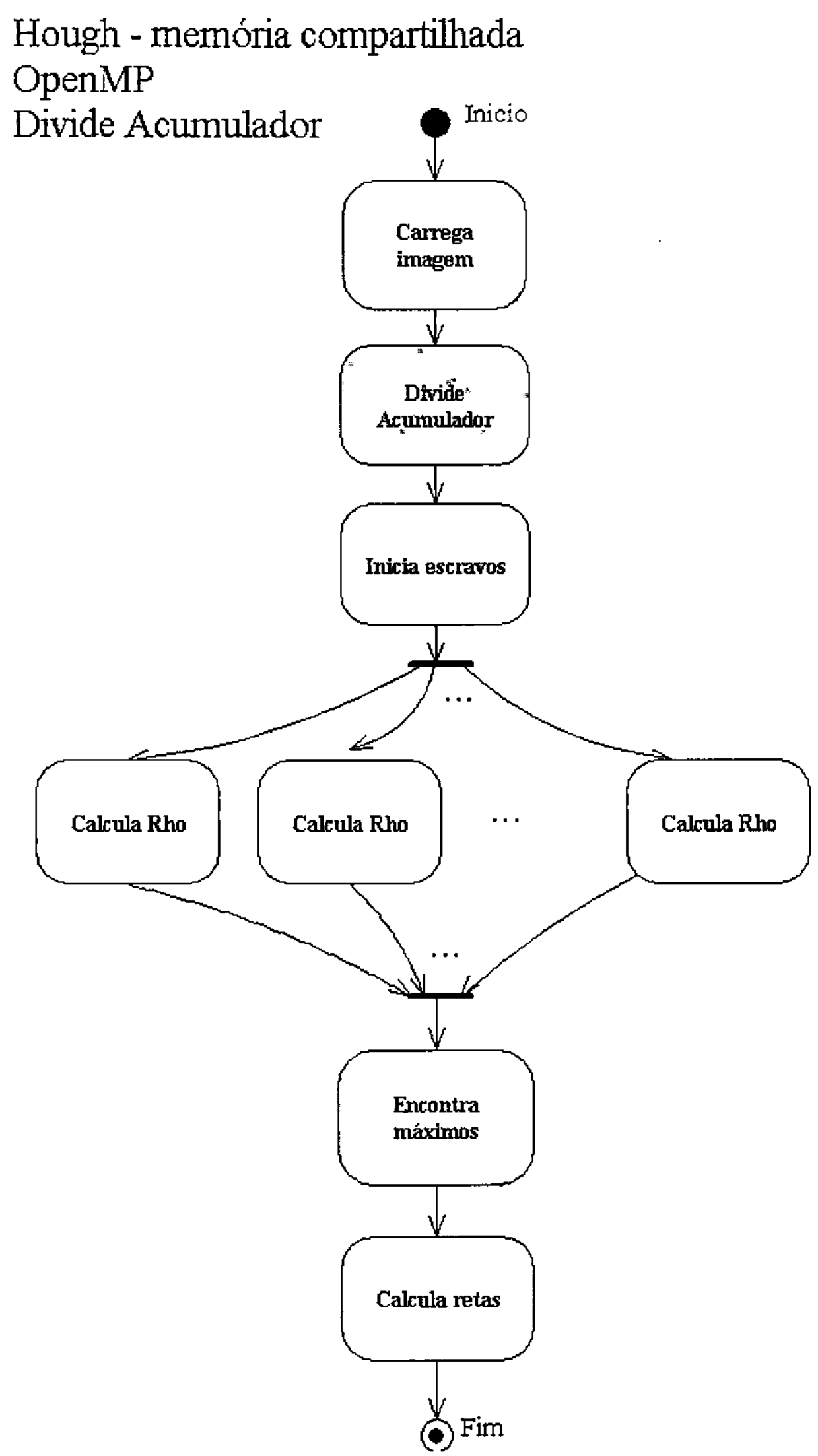

Figura 4.6. Diagrama de estados da $\mathrm{TH}$, estratégia divisão do acumulador utilizando as ferramentas OpenMP e Pthreads. 
A Figura 4.7, apresenta o diagrama de estados para a estratégia de paralelização divisão do arranjo acumulador da TH utilizando a ferramenta MPI. Vale ressaltar que o MPI foi utilizado para a paralelização da $\mathrm{TH}$, em arquiteturas MIMD com memória compartilhada e distribuída, não existindo diferença entre as implementações. Desta forma, somente o diagrama de estados para máquinas MIMD com memória distribuída são apresentados nas Figuras 4.5 e 4.7.

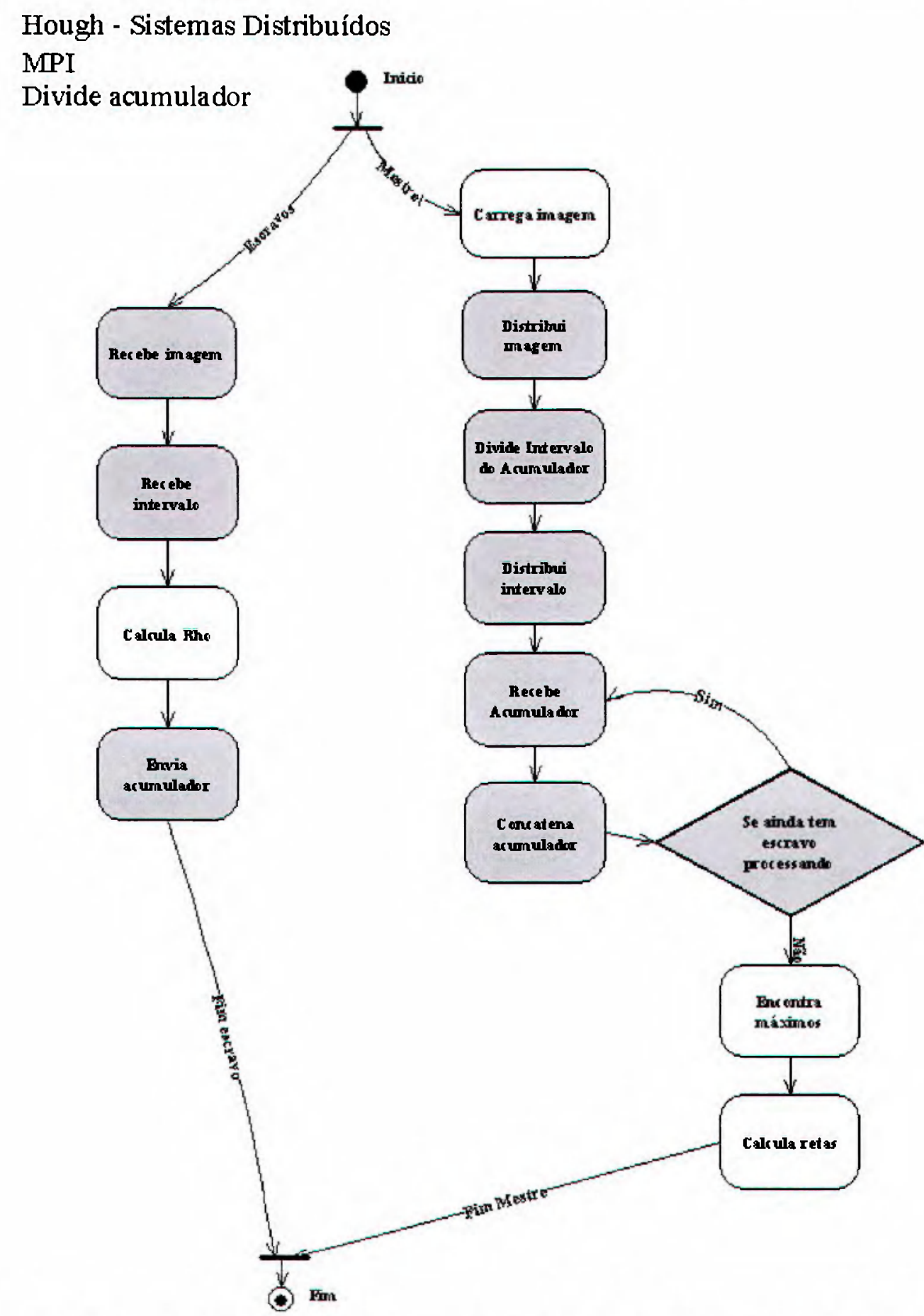

Figura 4.7. Diagrama de estados da TH para a estratégia de divisão do acumulador utilizando MPI. 


\subsection{Broadcasting da imagem}

Esse método, é utilizado em combinação com os anteriores, só que em vez de enviar a imagem para cada escravo, um escravo por vez, a imagem será enviada a todos os escravos de uma vez, por broadcasting (LAWRENCE, 2003c), diminuindo assim o tempo de processamento do envio da imagem.

Após os escravos receberem a imagem, é realizado o processamento de toda a imagem para a amostra de $\theta$ que foi destinada ao escravo. Após o escravo processar a imagem podem-se possuir duas abordagens para que sejam encontrados os picos na imagem. Na primeira, o próprio escravo pode encontrar os picos no arranjo acumulador e posteriormente enviar ao mestre somente os valores das coordenadas $\theta$ e $\rho$ bem como a valor do pico nessas coordenadas. Na segunda abordagem, pode-se enviar o arranjo acumulador inteiro para o mestre para que ele realize o encontro dos picos em todos os arranjos acumuladores vindos dos escravos.

A Figura 4.8 demonstra à estratégia de broadcasting da imagem, esta estratégia é semelhante a anterior, diferindo na distribuição da imagem que é enviada a todos os elementos de processamento escravos de uma única vez.

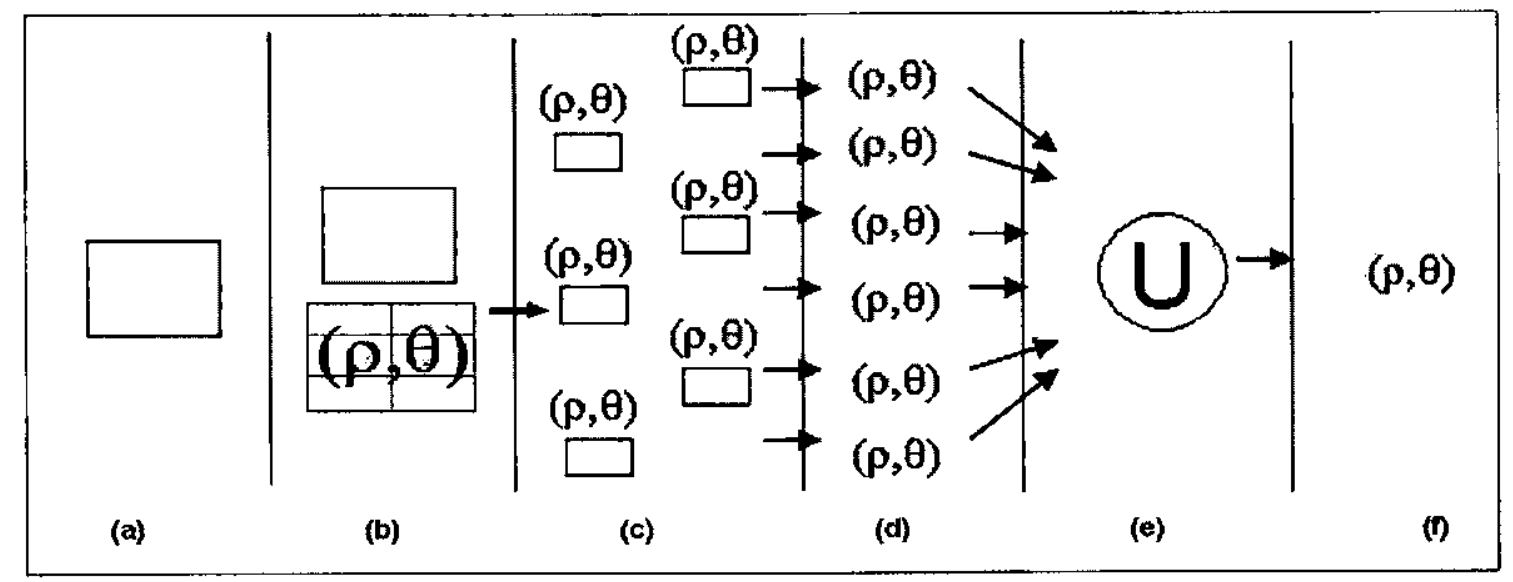

Figura 4.8 Estratégia de paralelismo da distribuição do arranjo acumulador, onde em (a) tem-se a imagem original, em (b) é realizada a divisão do arranjo acumulador e o envio juntamente com a imagem a cada elemento de processamento escravo para ser realizado o processamento, em (c) é realizado o processamento para toda a imagem na porção do arranjo acumulador que couber ao escravo, em (d) é cada arranjo acumulador resultante, em (e) é realizada a união dos arranjos acumuladores e na imagem (f) é o arranjo acumulador total resultante.

\subsection{Processor farm}


O conceito Processor Farm é muito similar ao conceito mestre/escravo. No conceito Processor Farm, existe o fazendeiro, que é similar ao mestre, que delega trabalho aos operários, que são os escravos. Sempre que um operário conclui sua tarefa, este avisa ao fazendeiro, que imediatamente delega outro trabalho da lista de trabalho que estão aguardando para serem executados, ao operário ocioso.

Esta estratégia de paralelismo da transformada de Hough possui algumas vantagens, como: balanceamento automático de carga de trabalho, não permitindo que um trabalhador trabalhe mais do que outro. Outra vantagem, é a que nenhum trabalhador ficará sem realizar alguma tarefa enquanto houver tarefas para ser executada.

Para obter as vantagens mencionadas acima, o arranjo acumulador ou a imagem podem ser divididos, por exemplo, pelo dobro de trabalhadores e, tão logo um trabalhador acabe a sua tarefa ele avisa ao fazendeiro que irá lhe atribuir outra parte do arranjo acumulador ou da imagem para ser processada. Como pode ser observado a estratégia processor farm sozinha não compõem uma estratégia de paralelismo, é preciso a união com outra estratégia, neste caso a divisão do acumulador e da imagem, para que o paralelismo possa ser empregado.

Uma ilustração dessa estratégia pode ser vista na Figura 2.8. Esta estratégia foi desenvolvida em arquiteturas MIMD de memória distribuída, pois esse tipo de arquitetura favorece a implementação e o controle desse tipo de estratégia, não sendo, esta estratégia, implementada em arquiteturas MIMD de memória compartilhada. $\mathrm{Na}$ Figura 4.9 pode ser observado o diagrama de estados dessa estratégia, combinada com a estratégia de divisão do acumulador, utilizando a ferramenta MPI. 
Hough - Sistemas Distribuídos

MPI - Processor Farm

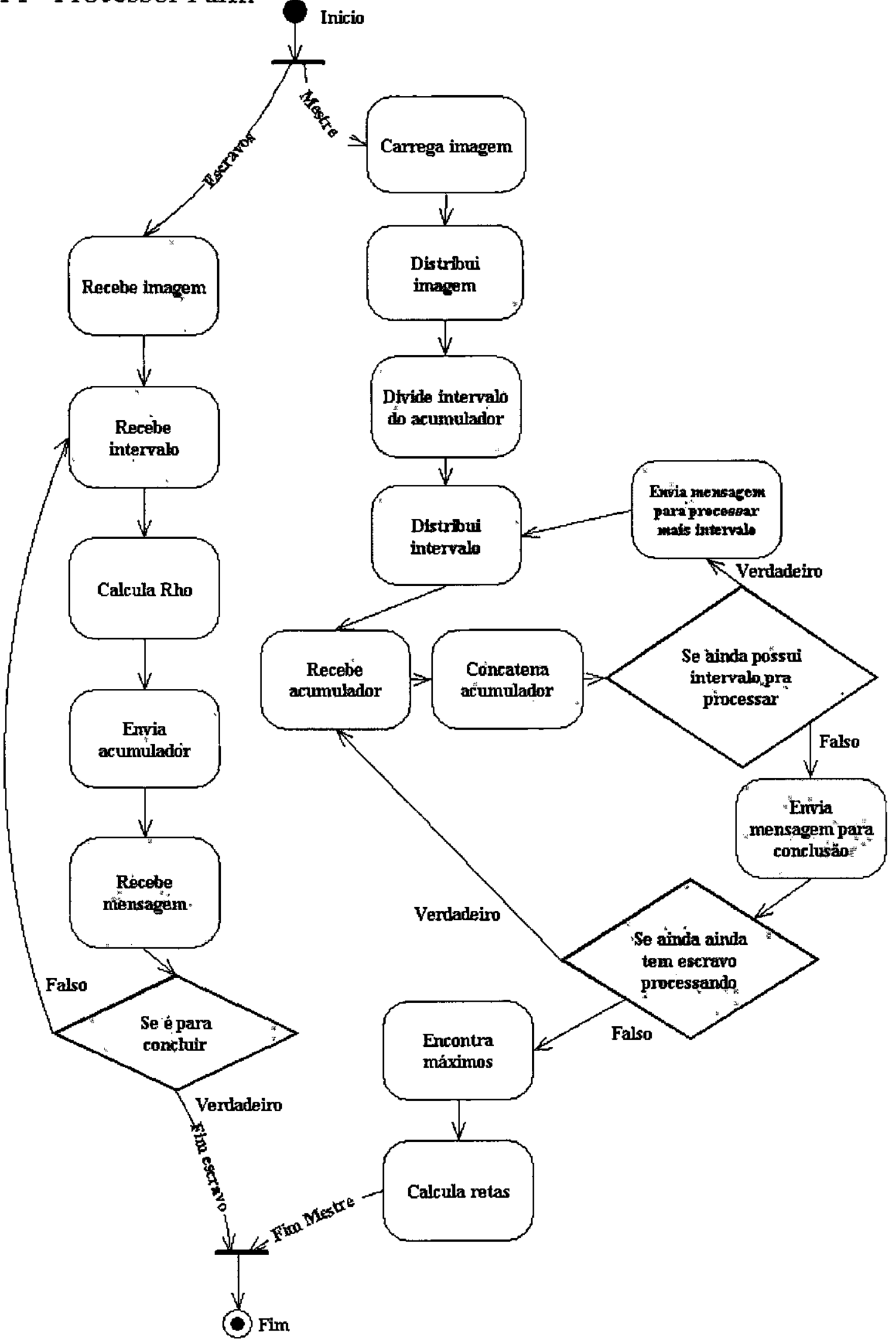

Figura 4.9. Diagrama de estados da TH para a estratégia processor farm combinado com a divisão do acumulador utilizando MPI. 
Na Figura 4.10 é observado o diagrama de estados dessa mesma estratégia só que combinada com a estratégia de divisão da imagem, também utilizando MPI.

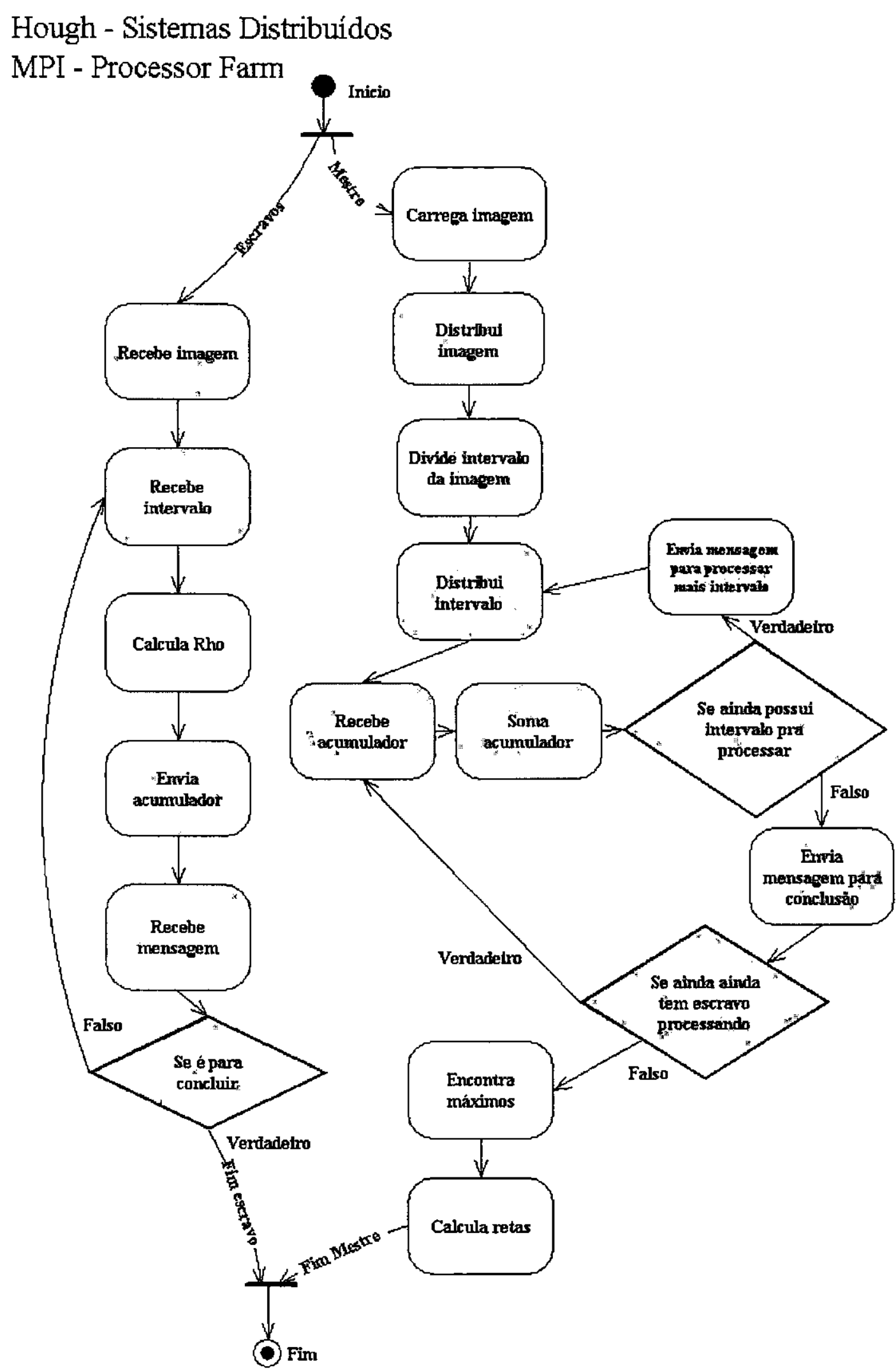

Figura 4.10 Diagrama de estados da TH para a estratégia processor farm combinado com a divisão da imagem utilizando MPI. 
O que difere entre os diagramas de estado das Figuras 4.9 e 4.10 é que na Figura 4.9 divide-se o intervalo do acumulador para ser enviado a cada escravo. Já no diagrama da Figura 4.10 é feita a divisão da imagem para que esta seja enviada para os escravos.

\subsection{Backmapping paralelo}

Como foi visto no capítulo 3, o backmapping é uma estratégia para identificar os picos existentes no arranjo acumulador da TH. O backmapping consiste em recalcular as senóides para cada uma dos pontos da imagem verificando qual posição da senóide possui o maior pico, indicando dessa maneira a existência de uma reta nessa posição.

Como o backmapping recalcula as senóides, sua paralelização pode ser realizada. Pode-se dividir a paralelização do backmapping em duas etapas, a primeira etapa consiste em realizar o cálculo do arranjo acumulador. Na segunda etapa, devem-se encontrar os picos no arranjo acumulador, gerado pela primeira etapa. Essa segunda etapa é o verdadeiro backmapping.

Na primeira etapa a paralelização pode ser realizada utilizando-se qualquer uma das estratégias apresentadas para obter o arranjo acumulador (subseções 4.1 a 4.4). Na segunda etapa, a paralelização do cálculo do backmapping, não pode ser realizado por todas as estratégias como na primeira etapa, pois para encontrar o maior valor de uma senóide, esta deve ser percorrida por inteiro, ou seja, do ângulo zero até o 180. Então, a única estratégia cabível é a que divide a imagem preservando o arranjo acumulador. Nesta estratégia, cada escravo irá receber um pedaço da imagem e o arranjo acumulador integral e, para cada ponto da imagem será percorrida a senóide correspondente em busca do maior valor.

$\mathrm{Na}$ Figura 4.11, é apresentado o diagrama de estados do backmapping (entendese por backmapping como sendo as duas etapas) para a estratégia de divisão da imagem nas duas etapas e utilizando a ferramenta OpenMP, não é demonstrado o diagrama de estados para a ferramenta Pthreads por ser o mesmo do OpenMP. 


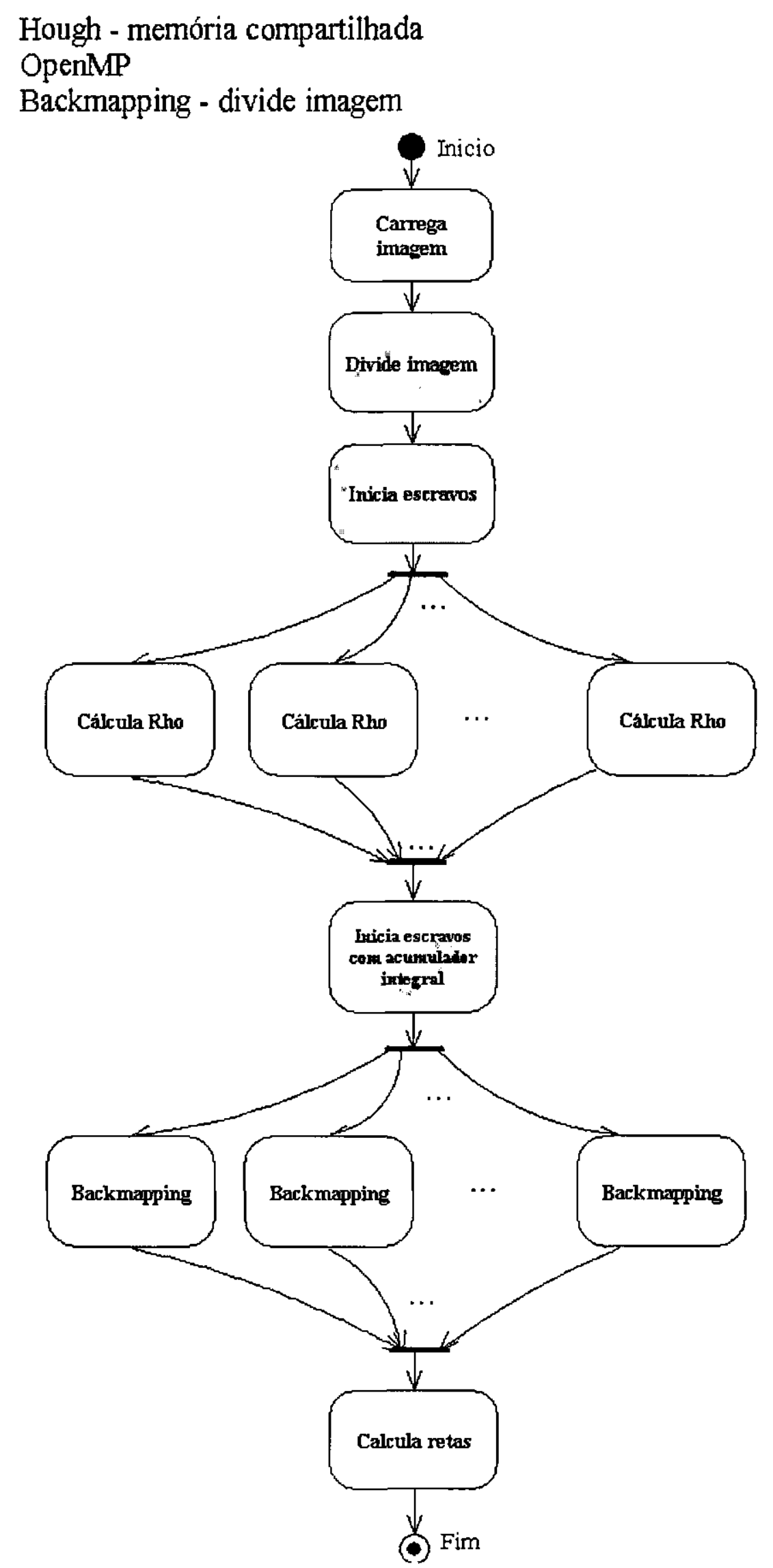

Figura 4.11 Diagrama de estados do backmapping para divisão da imagem com OpenMP.

Na Figura 4.12 é mostrado o diagrama de estados do backmapping para a 
estratégia de divisão da imagem utilizando a ferramenta MPI.

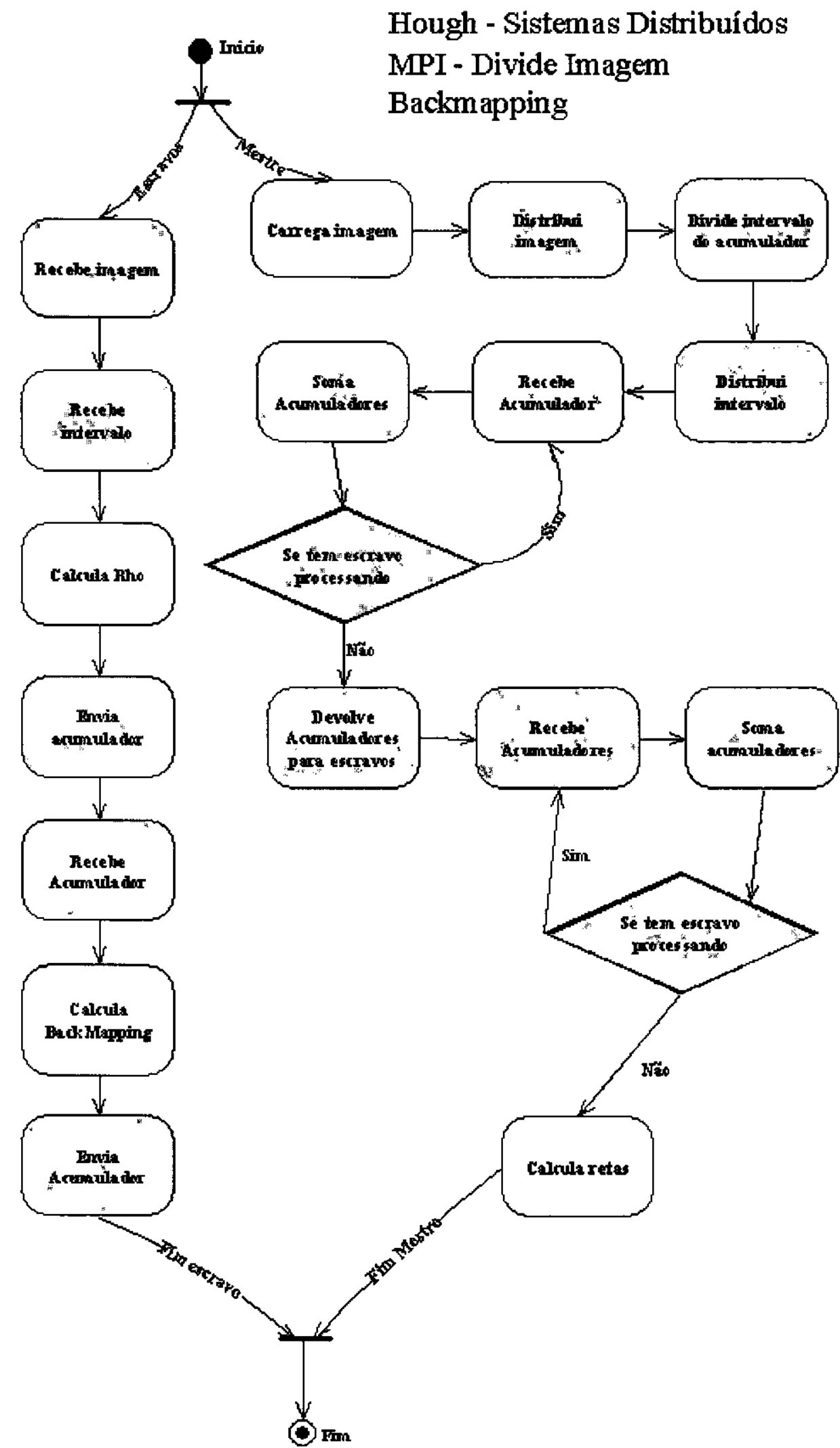

Figura 4.12 Diagrama de estados do backmapping para divisão da imagem com MPI.

4.6 Considerações 
Dentre as implementações, aquelas que utilizam MPI possuem uma complexidade maior para tornar uma aplicação paralela, como pode ser visto nos diagramas de estados de cada uma das estratégias. Isso se dá, devido a necessidade de realizar a troca de mensagens entre os processos, pois eles podem se encontrar em máquinas distintas. Já nas arquiteturas de memória compartilhada a comunicação entre os processos é realizada pelo compartilhamento de posições de memória, não necessitando realizar a troca de mensagens, como acontece nas arquiteturas de memória distribuída.

Para não obter uma conclusão precipitada, é necessário avaliar o desempenho de cada uma das implementações em relação à versão seqüencial, verificando se existe melhora e qual implementação é a mais adequada para os diferentes tipos de arquiteturas. O desempenho de cada uma das implementações será visto no capítulo seguinte. 


\section{Implementações e resultados}

Foram realizados diversos testes para avaliar o desempenho de cada uma das implementações da transformada de Hough paralela diante da versão seqüencial. Os testes foram realizados com imagens reais e imagens geradas artificialmente, os tamanhos das imagens com que foram realizados os testes foram $512 \times 512,1024 \times 1024 \mathrm{e}$ 2048x2048. A Figura 5.1 (a) apresenta a imagem que possui somente retas horizontais, a Figura 5.1 (b) demonstra a imagem que possui retas mistas, em todos os sentidos de orientação. A Figura 5.2 mostra a imagem real do canal da piracema em tons de cinza.

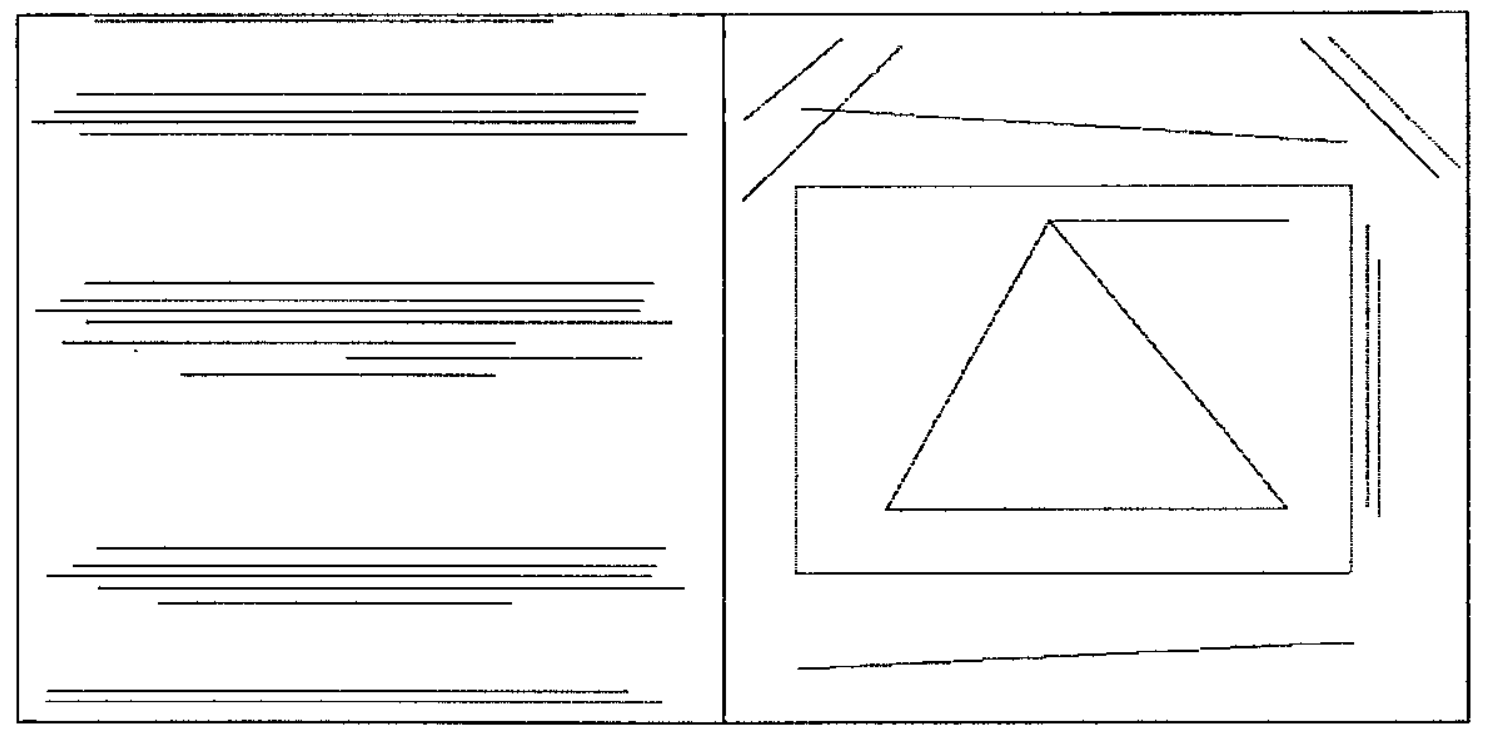

(a)

(b)

Figura 5.1 (a) retas horizontais, (b) retas mistas 


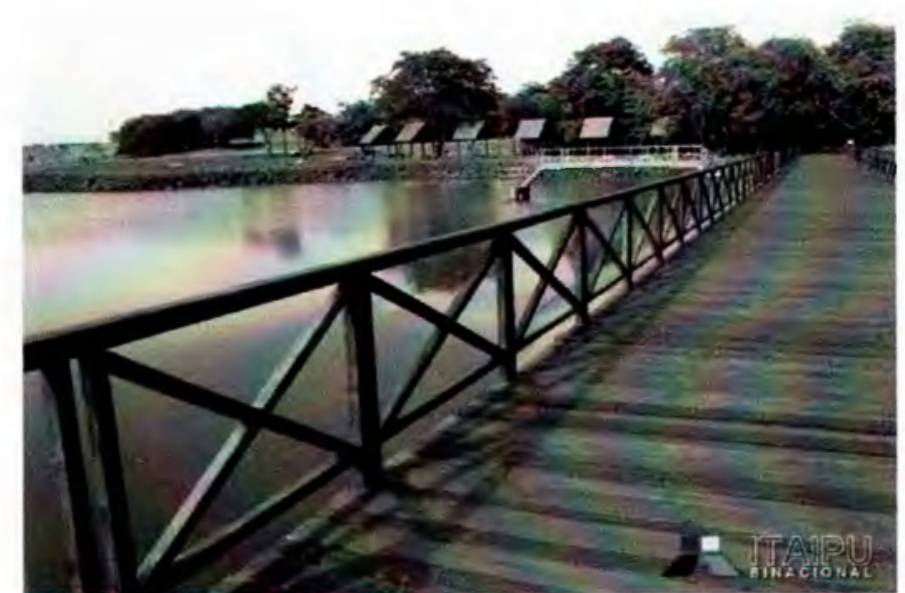

Figura 5.2 Imagem do canal da Piracema

As implementações na arquitetura MIMD de memória compartilhada, tiveram seu desempenho mensurado utilizando as ferramentas MPICH (GROPP \& LUSK, 2004), OpenMP (LAWRENCE, 2003b), (NATIONAL, 2004), (OpenMP, 2004) e (SILVA, 2004) e Pthreads (IEEE, 2004), (LAWRENCE, 2003) e (TORELLI \& MALLARA, 2003). Este último, compilado com o compilador gec e com o compilador Intel $\circledast$ icpc (INTEL $\otimes, 2004)$ próprio para arquiteturas de memória compartilhada. Já para a arquitetura MIMD de memória distribuída foi utilizada somente a ferramenta MPICH (GROPP \& LUSK, 2004)

Vale ressaltar que, para as implementações utilizando MPI, para ambas as arquiteturas, foram realizadas algumas melhorias buscando um aumento do desempenho nessas implementações. As melhorias implementadas foram, o envio da imagem por broadcast para os escravos e a compactação da imagem e do acumulador antes de seus respectivos envios, a Figura 5.3 ilustra o conceito de broadcast e a Figura 5.4 demonstra a estratégia de paralelismo da divisão do acumulador e a compactação da imagem.

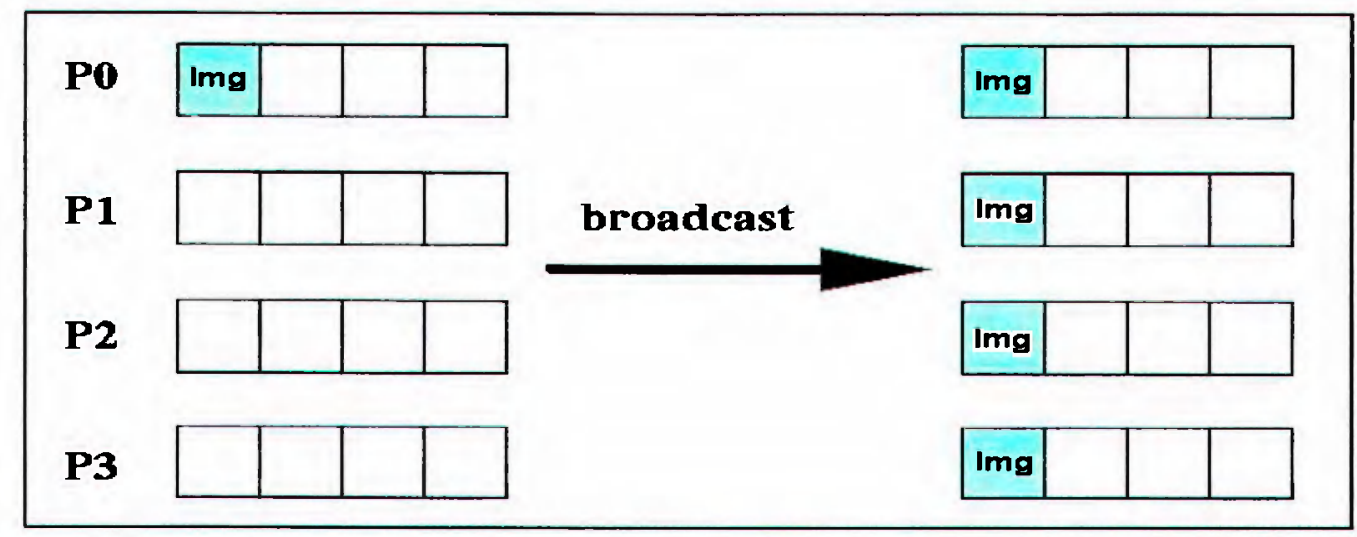

Figura 5.3 conceito de broadcast 


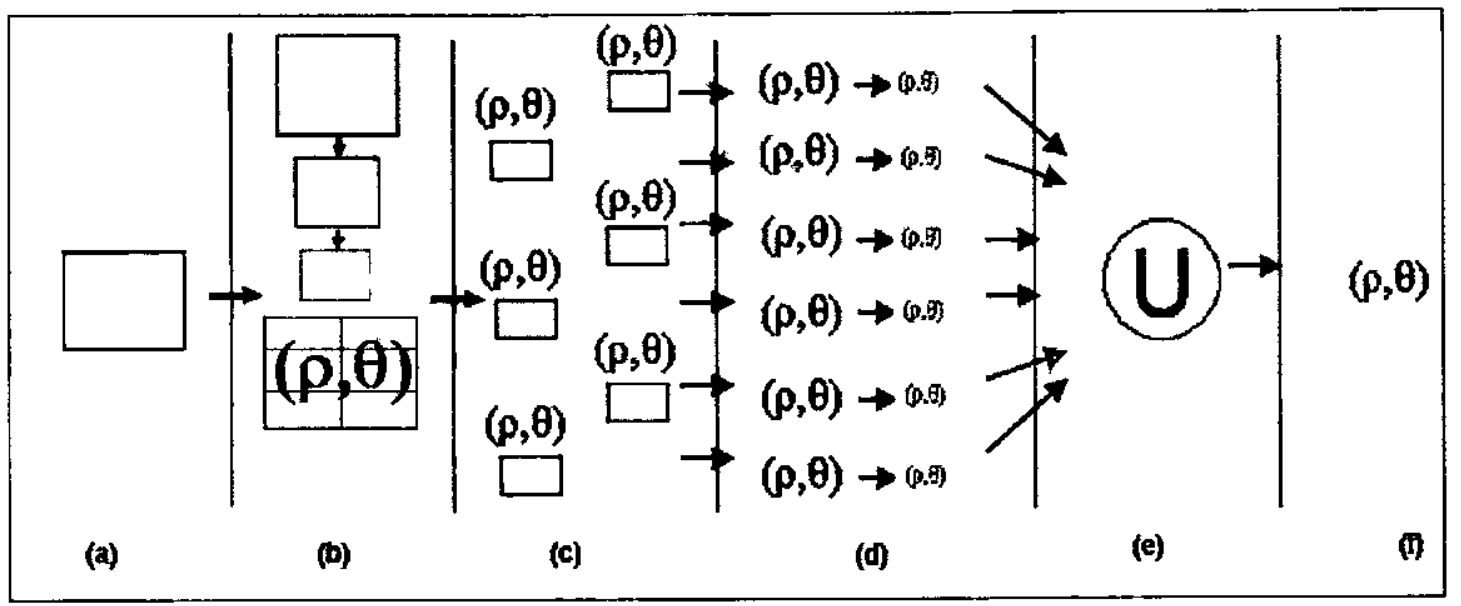

Figura 5.4 Estratégia de paralelismo da distribuição do arranjo acumulador com compactação da imagem para as implementações com MPI, onde em (a) tem-se a imagem original, em (b) é realizada a compactação da imagem e a divisão do arranjo acumulador e o envio a cada elemento de processamento escravo para ser realizado o processamento, em (c) é realizado o processamento para toda a imagem na porção do arranjo acumulador que couber ao escravo, em (d) têm-se cada arranjo acumulador resultante, sua compactação e o envio para o servidor, em (e) é realizada a união dos arranjos acumuladores e (f) é o arranjo acumulador total resultante.

A seção 5.1, apresenta a metodologia utilizada para mensurar o desempenho das versões paralelas diante da versão seqüencial. $\mathrm{Na}$ seção 5.2 , são demonstrados os resultados obtidos nas implementações para a arquitetura MIMD de memória compartilhada. Já na seção 5.3, são apresentadas as considerações alcançadas através das análises dos resultados obtidos.

\subsection{Metodologia para mensurar o desempenho}

Para avaliar o desempenho obtido em cada uma das implementações da transformada de Hough, foi coletado o tempo que se gasta para calcular o arranjo acumulador na versão seqüencial, e desse tempo é dividido o tempo que se gasta para calcular o arranjo acumulador em uma versão paralela. $O$ resultado obtido indica quantas vezes a versão paralela em questão foi mais rápida ou mais lenta no cálculo do arranjo acumulador, conforme indica a fórmula 2-1 da subseção 2.2 .6 do capítulo 2 .

$\mathrm{Na}$ versão seqüencial, o tempo de execução é obtido somente pela medida de tempo que se gasta para realizar o cálculo do acumulador, já nas versões paralelas à obtenção do tempo de execução para o cálculo do acumulador envolve outros componentes. No MPI, o tempo de execução do arranjo acumulador envolve, além do 
tempo de execução do próprio acumulador, o tempo gasto para o envio das mensagens e o tempo gasto no envio da imagem para os escravos, o tempo gasto dos escravos enviarem o arranjo acumulador para o servidor, o tempo gasto para o servidor juntar todos os arranjos acumuladores resultantes e o tempo de compactação e descompactação tanto do arranjo acumulador quanto da imagem. Para o OpenMP e o Pthreads o tempo de execução do arranjo acumulador envolve, também, o tempo gasto para iniciar cada escravo, já que para a arquitetura MIMD de memória compartilhada a comunicação se dá pelo compartilhamento de memória e não pela troca de mensagens como ocorre na arquitetura com memória distribuída.

\subsection{Experimentos para MIMD memória compartilhada}

Nesta subseção, são apresentados os resultados obtidos para as estratégias de divisão do acumulador e divisão da imagem para três tipos de imagens, as que possuem somente retas horizontais, as que possuem retas em todas as direções de orientação e por último as imagens reais, obtidas do canal da piracema, da Itaipu binacional.

A máquina utilizada, para obter o desempenho das implementações da TH para memória compartilhada, possui dois processadores Intel Xeon Pentium IV de 2,66 Giga Hertz cada um, com a tecnologia Hyper-threading, além de uma memória compartilhada de quatro Giga Bytes, utilizando o sistema operacional Linux SuSe 8.2, cada processador possui, ainda, uma memória cache de $512 \mathrm{~KB}$. A tecnologia Hyperthreading faz com que um processador possa executar duas tarefas em paralelo, como se existissem fisicamente 2 processadores (INTEL®, 2004). Dessa maneira, a máquina citada acima, pode executar quatro tarefas ao mesmo tempo, pois possui dois processadores com a tecnologia Hyper-threading. Permitindo atingir um speedup de no máximo quatro.

Nas Figuras 5.5 a 5.13, são apresentados os gráficos de desempenho para cada uma das estratégias em um determinado tipo de imagem. Estas figuras demonstram o speedup das implementações paralelas diante da implementação seqüencial compilada com gcc. A tabela 5.1 apresenta os resultado obtidos para a estratégia de divisão do acumulador, processando sobre as imagens com retas horizontais. 
Tabela 5.1 Resultados obtidos para a imagem horizontal, com seus respectivos desvios padrões e utilizando a estratégia de divisão do acumulador.

\begin{tabular}{|l|c|c|c|}
\hline Ferramenta & Imagem & Tempo de execução & Desvio Padrão \\
\hline Sequencial & $512 \times 512$ & 0,1652 & 0,0011 \\
\hline OpenMP & $512 \times 512$ & 0,0557 & 0,0073 \\
\hline MPI & $512 \times 512$ & 0,0925 & 0,0185 \\
\hline pThread & $512 \times 512$ & 0,1177 & 0,0136 \\
\hline pThread c/omp & $512 \times 512$ & 0,0540 & 0,0069 \\
\hline Sequencial & $1024 \times 1024$ & 0,5875 & 0,0016 \\
\hline OpenMP & $1024 \times 1024$ & 0,1546 & 0,0131 \\
\hline MPI & $1024 \times 1024$ & 0,2666 & 0,0209 \\
\hline pThread & $1024 \times 1024$ & 0,4100 & 0,0098 \\
\hline pThread c/omp & $1024 \times 1024$ & 0,1696 & 0,0113 \\
\hline Sequencial & $2048 \times 2048$ & 1,2650 & 0,0030 \\
\hline OpenMP & $2048 \times 2048$ & 0,3267 & 0,0398 \\
\hline MPI & $2048 \times 2048$ & 0,6788 & 0,0540 \\
\hline pThread & $2048 \times 2048$ & 0,9129 & 0,0181 \\
\hline pThread c/omp & $2048 \times 2048$ & 0,3452 & 0,0186 \\
\hline
\end{tabular}

A Figura 5.5, demonstra o resultado do speedup para a estratégia de divisão do acumulador, sobre retas horizontais.

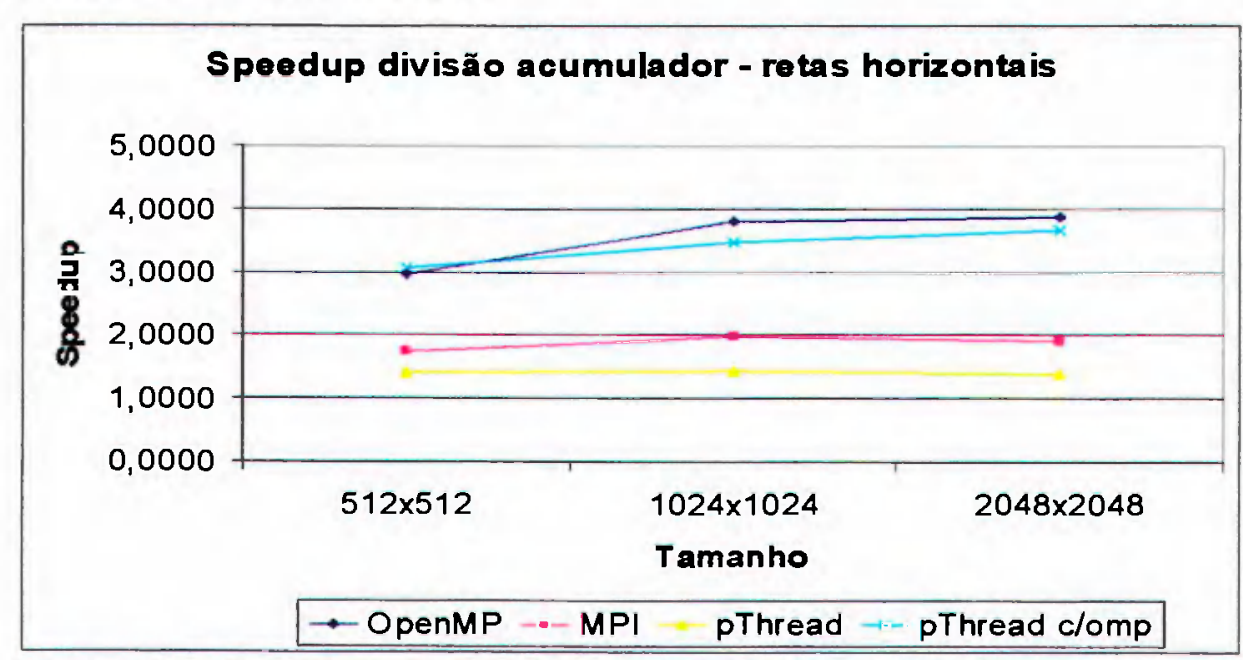

Figura 5.5 Speedup da implementação da TH com divisão do arranjo acumulador para retas horizontais.

Observa-se na Figura 5.5 em conjunto com a Tabela 5.1, que a versão utilizando a ferramenta OpenMP obteve os melhores desempenhos para as imagens de tamanho intermediário e maior, atingindo um speedup máximo de, aproximadamente 3,9 para a imagem de tamanho 2048×2048. Já para a imagem menor, o melhor desempenho foi obtido pelo Pthreads compilado com o compilador do OpenMP, icpc (ver Capítulo 2, subseção 2.4.1.2.1), que obteve um speedup de aproximadamente 3,0. Nota-se também, que o comportamento das implementações Pthreads, compilado com compilador do OpenMP e, o próprio OpenMP obtiveram um desempenho similar e muito superior as 
outras implementações. Isto se deve, a característica do compilador icpc (INTEL $\circledast$, 2004) ser otimizado para gerar códigos para as máquinas de memória compartilhada Característica essa que não esta presente no gcc

A tabela 5.2 apresenta os resultado obtidos para a estratégia de divisão do acumulador, processando sobre as imagens com retas mistas.

Tabela 5.2 Resultados obtidos para as imagens com retas mistas e seus respectivos desvios padrões, utilizando a estratégia de divisão do acumulador.

\begin{tabular}{|l|c|c|c|}
\hline Ferramentas & Imagem & Tempo de execução & Desvio Padrão \\
\hline Sequencial & $512 \times 512$ & 0,0994 & 0,0005 \\
\hline OpenMP & $512 \times 512$ & 0,0670 & 0,0122 \\
\hline MPI & $512 \times 512$ & 0,0711 & 0,0220 \\
\hline pThread & $512 \times 512$ & 0,0720 & 0,0075 \\
\hline pThread c/omp & $512 \times 512$ & 0,0488 & 0,0049 \\
\hline Sequencial & $1024 \times 1024$ & 0,3982 & 0,0111 \\
\hline OpenMP & $1024 \times 1024$ & 0,1273 & 0,0230 \\
\hline MPI & $1024 \times 1024$ & 0,1793 & 0,0212 \\
\hline pThread & $1024 \times 1024$ & 0,2553 & 0,0196 \\
\hline pThread c/omp & $1024 \times 1024$ & 0,1516 & 0,0105 \\
\hline Sequencial & $2048 \times 2048$ & 1,5966 & 0,0097 \\
\hline OpenMP & $2048 \times 2048$ & 0,4092 & 0,0134 \\
\hline MPI & $2048 \times 2048$ & 0,7869 & 0,0594 \\
\hline pThread & $2048 \times 2048$ & 1,0136 & 0,0217 \\
\hline pThread c/omp & $2048 \times 2048$ & 0,4306 & 0,0304 \\
\hline
\end{tabular}

A Figura 5.6, apresenta o speedup, das implementações da TH paralela para a estratégia de divisão do acumulador, sobre uma imagem que possui retas em todos os sentidos de orientação.

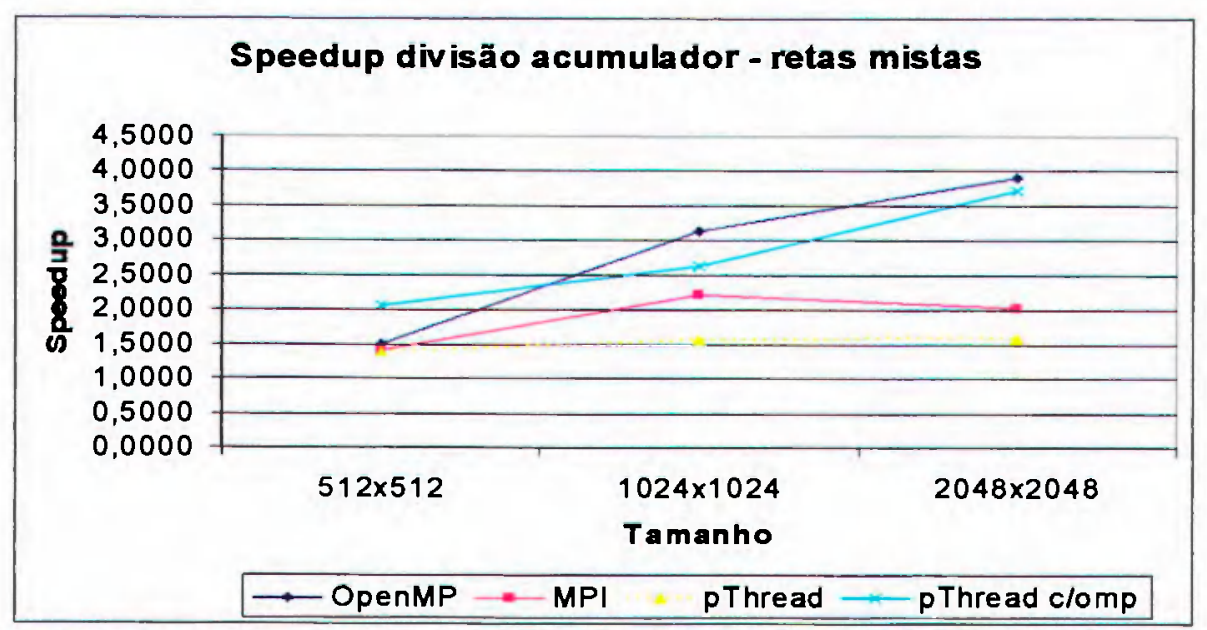

Figura 5.6 Speedup da implementação da TH com divisão do arranjo acumulador para retas horizontais, verticais e diagonais.

Pela Figura 5.6 e a Tabela 5.2, observa-se que a implementação utilizando OpenMP, novamente, obteve um desempenho superior às outras implementações, para a 
imagem de tamanho intermediário e maior. Nesta última, atingindo um speedup próximo a 3,9. E, outra vez, o melhor desempenho para a imagem menor, que possui retas em todos os sentidos de orientação, foi obtido pelo Pthreads compilado com o compilador icpc.

A tabela 5.3 apresenta os resultado obtidos para a estratégia de divisão do acumulador, processando sobre as imagens reais.

Tabela 5.3 Resultados obtidos para a imagem real, com seus respectivos desvios padrōes, utilizando a estratégia de divisão do acumulador.

\begin{tabular}{|l|c|c|c|}
\hline & Imagem & Tempo de execução & Desvio Padrão \\
\hline Sequencial & $512 \times 512$ & 0,1294 & 0,0009 \\
\hline OpenMP & $512 \times 512$ & 0,0632 & 0,0147 \\
\hline MPI & $512 \times 512$ & 0,0569 & 0,0004 \\
\hline pThread & $512 \times 512$ & 0,0928 & 0,0058 \\
\hline pThread c/omp & $512 \times 512$ & 0.0524 & 0,0064 \\
\hline Sequencial & $1024 \times 1024$ & 0,5294 & 0,0024 \\
\hline OpenMP & $1024 \times 1024$ & 0,1401 & 0,0199 \\
\hline MPI & $1024 \times 1024$ & 0,2241 & 0,0126 \\
\hline pThread & $1024 \times 1024$ & 0,3426 & 0,0334 \\
\hline pThread c/omp & $1024 \times 1024$ & 0,1794 & 0,0162 \\
\hline Sequencial & $2048 \times 2048$ & 1,8833 & 0,0039 \\
\hline OpenMP & $2048 \times 2048$ & 0.4815 & 0,0113 \\
\hline MPI & $2048 \times 2048$ & 0,8964 & 0,0381 \\
\hline pThread & $2048 \times 2048$ & 1,2660 & 0,0299 \\
\hline pThread c/omp & $2048 \times 2048$ & 0,5290 & 0,0529 \\
\hline
\end{tabular}

A Figura 5.7, também, apresenta o desempenho para a estratégia de divisão do acumulador, só que sobre uma imagem real.

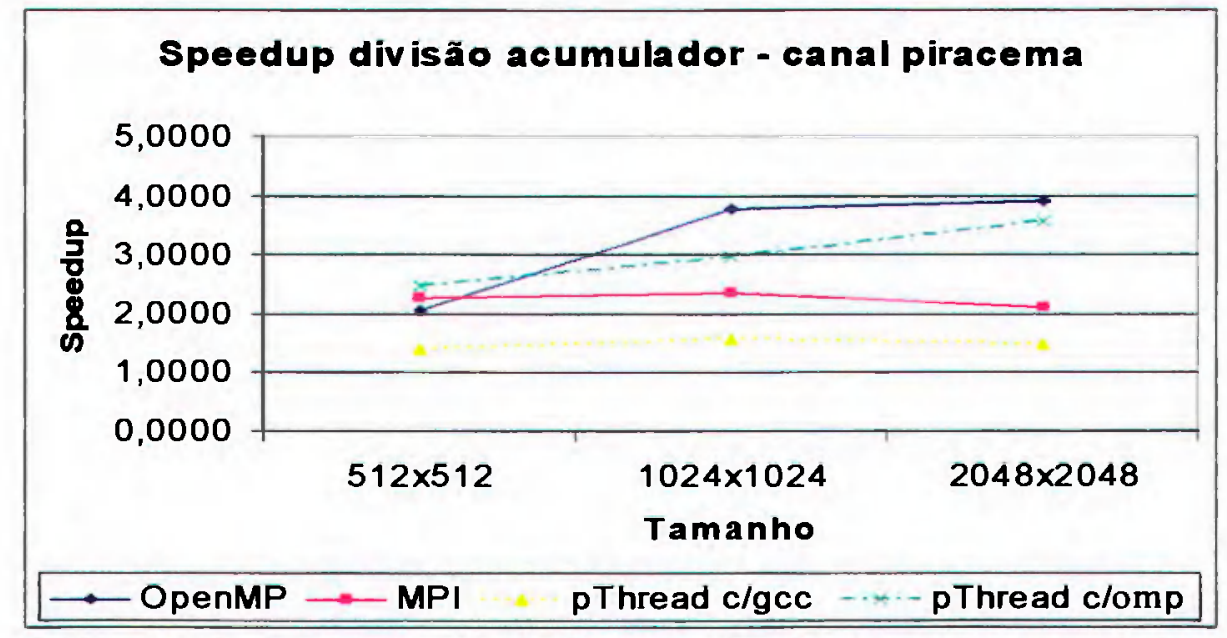

Figura 5.7 Speedup da implementação da TH com divisão do arranjo acumulador para uma imagem real.

Nota-se, observando-se a Tabela 5.3 e a Figura 5.7, que, a implementação utilizando a ferramenta MPI obteve um desempenho uniforme para os tamanhos de 
imagem menor e intermediário e desempenho próximo a 2,3 vezes mais rápido que a versão sequencial, alcançando o segundo melhor desempenho para a imagem de tamanho menor. As implementações que utilizam o Pthreads, compilada com o gcc, obteve o desempenho menos expressivo, atingindo um speedup próximo a 1,5. Já a implementação que utiliza o OpenMP novamente obteve o melhor desempenho para a imagem de tamanho intermediário e maior, atingindo um speechup de 3,8 e 3,9, respectivamente

A Tabela 5.4 apresenta os resultado obtidos para a estratégia de divisão imagem, processando sobre as imagens com retas horizontais.

Tabela 5.4 Resultados obtidos para a imagem horizontal, com seus respectivos desvios padrões, utilizando a estratégia de divisão da imagem.

\begin{tabular}{|l|c|c|c|}
\hline Ferramentas & Imagem & Tempo de execução & Desvio Padrão \\
\hline Sequencial & $512 \times 512$ & 0,1652 & 0,0011 \\
\hline OpenMP & $512 \times 512$ & 0,1086 & 0,0122 \\
\hline MPI & $512 \times 512$ & 0,0886 & 0,0237 \\
\hline pThread & $512 \times 512$ & 0,1136 & 0,0078 \\
\hline pThread c/omp & $512 \times 512$ & 0,0546 & 0,0081 \\
\hline Sequencial & $1024 \times 1024$ & 0,5875 & 0,0016 \\
\hline OpenMP & $1024 \times 1024$ & 0,2096 & 0,0219 \\
\hline MPI & $1024 \times 1024$ & 0,2826 & 0,0287 \\
\hline pThread & $1024 \times 1024$ & 0,4237 & 0,0321 \\
\hline pThread c/omp & $1024 \times 1024$ & 0,1964 & 0,0166 \\
\hline Sequencial & $2048 \times 2048$ & 1,2650 & 0,0030 \\
\hline OpenMP & $2048 \times 2048$ & 0,4149 & 0,0136 \\
\hline MPI & $2048 \times 2048$ & 0,9151 & 0,0517 \\
\hline pThread & $2048 \times 2048$ & 1,1146 & 0,1735 \\
\hline pThread c/omp & $2048 \times 2048$ & 0,4292 & 0,0263 \\
\hline
\end{tabular}

A Figura 5.8, apresenta o desempenho para a estratégia de divisão da imagem sobre retas horizontais.

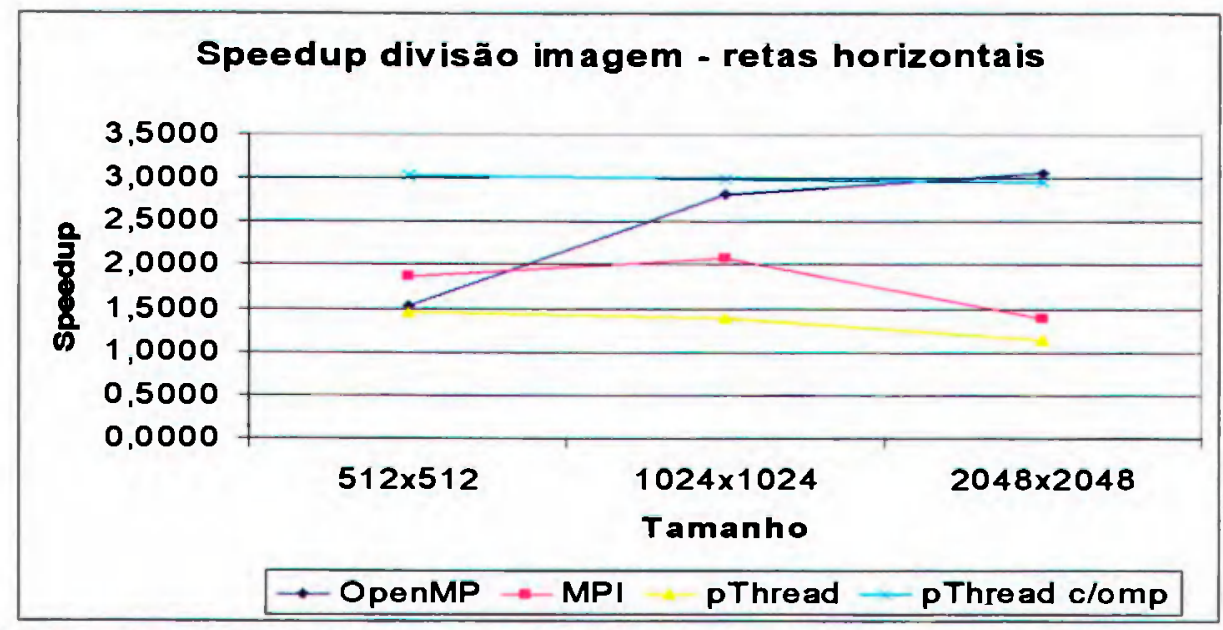

Figura 5.8 Speedup da implementação da TH com divisão da imagem para retas horizontais. 
Na Figura 5.8 e na Tabela 5.4, podem ser observados que a implementação que utiliza o Pthreads compilado com gcc, obteve um desempenho inferior às outras implementações para todos os tamanhos de imagem. A implementação do Pthreads compilada com o compilador do OpenMP obteve desempenho superior ao próprio OpenMP para as imagens de tamanho menor e intermediária. Já para a imagem de tamanho maior, o OpenMP apresentou o melhor resultado, alcançando um speedup próximo de 3,1 .

A Tabela 5.5 apresenta os resultados obtidos para a estratégia de divisão imagem, processando sobre as imagens com retas em todos os sentidos de orientação.

Tabela 5.5 Resultados obtidos para as imagens mistas, com seus respectivos desvios padrões, utilizando a estratégia de divisão da imagem.

\begin{tabular}{|l|c|c|c|}
\hline Ferramentas & Imagem & Tempo de execução & Desvio Padrão \\
\hline Sequencial & $512 \times 512$ & 0,0994 & 0,0005 \\
\hline OpenMP & $512 \times 512$ & 0,1082 & 0,0244 \\
\hline MPI & $512 \times 512$ & 0,0752 & 0,0189 \\
\hline pThread & $512 \times 512$ & 0,0743 & 0,0060 \\
\hline pThread c/omp & $512 \times 512$ & 0,0434 & 0,0017 \\
\hline Sequencial & $1024 \times 1024$ & 0,3982 & 0,0111 \\
\hline OpenMP & $1024 \times 1024$ & 0,1851 & 0,0342 \\
\hline MPI & $1024 \times 1024$ & 0,2335 & 0,0309 \\
\hline pThread & $1024 \times 1024$ & 0,2767 & 0,0194 \\
\hline pThread c/omp & $1024 \times 1024$ & 0,1510 & 0,0126 \\
\hline Sequencial & $2048 \times 2048$ & 1,5966 & 0,0097 \\
\hline OpenMP & $2048 \times 2048$ & 0,5068 & 0,0260 \\
\hline MPI & $2048 \times 2048$ & 0,8947 & 0,0932 \\
\hline pThread & $2048 \times 2048$ & 1,1109 & 0,0738 \\
\hline pThread c/omp & $2048 \times 2048$ & 0,4944 & 0,0299 \\
\hline
\end{tabular}

A Figura 5.9 mostra o desempenho da estratégia de divisão da imagem para as imagens que possuem retas mistas.

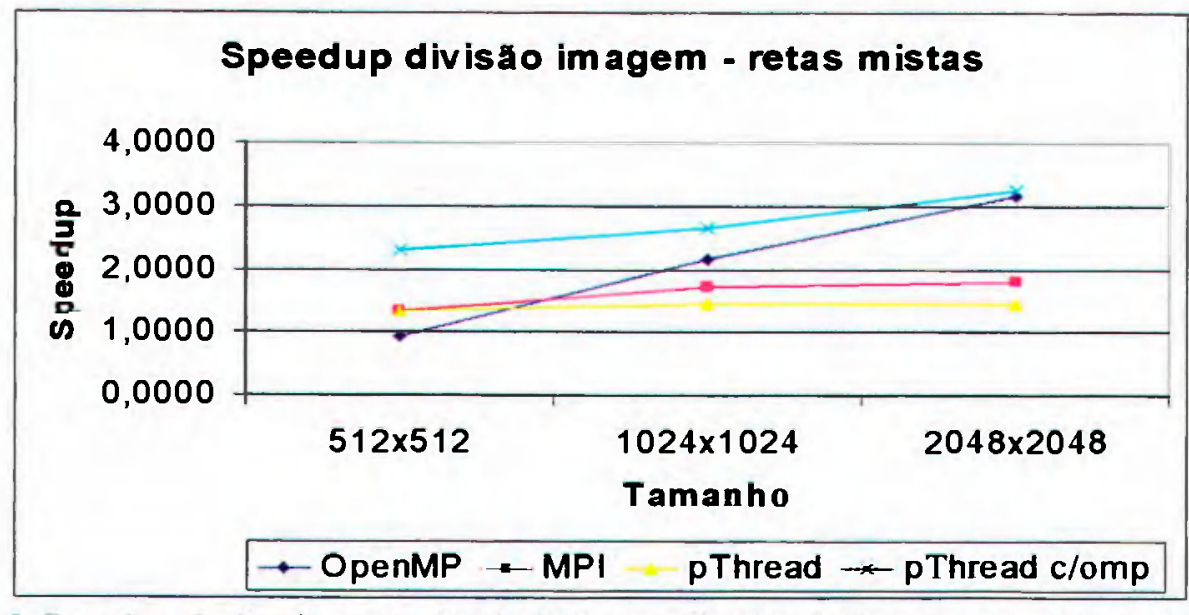

Figura 5.9 Speedup da implementação da TH com divisão da imagem para retas horizontais, verticais e diagonais. 
É possivel observar, na Figura 5.9 e na Tabela 5.5, que a implementação com o OpenMP obteve o pior desempenho, dentre as implementações, para a imagem de tamanho menor. A implementação do Pthreads compilada com o compilador do OpenMP obteve o melhor desempenho para todos os tamanhos de imagens, alcançando um speedup máximo de aproximadamente 3,2 , para a imagem de tamanho maior

A Tabela 5.6 apresenta os resultados obtidos para a estratégia de divisão imagem, processando sobre a imagem real, em seus diferentes tamanhos.

Tabela 5.6 Resultados obtidos para a imagem real, com seus respectivos desvios padrões, utilizando a estratégia de divisão da imagem.

\begin{tabular}{|l|c|c|c|}
\hline Ferramentas & Imagem & Tempo de execução & Desvio Padrão \\
\hline Sequencial & $512 \times 512$ & 0,1294 & 0,0009 \\
\hline OpenMP & $512 \times 512$ & 0,1239 & 0,0199 \\
\hline MPI & $512 \times 512$ & 0,1113 & 0,0101 \\
\hline pThread & $512 \times 512$ & 0,1102 & 0,0016 \\
\hline pThread c/omp & $512 \times 512$ & 0,0626 & 0,0027 \\
\hline Sequencial & $1024 \times 1024$ & 0,5294 & 0,0024 \\
\hline OpenMP & $1024 \times 1024$ & 0,2643 & 0,0349 \\
\hline MPI & $1024 \times 1024$ & 0,3089 & 0,0086 \\
\hline pThread & $1024 \times 1024$ & 0,4106 & 0,0277 \\
\hline pThread c/omp & $1024 \times 1024$ & 0,2114 & 0.0062 \\
\hline Sequencial & $2048 \times 2048$ & 1,8833 & 0,0039 \\
\hline OpenMP & $2048 \times 2048$ & 0,8744 & 0,0282 \\
\hline MPI & $2048 \times 2048$ & 1,2648 & 0,0299 \\
\hline pThread & $2048 \times 2048$ & 1,6789 & 0,1318 \\
\hline pThread c/omp & $2048 \times 2048$ & 0,8728 & 0,0550 \\
\hline
\end{tabular}

Na Figura 5.10, observa-se o desempenho sobre a imagem real utilizando a estratégia de divisão da imagem

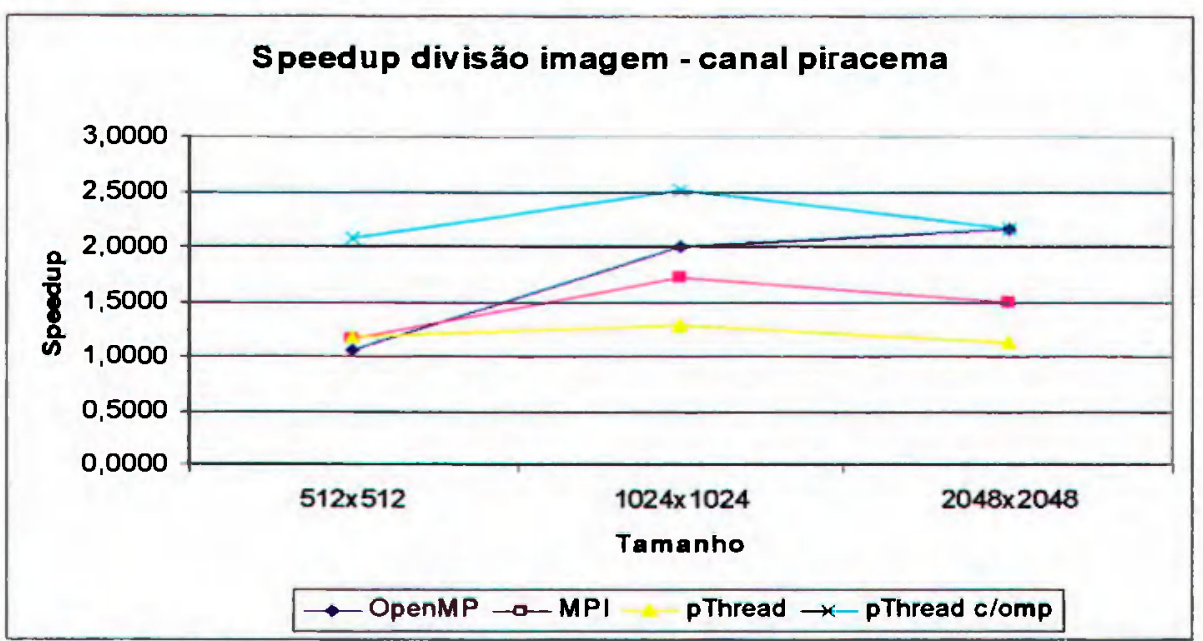

Figura 5.10 Speedup da implementação da TH com divisão da imagem para uma imagem real.

Nota-se, na Figura 5.10 e na Tabela 5.6, que o melhor desempenho para a imagem intermediária, $1024 \times 1024$, e menor, $512 \times 512$ foi obtido pela implementação 
que utiliza Pthreads e que foi compilada com o compilador do OpenMP. Já para a imagem de tamanho maior, ocorreu um empate entre as implementações OpenMP e Pthreads compilada com o icpc. É possivel observar, também, que para a imagem intermediária o Pthreads compilado com o icpc atingiu o melhor resultado, chegando a um speedup máximo de 2,5.

Os desempenhos observados até este ponto, foram obtidos utilizando a estratégia para detectar os valores de pico através de um limiar. Sendo que os valores abaixo do estabelecido, são transformados para zero e os valores que são iguais ou superiores ao limiar estabelecido permanecem os mesmos. De agora até o fim desta seção são apresentados os valores utilizando uma técnica diferente para encontrar os valores de pico, chama-se backmapping. No backmapping os picos são obtidos através de um novo cálculo das senóides, para que seja percorrida a senóide em busca do máximo valor existente. Os valores encontrados correspondem aos picos existentes no arranjo acumulador (ver capítulo 3, seção 3.5).

A Tabela 5.7 apresenta os resultados obtidos para a estratégia backmapping, processando sobre a imagem com retas horizontais, em seus diferentes tamanhos.

Tabela 5.7 Resultados obtidos para a imagem horizontal, com seus respectivos desvios padrões, utilizando a estratégia backmapping.

\begin{tabular}{|l|c|c|c|}
\hline & Imagem & Tempo de execução & Desvio Padrão \\
\hline Sequencial & $512 \times 512$ & 0,3252 & 0,0023 \\
\hline OpenMP & $512 \times 512$ & 0,1318 & 0,0405 \\
\hline MPI & $512 \times 512$ & 0,2322 & 0,0091 \\
\hline pThread & $512 \times 512$ & 0,2382 & 0,0031 \\
\hline pThread c/omp & $512 \times 512$ & 0,1560 & 0,0064 \\
\hline Sequencial & $1024 \times 1024$ & 1,3208 & 0,0078 \\
\hline OpenMP & $1024 \times 1024$ & 0,3736 & 0,0414 \\
\hline MPI & $1024 \times 1024$ & $\mathbf{0 , 7 0 3 1}$ & 0,0060 \\
\hline pThread & $1024 \times 1024$ & 0,8200 & 0,0500 \\
\hline pThread c/omp & $1024 \times 1024$ & 0,3924 & 0,0119 \\
\hline Sequencial & $2048 \times 2048$ & 2,8438 & 0,0118 \\
\hline OpenMP & $2048 \times 2048$ & 0,8294 & 0,0328 \\
\hline MPI & $2048 \times 2048$ & 1,6496 & 0,0473 \\
\hline pThread & $2048 \times 2048$ & 1,7064 & 0,0826 \\
\hline pThread c/omp & $2048 \times 2048$ & 0,8746 & 0,0500 \\
\hline
\end{tabular}

Na Figura 5.11, é apresentado o speedup obtido através do backmapping para as imagens com retas horizontais 


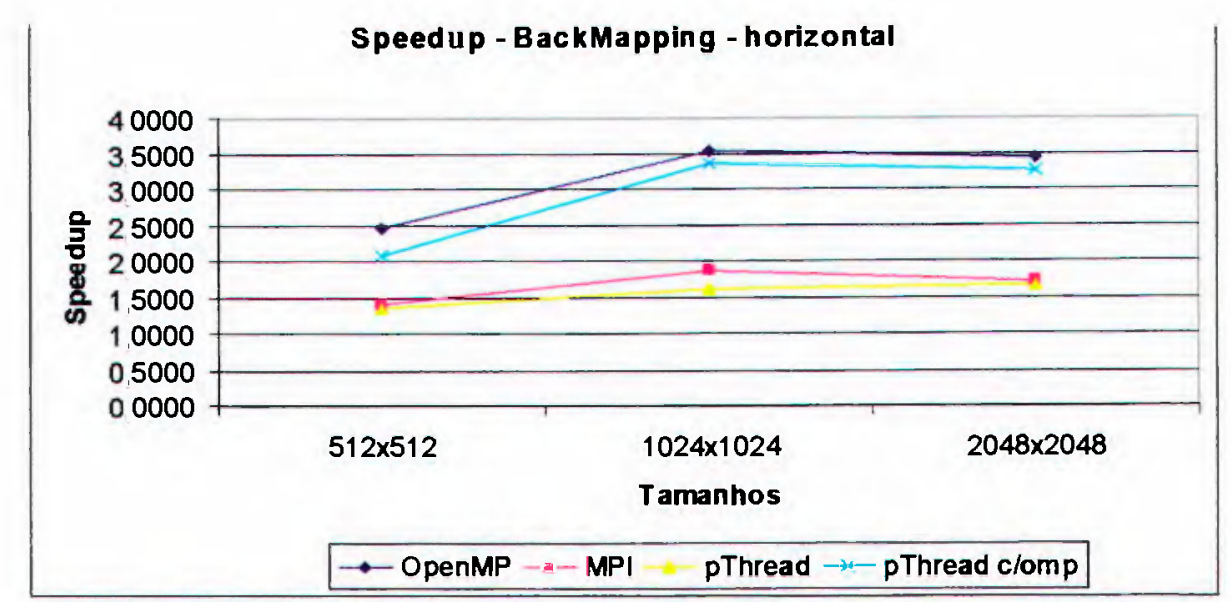

Figura 5.11 Speedup da implementação da TH utilizando BackMapping para as imagens com retas horizontais

De acordo com a Figura 5.11 e a Tabela 5.7, é possivel observar que a implementação que utiliza o OpenMP obteve o melhor desempenho em todos os tamanhos de imagens. Chegando a ser executado quase 3,5 vezes mais rápido que a versão sequencial, para a imagem de tamanho maior. Este bom desempenho, se deve ao compilador icpc ser otimizado para arquiteturas paralelas, o que não ocorre com o compilador gcc, como demonstra a Figura 5.11. Já a versão do Pthreads compilada com o compilador do OpenMP obteve o segundo melhor desempenho, com um speedup próximo ao alcançado pelo próprio OpenMP.

A Tabela 5.8 apresenta os resultados obtidos para a estratégia backmapping, processando sobre a imagem com retas mistas, em seus diferentes tamanhos

Tabela 5.8 Resultados obtidos para a imagem mista, com seus respectivos desvios padrões, utilizando a estratégia backmapping.

\begin{tabular}{|l|c|c|c|}
\hline Ferramentas & Imagem & Tempo de execuçäo & Desvio Padräo \\
\hline Sequencial & $512 \times 512$ & 0,1964 & 0,0021 \\
\hline OpenMP & $512 \times 512$ & 0,1149 & 0,0131 \\
\hline MPI & $512 \times 512$ & 0,1260 & 0,0036 \\
\hline pThread & $512 \times 512$ & 0,1572 & 0,0132 \\
\hline pThread c/omp & $512 \times 512$ & 0,1010 & 0,0047 \\
\hline Sequencial & $1024 \times 1024$ & 0,7850 & 0,0042 \\
\hline OpenMP & $1024 \times 1024$ & 0,2798 & 0,0208 \\
\hline MPI & $1024 \times 1024$ & 0,4204 & 0,0141 \\
\hline pThread & $1024 \times 1024$ & 0,5480 & 0,0106 \\
\hline pThread c/omp & $1024 \times 1024$ & 0,2758 & 0,0337 \\
\hline Sequencial & $2048 \times 2048$ & 3,2194 & 0,0091 \\
\hline OpenMP & $2048 \times 2048$ & 0.9066 & 0.0459 \\
\hline MPI & $2048 \times 2048$ & 1,8228 & 0,0659 \\
\hline pThread & $2048 \times 2048$ & 2,1316 & 0,0574 \\
\hline pThread c/omp & $2048 \times 2048$ & 1,0186 & 0,0411 \\
\hline
\end{tabular}


Os resultados, obtidos pela estratégia backmapping, para as retas mistas, pode ser verificado na Figura 5.12 a seguir.

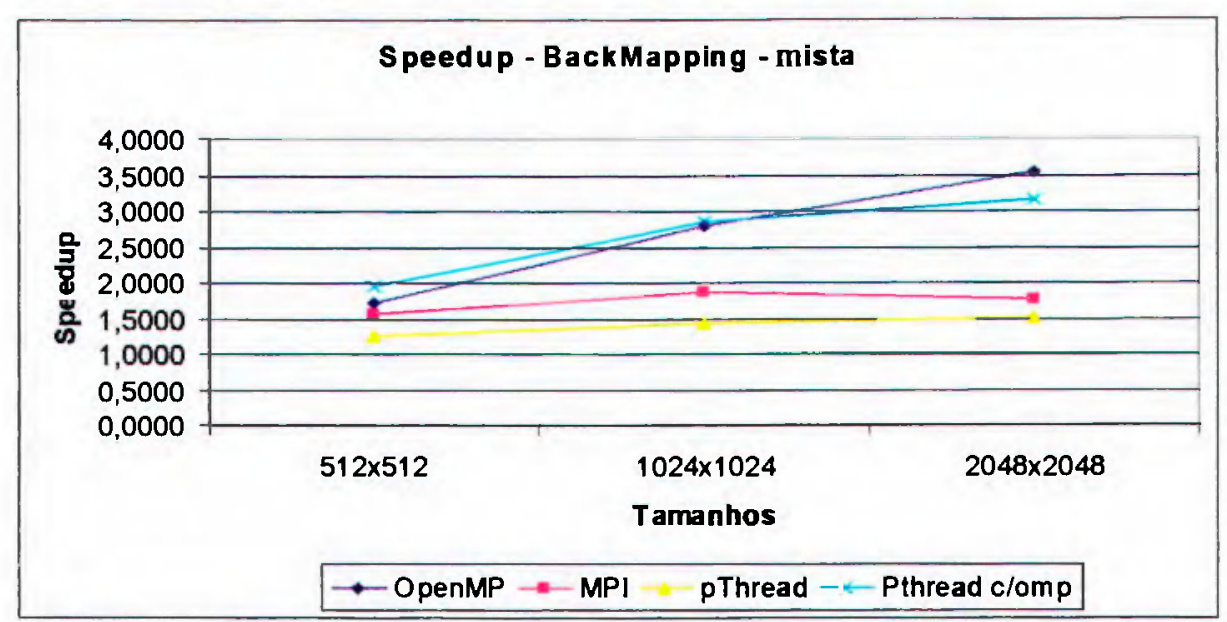

Figura 5.12 Speedup da implementação da TH utilizando BackMapping para a imagem com retas mistas.

Na Figura 5.12 em conjunto com a Tabela 5.8, nota-se, novamente, que a implementação com o OpenMP, ficou com o melhor desempenho dentre todas as implementações, para a imagem maior. Da mesma forma, a implementação o Pthreads compilada com o compilador do OpenMP obteve o segundo melhor desempenho. Já a versão do Pthreads compilada com o compilador gcc, não obteve um desempenho satisfatório em relação às outras implementações. E para a imagem menor e intermediária, o melhor desempenho foi atingido pelo Pthreads compilado com o icpc.

A Tabela 5.9 apresenta os resultados obtidos para a estratégia backmapping, processando sobre a imagem real, em seus diferentes tamanhos

Tabela 5.9 Resultados obtidos para a imagem real, com seus respectivos desvios padrões, utilizando a estratégia backmapping.

\begin{tabular}{|l|c|c|c|}
\hline Ferramentas & Imagem & Tempo de execucão & Desvio Padrão \\
\hline Sequencial & $512 \times 512$ & 0,2572 & 0,0018 \\
\hline OpenMP & $512 \times 512$ & 0,1691 & 0,0153 \\
\hline MPI & $512 \times 512$ & 0,2025 & 0,0095 \\
\hline pThread & $512 \times 512$ & 0,2104 & 0,0128 \\
\hline pThread c/omp & $512 \times 512$ & 0,1380 & 0,0128 \\
\hline Sequencial & $1024 \times 1024$ & 0,9996 & 0,0085 \\
\hline OpenMP & $1024 \times 1024$ & 0,4712 & 0,0320 \\
\hline MPI & $1024 \times 1024$ & 0,7108 & 0,0316 \\
\hline pThread & $1024 \times 1024$ & 0,8150 & 0,0519 \\
\hline pThread c/omp & $1024 \times 1024$ & 0,4422 & 0,0163 \\
\hline Sequencial & $2048 \times 2048$ & 4,1330 & 0,0271 \\
\hline OpenMP & $2048 \times 2048$ & 1,7177 & 0,0394 \\
\hline MPI & $2048 \times 2048$ & 3,0574 & 0,0960 \\
\hline pThread & $2048 \times 2048$ & 3,2898 & 0.0694 \\
\hline pThread c/omp & $2048 \times 2048$ & 1,7586 & 0,0435 \\
\hline
\end{tabular}


A Figura 5.13, apresenta o desempenho para as imagens reais da estratégia backmapping.

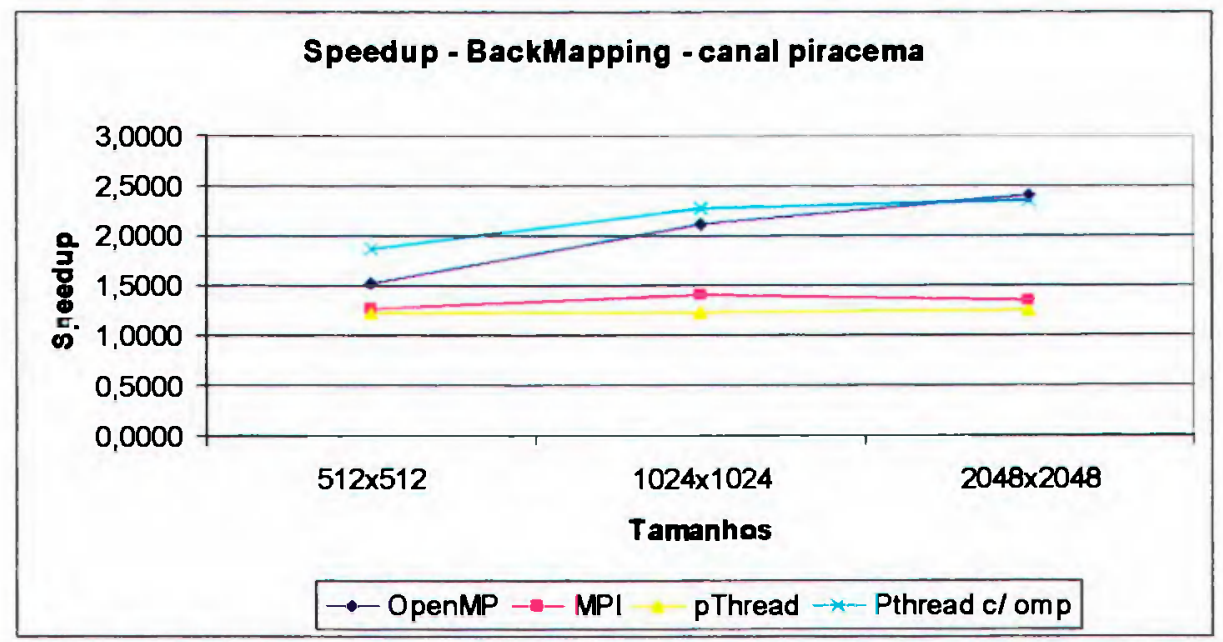

Figura 5.13 Speedup da implementação da TH utilizando Backmapping para a imagem do canal da piracema.

O melhor desempenho, conforme demonstra a Figura 5.13 e a Tabela 5.9, foi obtido pela estratégia Pthreads compilada com o compilador do OpenMP, para as imagens $512 \times 512$ e $1024 \times 1024$. Já o segundo melhor desempenho, para os dois tamanhos de imagem, foi obtido pelo OpenMP. Para a imagem de tamanho maior o melhor desempenho foi obtido pelo OpenMP, seguido de perto pelo Pthreads compilado com o compilador do OpenMP.

\subsubsection{Considerações sobre desempenho em MIMD compartilhada}

Através dos resultados obtidos, na arquitetura MIMD de memória compartilhada, pode-se observar que o desempenho da estratégia que utiliza o OpenMP, foi superior em todos os resultados, para as imagens de tamanho maior, exceto na estratégia de divisão da imagem, para as imagens que possuem retas mistas, onde o melhor resultado foi obtido pela estratégia que utiliza o Pthreads compilado com o icpc e, para a imagem real, também utilizando o Pthreads compilado com o icpc com a estratégia de divisão da imagem, em que o resultado entre as duas implementações (utilizando OpenMP e Pthreads compilado com icpc) foi o mesmo. A Figura 5.14 apresenta um comparativo entre as ferramentas e estratégias, para a imagem real e de tamanho maior. 


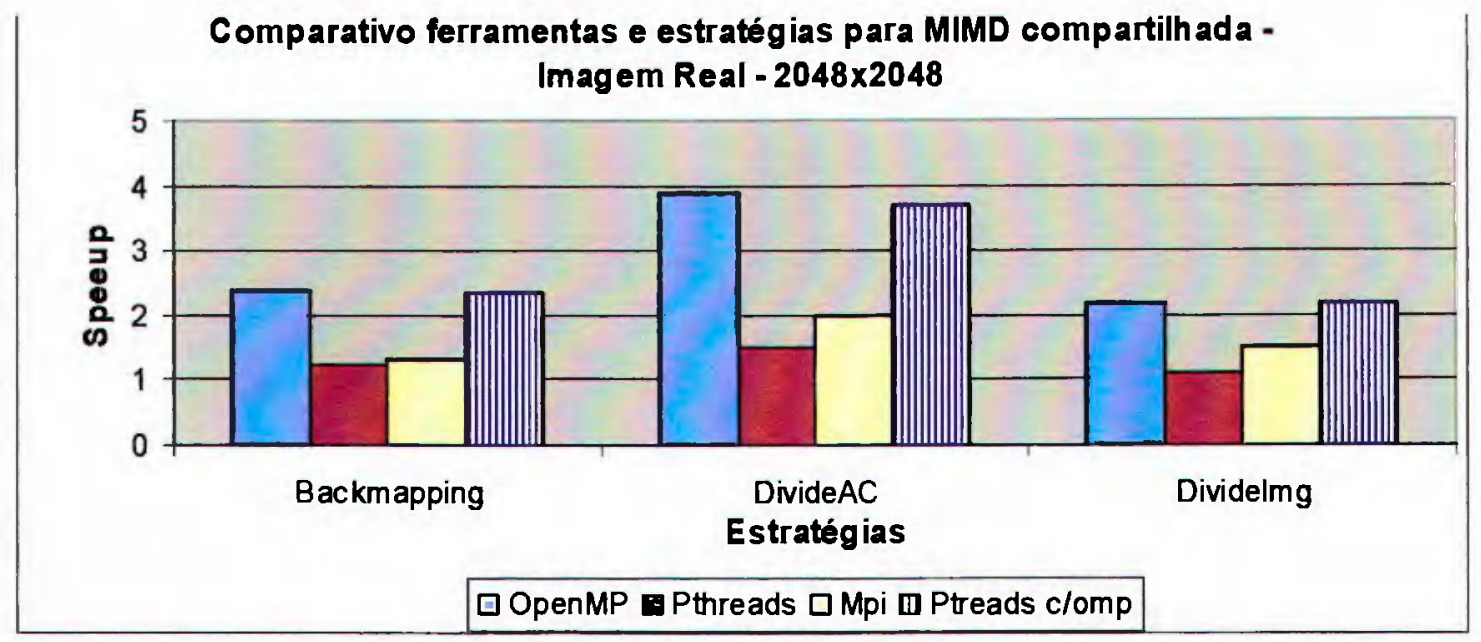

Figura 5.14 Comparativo entre as estratégia e ferramentas, para MIMD compartilhada, sobre a imagem real e de tamanho maior.

Pela Figura 5.14, observa-se que os melhores resultados, para a imagem real, foram obtidos utilizando-se a ferramenta OpenMP e que o melhor resultado foi obtido pela estratégia de divisão do acumulador.

Na Figura 5.15, é possível observar um comparativo entre as ferramentas e estratégias, para a imagem real e de tamanho intermediário.

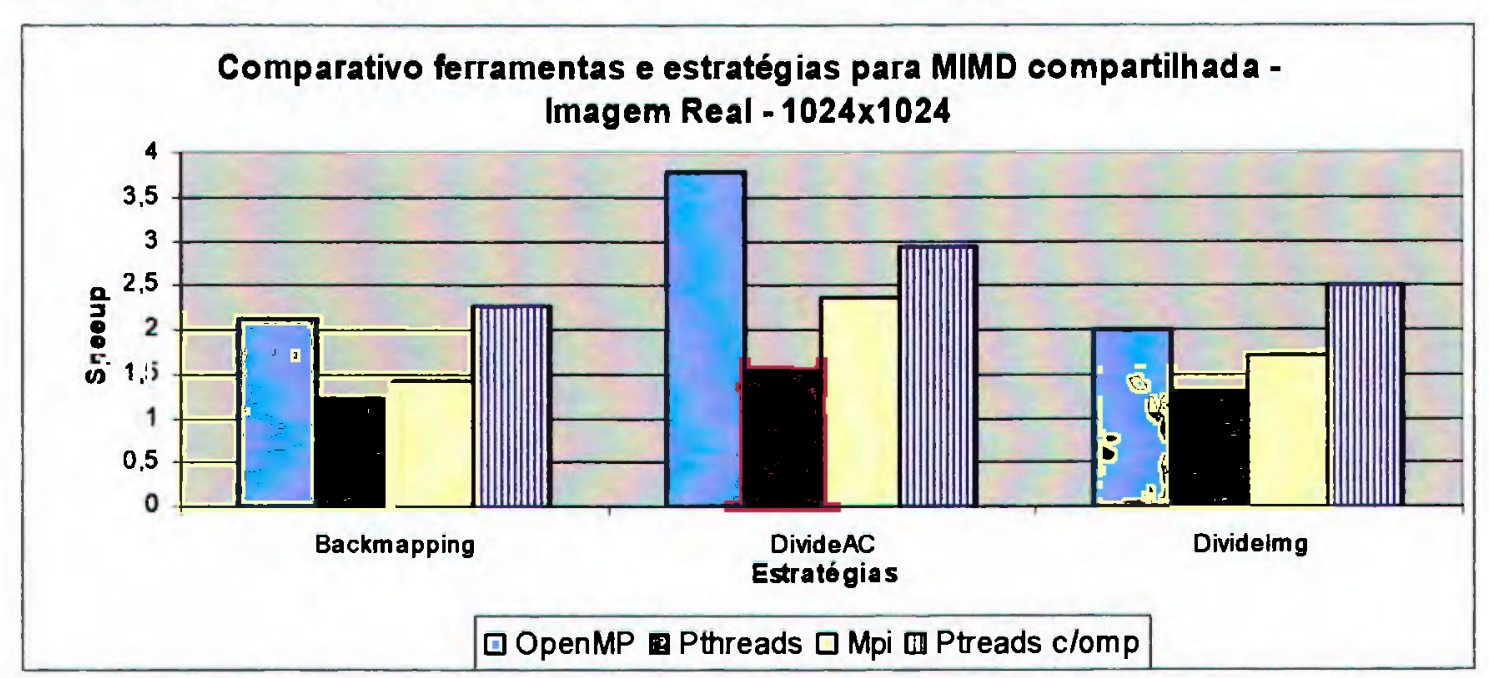

Figura 5.15 Comparativo entre as estratégia e ferramentas, para MIMD compartilhada, sobre a imagem real e de tamanho intermediário.

De acordo com a Figura 5.15, é possível observar que o melhor resultado foi obtido pela estratégia de divisão do acumulador utilizando a ferramenta OpenMP

O comparativo entre as ferramentas e estratégias, para a imagem real e de tamanho menor, é possível ser observado na Figura 5.16 a seguir. 


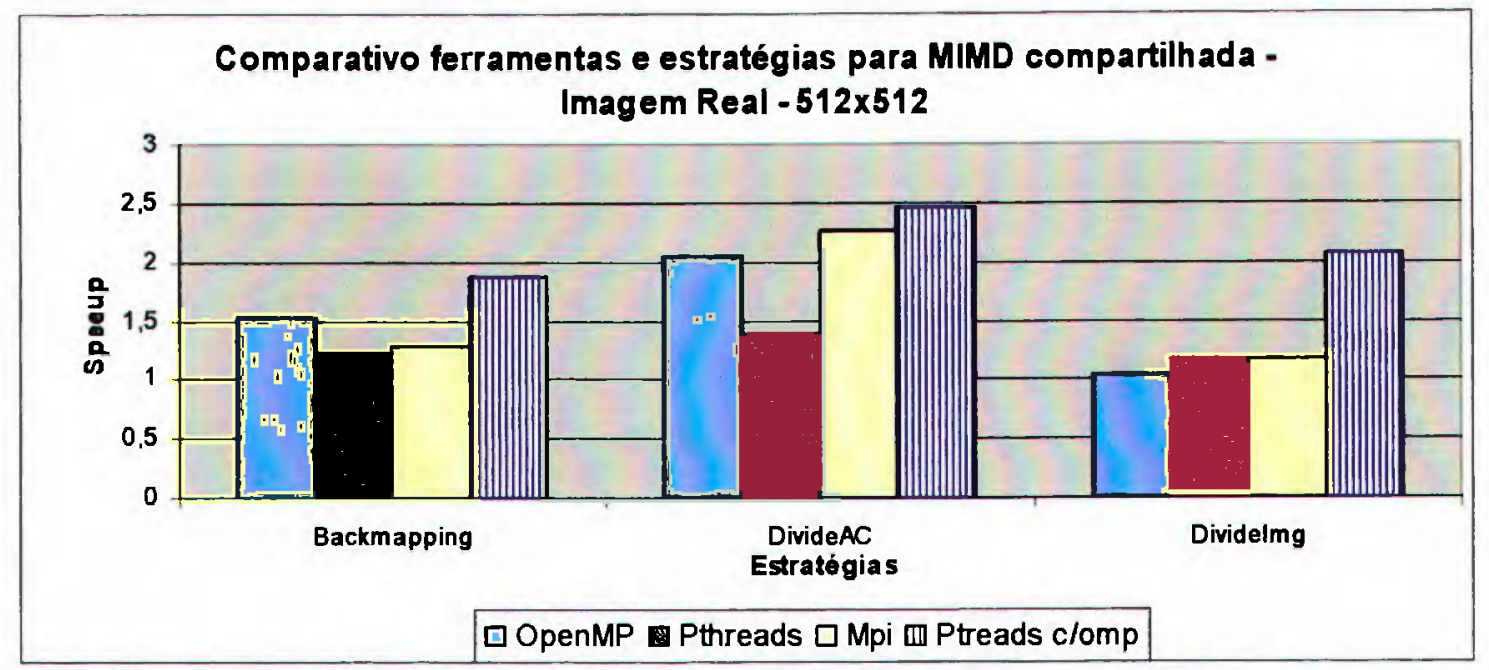

Figura 5.16 Comparativo entre as estratégia e ferramentas, para MIMD compartilhada, sobre a imagem real e de tamanho menor.

A Figura 5.16, apresenta o comparativo realizado, entre as estratégias e ferramentas, para a imagem real e de tamanho menor. Por este comparativo, é possível observar, que novamente a estratégia que obteve o melhor desempenho foi a divisão do arranjo acumulador, mas desta vez utilizando a ferramenta Pthreads compilada com o compilador icpc do OpenMP

Já para as imagens de tamanho menor, o OpenMP não obteve um bom desempenho. Sendo que, cinco resultados foram ruins, ficando na terceira ou última posição, três foram razoáveis, indicando a segunda posição e em apenas um resultado obteve o melhor desempenho para as imagens menores. Em contrapartida, nessas mesmas imagens menores em que o OpenMP obteve um resultado ruim, a versão do Pthreads compilada com o icpc obteve o melhor desempenho em oito dos nove experimentos avaliados e o único desempenho razoável, onde ficou em segundo lugar, ocorreu onde o OpenMP obteve o melhor resultado.

Nas imagens intermediárias, o Pthreads, compilado com o icpc, obteve cinco melhores resultados, dos nove experimentos avaliados, os outros quatro melhores resultados foram obtidos pelo OpenMP

A hegemonia, obtida em todos os tamanhos de imagem e em todos os experimentos, foi obtido pelas versões que utilizaram o compilador icpc (OpenMP e Pthreads), compilador esse que é específico para arquiteturas MIMD de memória compartilhada. O MPI surpreendeu por estar sempre a frente da implementação Pthreads compilada com o gcc, esse desempenho ocorreu devido ao MPI não realizar a troca de mensagens, em arquiteturas MIMD de memória compartilhada, pela rede de 
comunicação e sim pela própria memória compartilhada

\subsection{Experimentos MIMD memória distribuida.}

Os resultados apresentados, nesta seção, foram obtidos utilizando-se de um a dez processadores do cluster, descrito no parágrafo seguinte, através da ferramenta de apoio de troca de mensagens MPI (GROPP \& LUSK, 2004), (LAWRENCE, 2003d), (LAWRENCE, 2003e), (MPI, 2003), (NATIONAL, 2003), (PACHECO, 1997) e (PACS, 2004), utilizando a versão MPICH (GROPP \& LUSK, 2004).

Para memória distribuída foi utilizado um cluster, pertencente ao Instituto de Física de São Carlos, possuindo 10 nós, cada um contendo um processador Intel Pentium IV com 2,8 Giga Hertz com 1,5 GB de memória e memória cachè de 512 KB. O sistema operacional é o GNU/Linux openmosix-2.4.24. A rede que liga os nós do cluster possui uma taxa de transferência de 100 Megabits por segundo.

Os melhores resultados obtidos para o cluster encontram-se na tabela $5.10 \mathrm{e}$ representam os resultados obtidos para a estratégia de divisão do arranjo acumulador processando sobre retas horizontais.

Tabela 5.10 Melhores resultados obtidos pela estratégia de divisão do acumulador processando sobre retas horizontais.

\begin{tabular}{|c|c|c|c|}
\hline Tamanho da imagem & Quantidade de processadores & Tempo & Desvio padrão \\
\hline $512 \times 512$ & 3 & 0,1195 & 0,0026 \\
\hline $1024 \times 1024$ & 6 & 0,2894 & 0,0006 \\
\hline $2048 \times 2048$ & 6 & 0,8039 & 0,0130 \\
\hline
\end{tabular}

A Figura 5.17 apresenta o desempenho obtido utilizando a estratégia de divisão do arranjo acumulador sobre imagens que possuem retas horizontais.

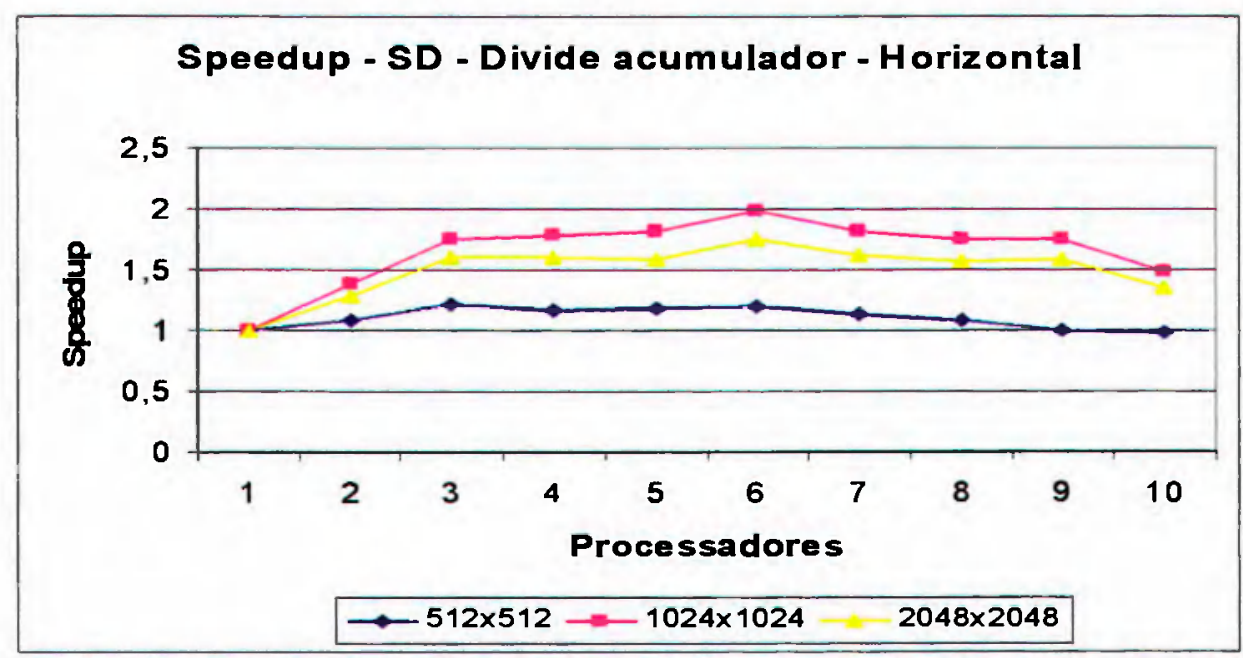

Figura 5.17 Speedup, obtido em cluster, da implementação da TH com divisão do arranjo acumulador para imagem horizontal. 
É possivel observar, na Figura 5.17 e na Tabela 5.10, que os melhores desempenhos, para a estratégia de divisão do acumulador para cluster, foram obtidos utilizando seis processadores sobre a imagem de tamanho $1024 \times 1024$. Este desempenho obtido sem o uso de todos os processadores dá-se pelo fato de que quanto mais processadores forem sendo acrescentados, mais trocas de mensagens devem ser utilizadas, o que prejudica o desempenho da implementação, chegando, como observado para dez processadores sobre a imagem de tamanho $512 \times 512$, a ser inferior ao desempenho sequencial utilizando apenas um processador. Outra importante observação, é a de que o melhor desempenho foi obtido quando do processamento da imagem intermediária e não no processamento da imagem maior, como era de se esperar pela quantidade de dados envolvida. Este problema, ocorre devido à quantidade de dados que é enviado para os escravos ser quatro vezes maior que quantidade de dados da imagem intermediária. Pois, a imagem maior possui quatro vezes o tamanho da imagem intermediária, gastando-se desta forma um tempo maior para trafegar os dados pela rede, tendo em vista que a rede permite trafegar até 100 megabits por segundo, não sendo possivel transmitir a imagem toda de uma única vez.

A Tabela 5.11 a seguir apresenta os melhores resultados obtidos pela estratégia de divisão da imagem operando sobre retas horizontais.

Tabela 5.11 Melhores resultados obtidos pela estratégia de divisão da imagem processando sobre retas horizontais.

\begin{tabular}{|c|c|c|c|}
\hline Tamanho da imagem & Quantidade de processadores & Tempo & Desvio padrão \\
\hline $512 \times 512$ & 7 & 0.1047 & 0.0044 \\
\hline $1024 \times 1024$ & 7 & 0.3082 & 0.0026 \\
\hline $2048 \times 2048$ & 9 & 0.8480 & 0,0010 \\
\hline
\end{tabular}

Na Figura 5.18, é apresentado o desempenho, para cluster, utilizando a estratégia de divisão da imagem.

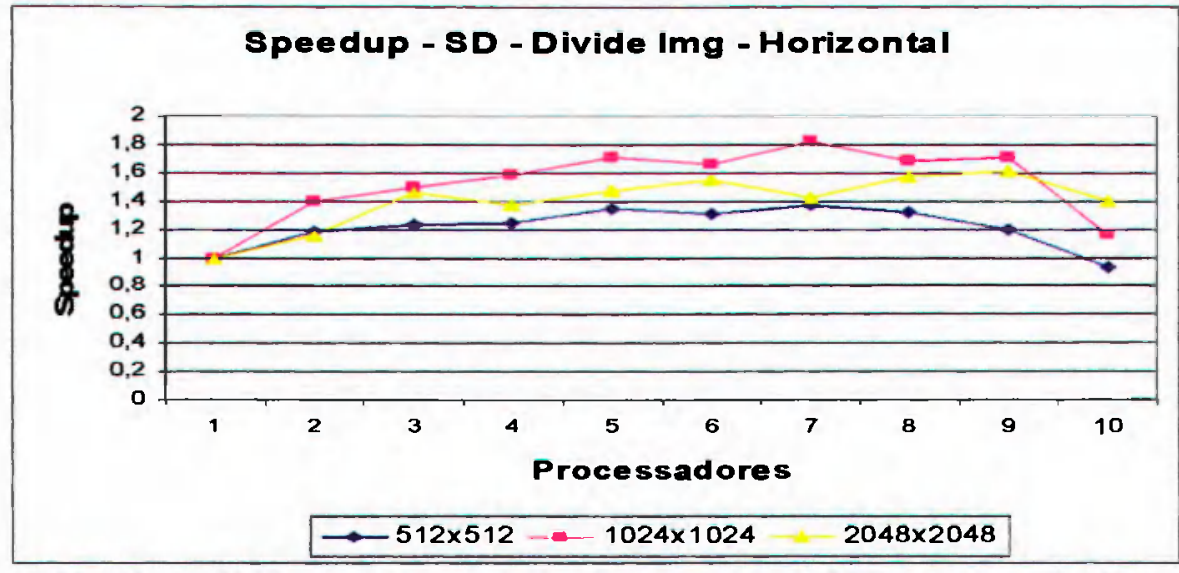

Figura 5.18 Speedup, obtido em cluster, da implementação da TH com divisão da imagem para imagem horizontal. 
Observa-se, na Figura 5.18 e na Tabela 5.11, que o desempenho máximo, para a estratégia de divisão da imagem nas imagens menor e intermediária, é obtido utilizandose sete processadores. E para a imagem maior, o melhor desempenho foi obtido utilizando-se nove processadores. Nota-se também, assim como ocorreu na estratégia de divisão do acumulador, que o desempenho utilizando dez processadores, para a imagem menor, foi pior que o desempenho utilizando somente um processador, pois o número de troca de mensagens entre os escravos e o servidor é muito elevado e a quantidade de dados, envolvida para processamento, também é baixa, acarretando o baixo desempenho. Outra observação, é a oscilação do desempenho para determinado número de processadores, esse fato ocorre, devido a estratégia de divisão da imagem não garantir que todos os processadores recebam dados para processar, já que em determinadas área da imagem pode não possuir retas, ocasionando a ociosidade de alguns processadores e prejudicando, dessa forma, o desempenho geral

Pela Tabela 5.12 é possível observar os melhores resultados obtidos pela estratégia backmapping operando sobre retas horizontais.

Tabela 5.12 Melhores resultados obtidos pela estratégia de backmapping processando sobre retas horizontais.

\begin{tabular}{|c|c|c|c|}
\hline Tamanho da imagem & Quantidade de processadores & Tempo & Desvio padrão \\
\hline $512 \times 512$ & 8 & 0,2248 & 0.0030 \\
\hline $1024 \times 1024$ & 7 & 0.5553 & 0,0068 \\
\hline $2048 \times 2048$ & 8 & 1.4732 & 0,0193 \\
\hline
\end{tabular}

A Figura 5.19, representa o desempenho obtido para processar a $\mathrm{TH}$, sobre imagens que possuem retas horizontais, utilizando a estratégia backmapping

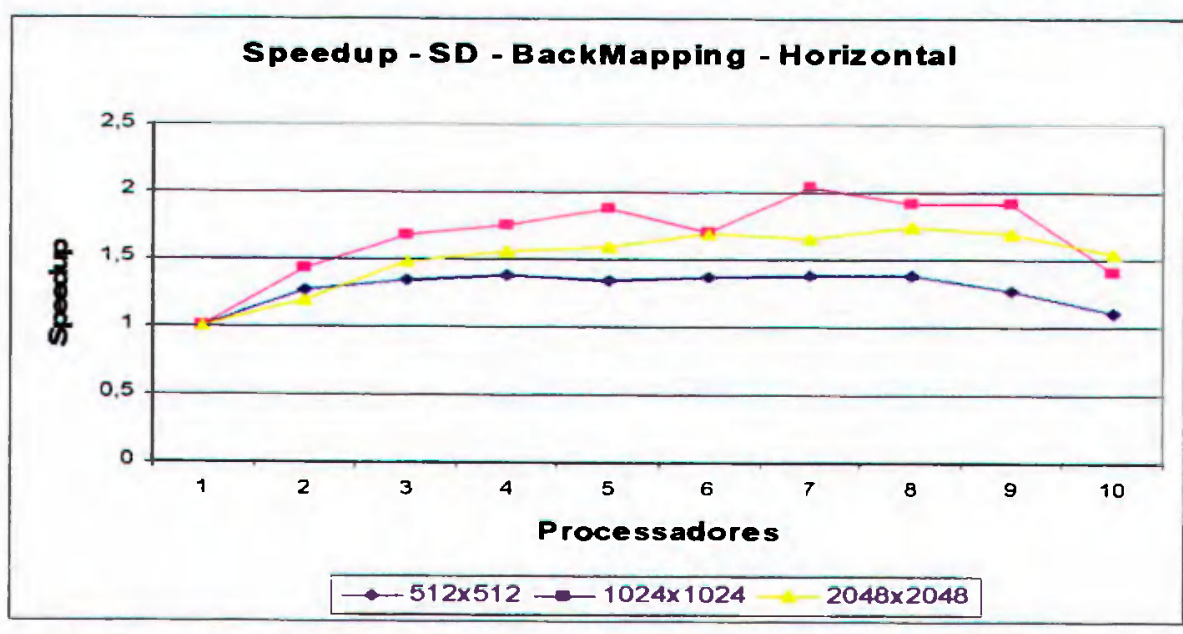

Figura 5.19 Speedup, obtido em cluster, da implementação da TH com Backmapping para imagem horizontal.

No gráfico, da Figura 5.19 e na Tabela 5.12, observa-se que em nenhuma das imagens o desempenho ficou abaixo da versão seqüencial. Nota-se, também, que o 
melhor desempenho, novamente foi obtido realizando o processamento sobre a imagem intermediária. O tempo de execução atingido, para a imagem $1024 \times 1024$, foi duas vezes menor que o tempo de execução para a versão sequencial utilizando-se 7 processadores dos 10 existentes no cluster. A Figura 5.19, também, apresenta uma queda de desempenho do quinto processador para o sexto e uma retomada do desempenho do sexto para o sétimo processador. Isso ocorreu, conforme indica a Figura 5.20, porque com seis processadores o processador " $3: 0$ " recebe uma porção da imagem sem retas para processar, a Figura 5.20 (a) ilustra esse acontecimento onde não possui porção azul de processamento, o mesmo não ocorre para sete processadores, já que cada processador recebe uma porção da imagem com retas para processar, conforme mostra a Figura 5.20 (b)

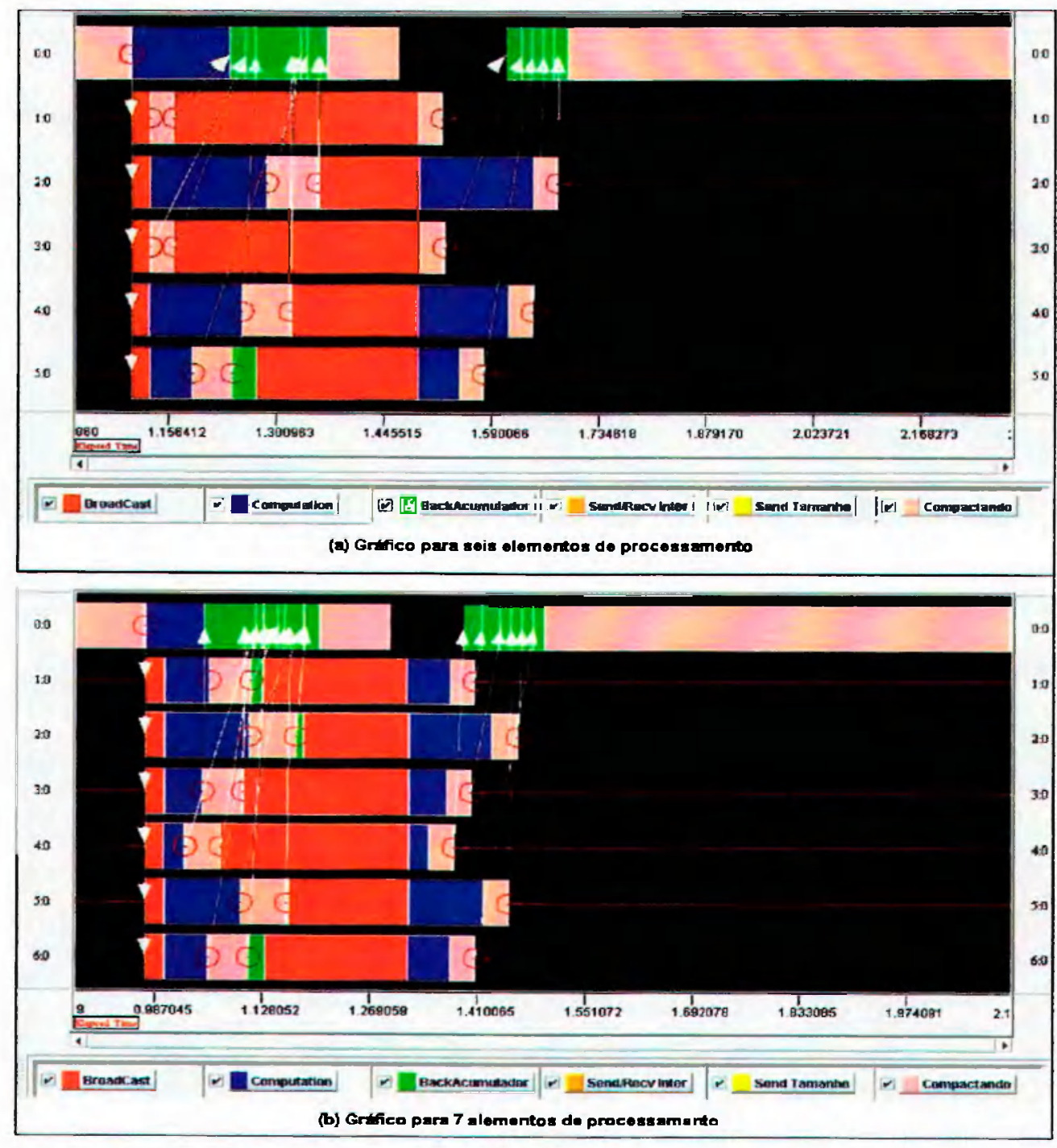

Figura 5.20 - Gráfico de processamento para seis (a) e (b) sete processadores

Pela Tabela 5.13 é possível observar os melhores resultados obtidos pela estratégia de divisão do acumulador operando sobre retas mistas. 
Tabela 5.13 Melhores resultados obtidos pela estratégia de divisão do acumulador processando sobre retas mistas.

\begin{tabular}{|c|c|c|c|}
\hline Tamanho da imagem & Quantidade de processadores & Tempo & Desvio padrão \\
\hline $512 \times 512$ & 1 & 0,0988 & 0,0064 \\
\hline $1024 \times 1024$ & 5 & 0,2686 & 0,0008 \\
\hline $2048 \times 2048$ & 5 & 0,8454 & 0,0018 \\
\hline
\end{tabular}

A Figura 5.21, demonstra o resultado obtido para a estratégia de divisão do arranjo acumulador que realiza o processamento sobre uma imagem que possui retas em todos os sentidos de orientação.

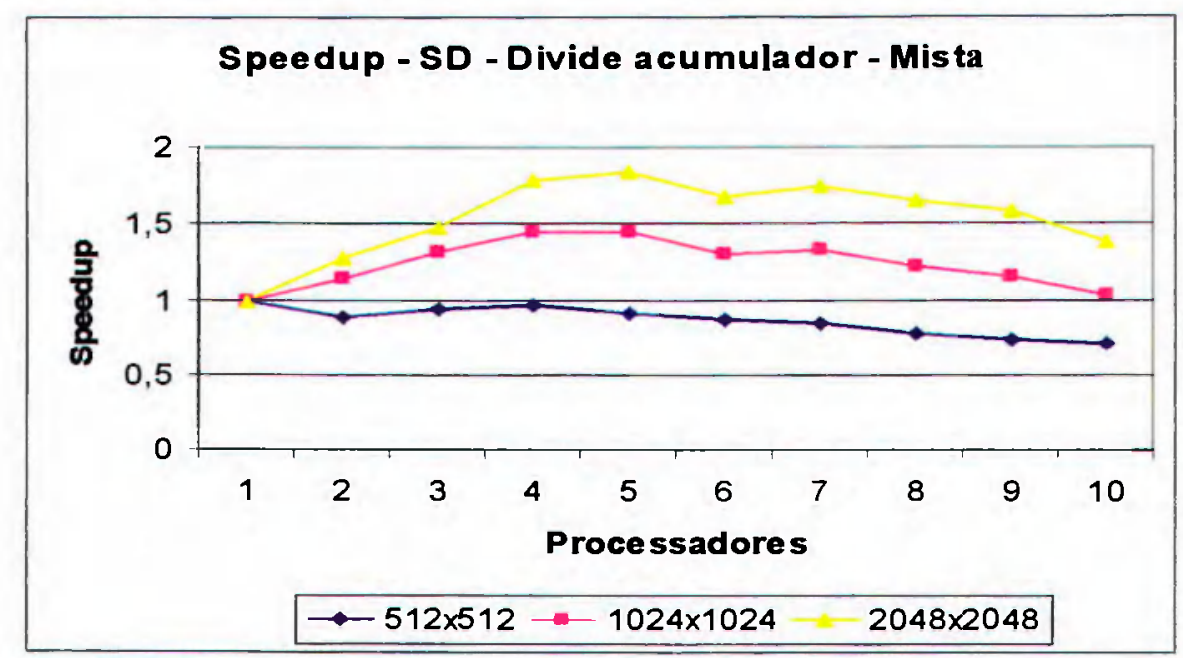

Figura 5.21 Speedup, obtido em cluster, da implementação da TH com divisão do arranjo acumulador para imagem mista

Na Figura 5.21 e Tabela 5.13, é possivel observar, que a imagem maior obteve um desempenho melhor em comparação com a imagem intermediária, que vinha obtendo um desempenho superior para a arquitetura MIMD de memória distribuída. Este resultado, mais lógico, que os anteriores, ocorre por existir uma maior quantidade de dados para serem processados, devido ao tipo de imagem que está sendo processada possuir uma quantidade de dados maior, já que as retas se dão em todos os sentidos de orientação, sendo, assim, mais condizente com as imagens reais. $\mathrm{Na}$ imagem intermediária, o desempenho obtido utilizando-se os 10 processadores do cluster foi muito próximo ao desempenho da versão seqüencial devido ao aumento de troca de mensagens. Já para a imagem menor, o desempenho nos diversos processadores não foi superior ao desempenho utilizando-se apenas um processador

Pela Tabela 5.14 é possível observar os melhores resultados obtidos pela estratégia de divisão da imagem operando sobre retas mistas. 
Tabela 5.14 Melhores resultados obtidos pela estratégia de divisão da imagem processando sobre retas mistas.

\begin{tabular}{|c|c|c|c|}
\hline Tamanho da imagem & Quantidade de processadores & Tempo & Desvio padrão \\
\hline $512 \times 512$ & 5 & 0,0985 & 0,0002 \\
\hline $1024 \times 1024$ & 9 & 0,2850 & 0,0011 \\
\hline $2048 \times 2048$ & 9 & 0,8658 & 0,0014 \\
\hline
\end{tabular}

Na Figura 5.22, é verificado o desempenho para imagens mistas utilizando a estratégia de divisão da imagem

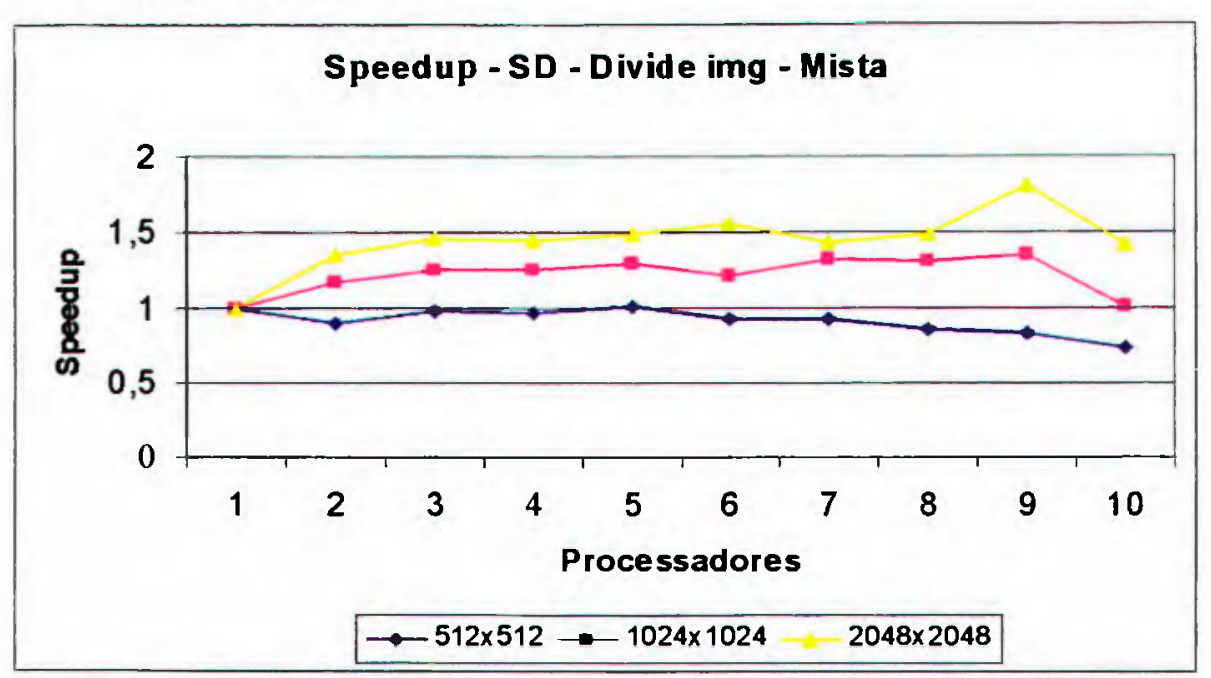

Figura 5.22 Speedup, obtido em cluster, da implementação da TH com divisão da imagem para imagem mista.

Pode-se observar, pela Figura 5.22 e Tabela 5.14, que na estratégia de divisão da imagem o melhor desempenho é obtido para a imagem maior, atingindo um pico de speedup, aproximadamente 1,8 , superando, novamente, o desempenho obtido para a imagem intermediária. Já para a imagem menor o desempenho ficou abaixo do obtido pela implementação sequencial, isto se dá, devido a realização das trocas de mensagens entre os escravos e o servidor consumir um tempo maior do que se a imagem fosse processada sequencialmente

Pela Tabela 5.15 é possível observar os melhores resultados obtidos pela estratégia backmapping operando sobre retas mistas.

Tabela 5.15 Melhores resultados obtidos pela estratégia backmapping processando sobre retas mistas.

\begin{tabular}{|c|c|c|c|}
\hline Tamanho da imagem & Quantidade de processadores & Tempo & Desvio padrã̃o \\
\hline $512 \times 512$ & 4 & 0.2041 & 0,0015 \\
\hline $1024 \times 1024$ & 5 & 0,5402 & 0,0014 \\
\hline $2048 \times 2048$ & 9 & 1,5705 & 0,0048 \\
\hline
\end{tabular}

Os resultados obtidos utilizando a estratégia backmapping, para as imagens mistas, são demonstrados na Figura 5.23 a seguir. 


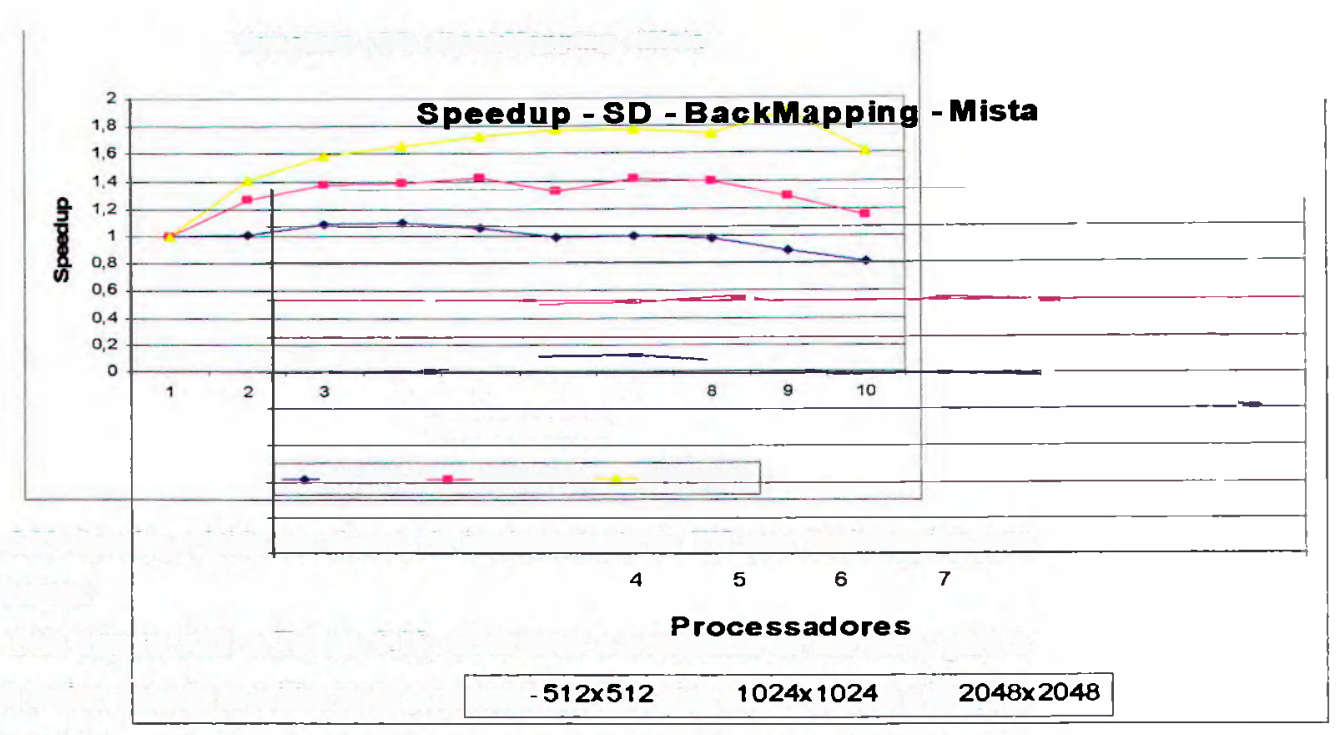

Figura 5.23 Speedup, obtido em cluster, da implementação da TH com Backmapping para imagem mista

Pela Figura 5.23 e Tabela 5.15, observa-se a ocorrência de um pico, para a imagem maior, quando se utiliza nove processadores. Este pico ocorre porque a imagem quando dividida em 9 partes iguais representou uma melhor distribuição dos dados para ser processado entre os escravos, não sobrecarregando nenhum escravo. Já para oito processadores algum dos escravos ficou sobrecarregado o que resultou em uma perda de desempenho em relação ao desempenho obtido com sete processadores, interrompendo, déssa forma, o aumento de desempenho constante que vinha ocorrendo. $\mathrm{Na}$ imagem menor ocorre um ligeiro desempenho, diante da versão sequencial, entre três e cinco processadores e após oito processadores o desempenho é inferior ao desempenho sequencial. Esse desempenho ruim ocorre devido ao aumento de troca de mensagens ocorrido.

Pela Tabela 5.16 é possivel observar os melhores resultados obtidos pela estratégia de divisão do acumulador operando sobre a imagem real.

Tabela 5.16 Melhores resultados obtidos pela estratégia de divisão do acumulador

\begin{tabular}{|c|c|c|c|}
\hline Tamanho da imagem & Quantidade de processadores & Tempo & Desvio padrão \\
\hline $512 \times 512$ & 4 & 0.2041 & 0,0015 \\
\hline $1024 \times 1024$ & 5 & 0,5402 & 0,0014 \\
\hline $2048 \times 2048$ & 9 & 1,5705 & 0,0048 \\
\hline
\end{tabular}

Para a imagem real, o desempenho pode ser observado das Figuras 5.24 a 5.26. $\mathrm{O}$ desempenho da estratégia de divisão do acumulador sobre a imagem real pode ser observado na Figura 5.24. 


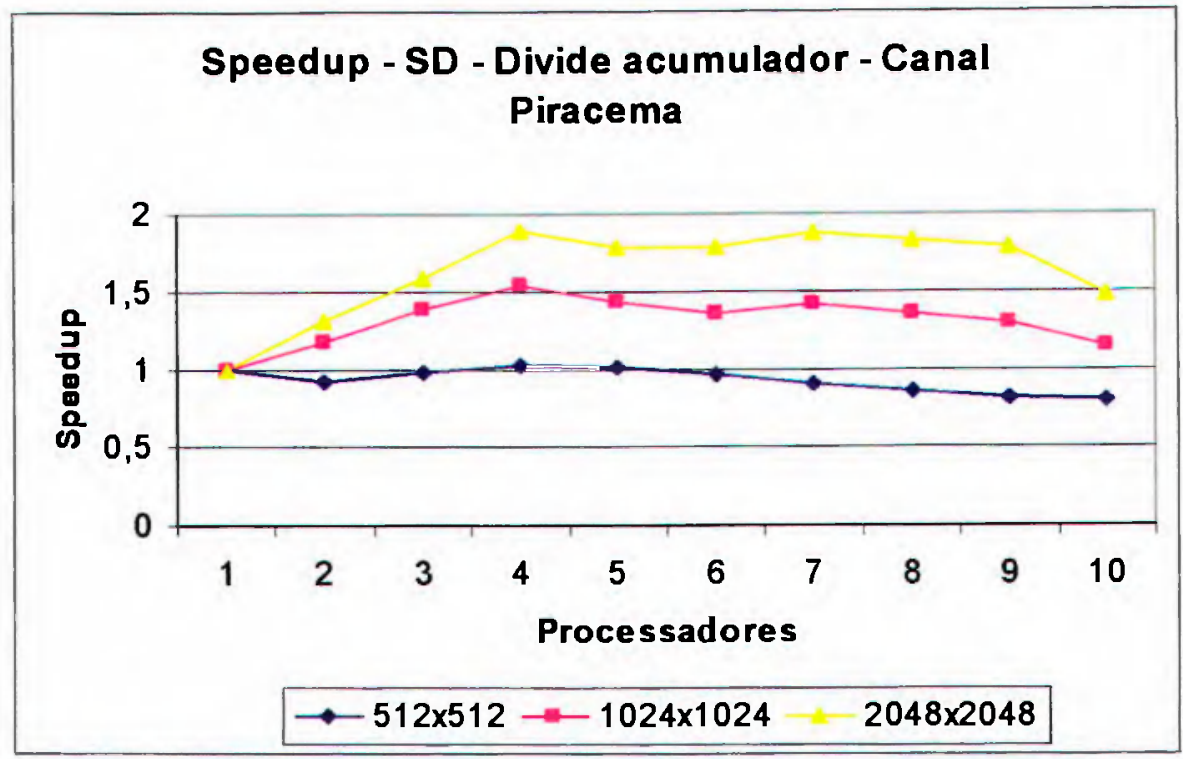

Figura 5.24 Speedup, obtido em cluster, da implementação da TH com divisão do arranjo acumulador para imagem do canal da piracema.

O que se pode observar, na Figura 5.24 e na Tabela 5.16, é que o melhor desempenho foi atingido realizando-se o processamento da TH para imagens $2048 \times 2048$, chegando a 1,9 para quatro processadores e permanecendo um desempenho entre 1,8 e 1,9 de quatro até nove processadores. Para a imagem $512 \times 512$, o desempenho dos diversos processadores em nenhum momento obteve um resultado significativo diante da versão sequencial. $\mathrm{O}$ que ocorreu foi justamente o contrário, a versão sequencial é que obteve um desempenho melhor diante da implementação paralela.

Pela Tabela 5.17 é possível observar os melhores resultados obtidos pela estratégia de divisão da imagem operando sobre a imagem real.

Tabela 5.17 Melhores resultados obtidos pela estratégia de divisão da imagem processando sobre a imagem real.

\begin{tabular}{|c|c|c|c|}
\hline Tamanho da imagem & Quantidade de processadores & Tempo & Desvio padrão \\
\hline $512 \times 512$ & 2 & 0,1069 & 0,0004 \\
\hline $1024 \times 1024$ & 9 & 0,4107 & 0.0023 \\
\hline $2048 \times 2048$ & 3 & 1,3668 & 0,0036 \\
\hline
\end{tabular}

Na Figura 5.25, é possível verificar o desempenho obtido pela estratégia de divisão da imagem sobre as imagens reais 


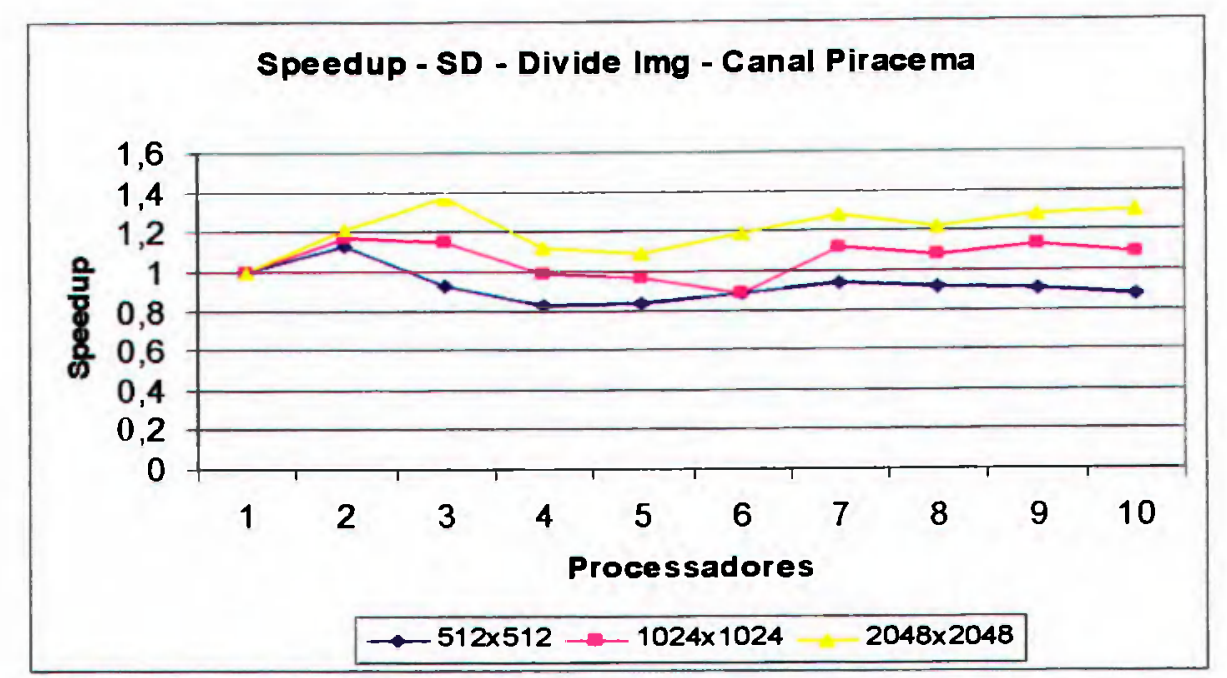

Figura 5.25 Speedup, obtido em cluster, da implementação da TH com divisão da imagem para imagem do canal da piracema.

Realizando a comparação entre as Figuras 5.24 e 5.25 é possível observar o modesto desempenho obtido pela estratégia de divisão da imagem diante da estratégia de divisão do acumulador apresentado na Figura 5.24. Na Figura 5.25, é possível averiguar, também, que o desempenho alcançado, processando a imagem 1024x1024, utilizando seis processadores ficou abaixo do desempenho atingido pela execução sequencial da TH. Outro aspecto que a Figura 5.25 e a Tabela 5.17 apresentam, é o máximo desempenho obtido, ocorreu com três processadores para a imagem maior $\mathrm{e}$ não foi superior a 1,4 vezes o desempenho da versão sequencial.

Pela Tabela 5.18 é possível observar os melhores resultados obtidos pela estratégia backmapping operando sobre as imagens reais.

Tabela 5.18 Melhores resultados obtidos pela estratégia backmapping processando sobre as imagens reais.

\begin{tabular}{|c|c|c|c|}
\hline Tamanho da imagem & Quantidade de processadores & Tempo & Desvio padrăo \\
\hline $512 \times 512$ & 7 & 0,2382 & 0,0015 \\
\hline $1024 \times 1024$ & 7 & 0,7256 & 0,0054 \\
\hline $2048 \times 2048$ & 7 & 2,4797 & 0,0137 \\
\hline
\end{tabular}

Pela Figura 5.26 é possível observar o desempenho atingido pela estratégia backmapping para processar as imagens do canal da piracema. 


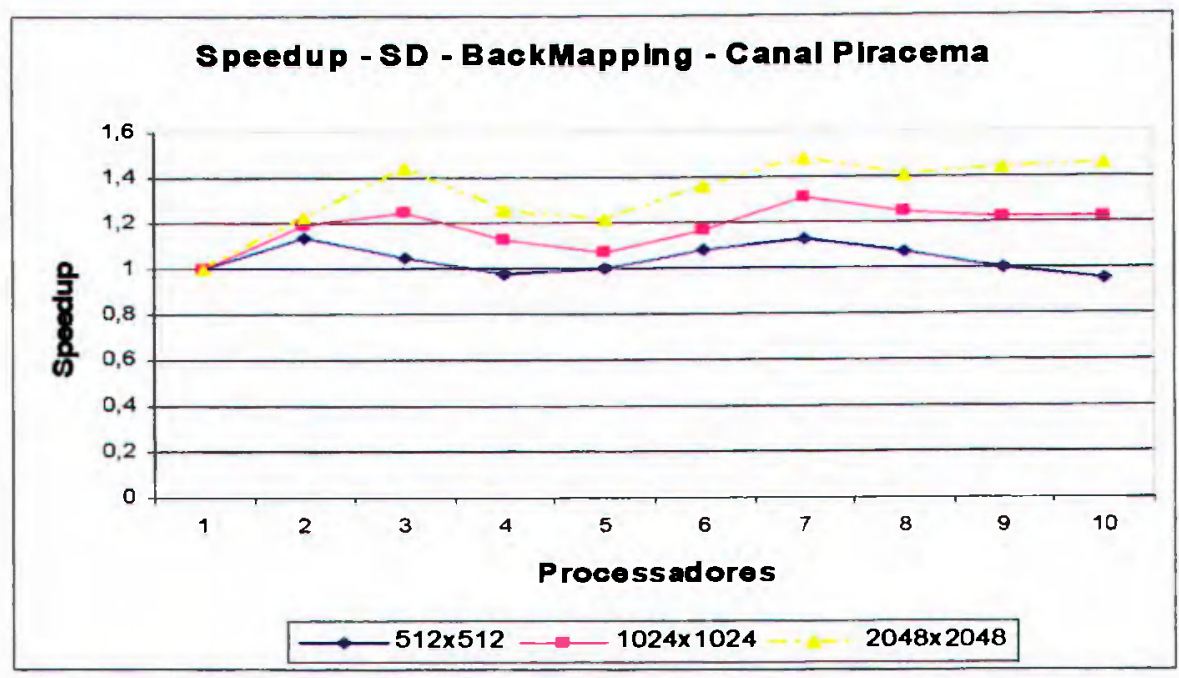

Figura 5.26 Speedup obtido em cluster da implementação da TH com Backmapping para imagem do canal da piracema.

A Figura 5.26 e a Tabela 5.18, apresentam os resultados obtidos para a estratégia de backmapping, sobre o processamento da imagem real. O melhor desempenho foi obtido para a imagem $2048 \times 2048$ e ficou próximo a 1,4 vezes mais rápido que a execução sequencial. Na Figura 5.21, nota-se, que para quatro e cinco processadores, nas imagens $1024 \times 1024$ e 2048x2048, ocorreu uma redução no desempenho, esse fato dá-se devido à quantidade de partes que a imagem foi dividida, o que ocasionou a sobrecarga de alguns dos processadores e a ociosidade de outros, como ocorreu em outros experimentos conforme a Figura 5.20 demonstra. Outra observação, é que não se faz necessário dividir a imagem em mais de três processadores, pois o desempenho máximo já foi praticamente atingido

A partir da Figura 5.27 até a Figura 5.32, são apresentados os gráficos de speedup para a estratégia Processor Farm em conjunto com as estratégias de divisão do arranjo acumulador e de divisão da imagem. Esta estratégia foi implementada, somente para a arquitetura MIMD de memória distribuída, por que este tipo de arquitetura permite o desenvolvimento, deste tipo de estratégia, de forma mais apropriada

Para realizar a implementação, da estratégia processor farm, necessitou-se realizar algumas melhorias, em relação ao conceito em sua forma natural, como a divisão do arranjo acumulador e da imagem por quatro vezes a quantidade de processadores escravos, dessa maneira se, por exemplo, existissem quatro processadores, a imagem ou o arranjo acumulador, dependendo da estratégia que estiver sendo adotada, seriam divididos em 16 partes. Assim, quando um escravo solicitar trabalho, lhe é designada uma dessas 16 partes para que ele faça o processamento e, 
quando este acabar, deverá solicitar mais trabalho. A outra melhoria, diz respeito a devolução do arranjo acumulador, por parte dos escravos ao mestre. Se os escravos devolvessem o arranjo acumulador a cada novo trabalho concluído, na estratégia de divisão da imagem utilizando os quatros escravos exemplificados, ter-se-ia a devolução de 16 arranjos acumuladores, já que cada parte da imagem gera um arranjo acumulador. Desse modo, o tráfego na rede de comunicação, ficaria saturado e o processamento lento, pois a cada novo pedido de trabalho o escravo teria que primeiro enviar o arranjo acumulador e esperar o recebimento por completo desse arranjo pelo mestre, para que depois o mestre lhe fornecesse mais trabalho. Ficando o escravo, dessa maneira, muito tempo ocioso. Essa última melhoria foi implementada também para a estratégia processor farm com divisão do arranjo acumulador, para evitar que o escravo fique aguardando uma nova parte do trabalho para ser processada enquanto que o mestre está recebendo a porção do arranjo acumulador que o escravo lhe enviou, embora pela estratégia de divisão do arranjo o número de arranjos acumuladores gerados seja sempre um, já que cada escravo sempre processa em pedaço do arranjo acumulador, que somados compõe o arranjo acumulador na íntegra. Se as estratégias fossem implementadas sem essas alterações e melhorias, ficaria claro que o ganho de desempenho seria muito aquém do esperado ou, até mesmo, não existiria.

Pela Tabela 5.19 é possivel observar os melhores resultados obtidos pela estratégia de divisão do acumulador em conjunto com a estratégia processor farm operando sobre retas horizontais.

Tabela 5.19 Melhores resultados obtidos pela estratégia processor farm em união com a estratégia de divisão do acumulador processando sobre retas horizontais.

\begin{tabular}{|c|c|c|c|}
\hline Tamanho da imagem & Quantidade de processadores & Tempo & Desvio padrão \\
\hline $512 \times 512$ & 3 & 0,1461 & 0,0007 \\
\hline $1024 \times 1024$ & 4 & 0,4360 & 0,0014 \\
\hline $2048 \times 2048$ & 4 & 1,1467 & 0,0022 \\
\hline
\end{tabular}

$\mathrm{Na}$ Figura 5.27, é possível observar o desempenho para a estratégia de divisão do acumulador, em conjunto com a estratégia processor farm, para as imagens que possuem retas horizontais. 


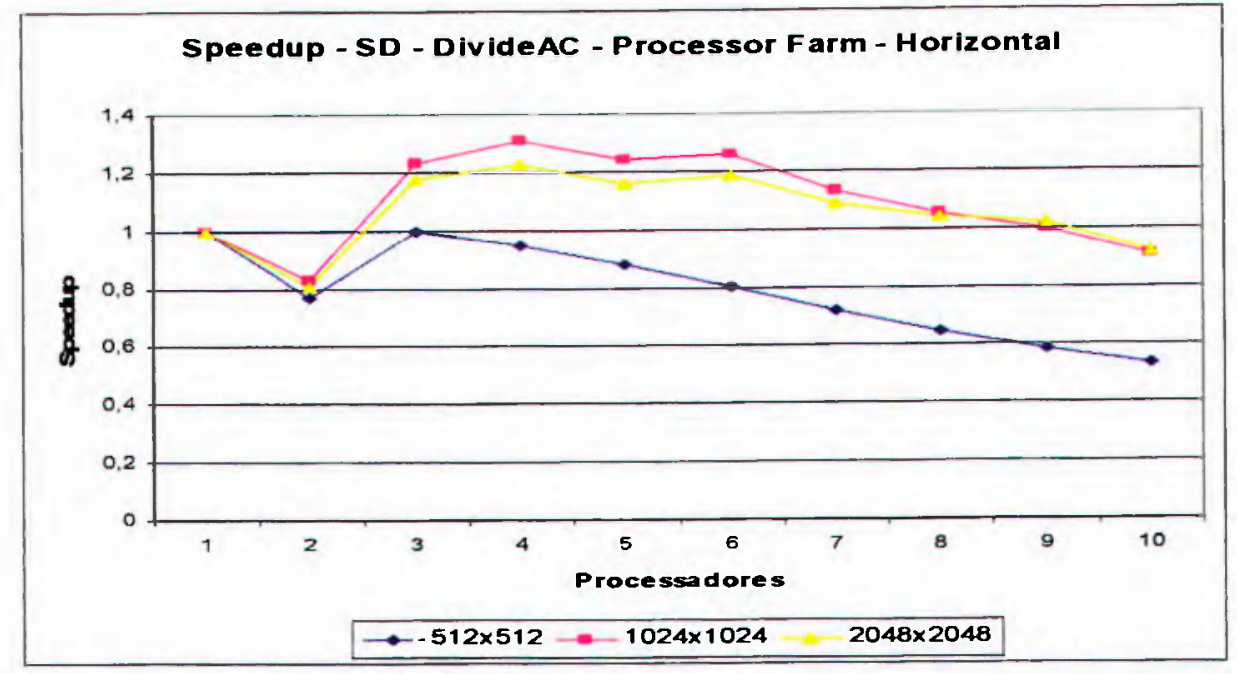

Figura 5.27 Speedup obtido em cluster da implementação da TH com processor farm e divisão do arranjo acumulador para imagens com retas horizontais.

Pela Figura 5.27 e Tabela 5.19, é possível observar que o máximo speedup alcançado ficou próximo a 1,3, para a imagem de tamanho intermediário, o que é um desempenho muito modesto para uma estratégia que vinha obtendo um desempenho em torno de 1,8 a 2,0 . Nota-se, também, que para a imagem menor, devido a sua quantidade de dados, não ocorreu speedup.

Pela Tabela 5.20 é possível observar os melhores resultados obtidos pela estratégia de divisão do acumulador em conjunto com a estratégia processor farm operando sobre retas mistas.

Tabela 5.20 Melhores resultados obtidos pela estratégia processor farm em uniăo com a estratégia de divisão do acumulador processando sobre retas mistas.

\begin{tabular}{|c|c|c|c|}
\hline Tamanho da imagem & Quantidade de processadores & Tempo & Desvio padrão \\
\hline $512 \times 512$ & 1 & 0,1063 & 0,0094 \\
\hline $1024 \times 1024$ & 3 & 0,3867 & 0,0170 \\
\hline $2048 \times 2048$ & 4 & 1,2246 & 0,0205 \\
\hline
\end{tabular}

Observa-se, na Figura 5.28, o desempenho obtido pela estratégia processor farm, com a estratégia de divisão do arranjo acumulador, para as imagens que possuem retas em todos os sentidos de orientação. 


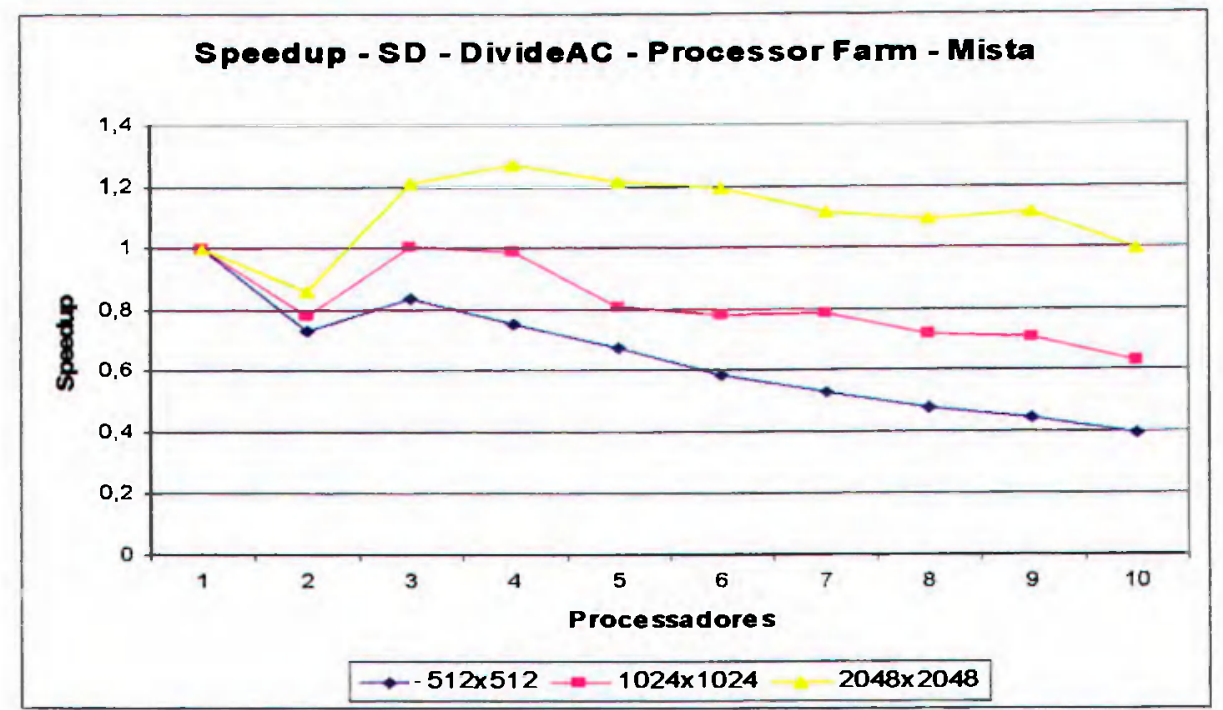

Figura 5.28 Speedup obtido em cluster da implementação da TH com processor farm e divisão do arranjo acumulador para imagens com retas mistas.

Na Figura 5.28 e na Tabela 5.20, o que chama a atenção, não é o baixo desempenho alcançado sobre o processamento da imagem maior e sim a ausência de desempenho ocorrido para a imagem intermediária, sendo até o momento o pior desempenho em cluster para esse tamanho de imagem. Para a imagem menor, novamente não ocorreu speedup.

Pela Tabela 5.21 é possível observar os melhores resultados obtidos pela estratégia de divisão do acumulador em conjunto com a estratégia processor farm operando sobre imagens reais.

Tabela 5.21 Melhores resultados obtidos pela estratégia processor farm em uniăo com a estratégia de divisão do acumulador processando sobre imagens reais.

\begin{tabular}{|c|c|c|c|}
\hline Tamanho da imagem & Quantidade de processadores & Tempo & Desvio padrão \\
\hline $512 \times 512$ & 1 & 0,1210 & 0.0002 \\
\hline $1024 \times 1024$ & 4 & 0,4164 & 0.0049 \\
\hline $2048 \times 2048$ & 6 & 1,3131 & 0,0051 \\
\hline
\end{tabular}

Através da Figura 5.29, é possivel observar o desempenho alcançado pela estratégia processor farm, em união com a divisão do arranjo acumulador, para a imagem real. 


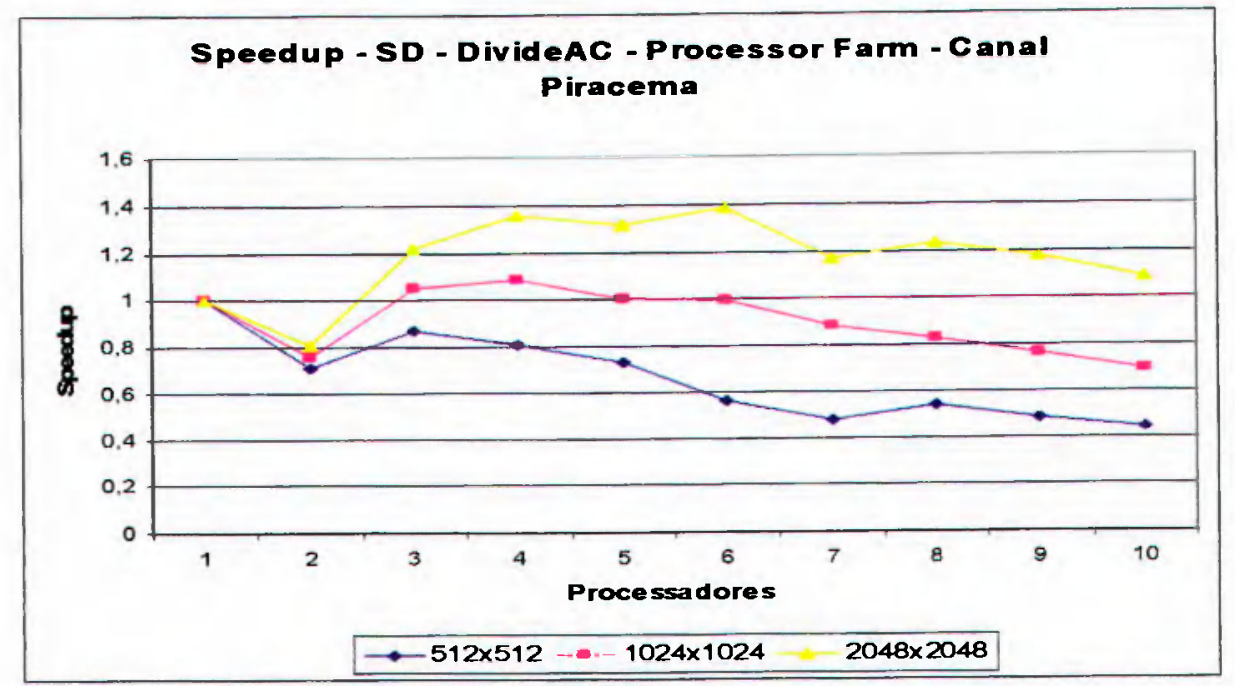

Figura 5.29 Speedup obtido em cluster da implementação da TH com processor farm e divisão do arranjo acumulador para as imagens reais.

Observando a Figura 5.29 e a Tabela 5.21, nota-se que o desempenho, obtido para a imagem maior, foi ligeiramente melhor. Atingindo um speedup muito próximo a 1,4. Na imagem intermediária o desempenho foi irrisório e de 1,1. Na imagem menor, outra vez não ocorreu desempenho

Pela Tabela 5.22 é possivel observar os melhores resultados obtidos pela estratégia de divisão da imagem em conjunto com a estratégia processor farm operando sobre retas horizontais.

Tabela 5.22 Melhores resultados obtidos pela estratégia processor farm em união com a estratégia de divisão da imagem processando sobre retas horizontais.

\begin{tabular}{|c|c|c|c|}
\hline Tamanho da imagem & Quantidade de processadores & Tempo & Desvio padrăo \\
\hline $512 \times 512$ & 3 & 0,1185 & 0,0007 \\
\hline $1024 \times 1024$ & 4 & 0.3208 & 0,0006 \\
\hline $2048 \times 2048$ & 4 & 0,6403 & 0,0013 \\
\hline
\end{tabular}

Da Figura 5.20 até a Figura 5.32, são apresentados os resultados obtidos pela estratégia processor farm em conjunto com a estratégia de divisão da imagem. $\mathrm{Na}$ Figura 5.30, são apresentados os resultados obtidos para as imagens que possuem retas horizontais 


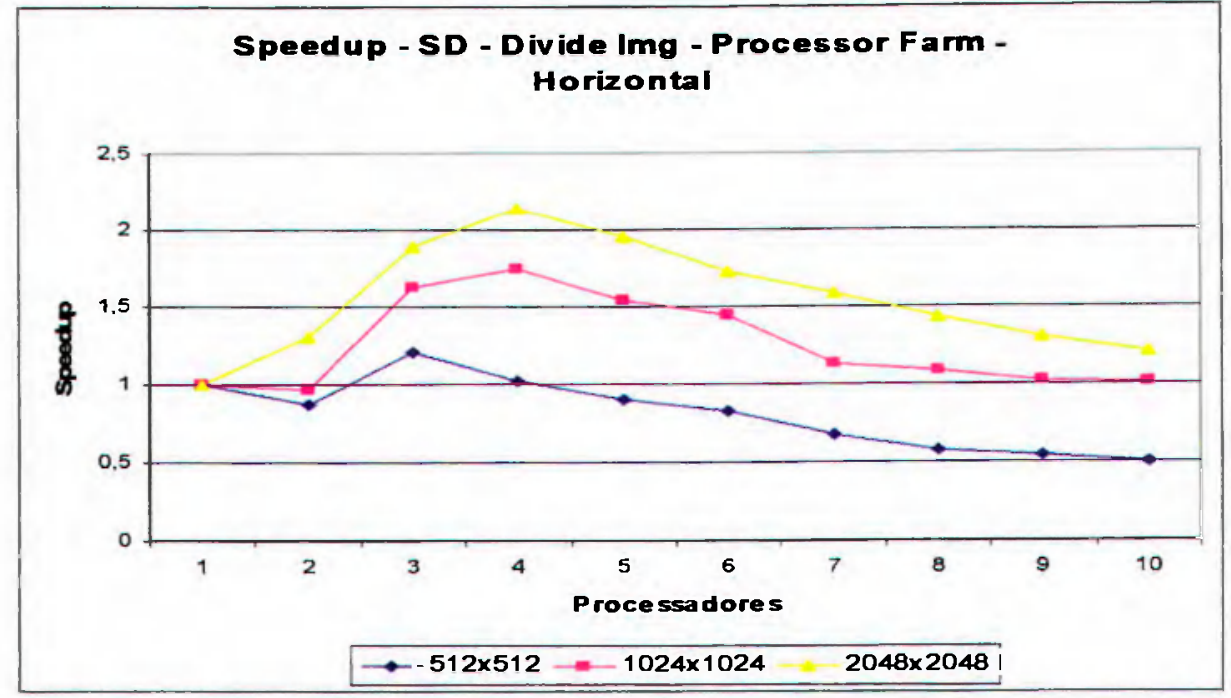

Figura 5.30 Speedup obtido em cluster da implementação da TH com processor farm e divisão da imagem para as imagens com retas horizontais

O melhor desempenho obtido para cluster, para a imagem maior, pode ser observado na Figura 5.30 e na Tabela 5.22. O speedup de aproximadamente 2,2, deve-se às melhorias implantadas como a da divisão da imagem em quatro vezes a quantidade de processadores escravos e, também, a melhoria na devolução do arranjo acumulador somente, quando não existirem mais porções de trabalho para serem processadas. Através dessas duas melhorias, em adição com a estratégia de divisão da imagem com processor farm, foi o que possibilitou esse bom desempenho. Já que a estratégia de divisão da imagem pela quantidade de processadores escravos existente, pode resultar na ociosidade de algum processador escravo, que recebe um pedaço da imagem onde não existe nada para ser processado. Em contrapartida, com a divisão da imagem por um número maior ao de escravos existentes, quando algum escravo receber uma imagem sem coisa alguma para processar, este solicita, quase que instantaneamente outra porção da imagem para ser processada. Permitindo, deste modo, um ganho de desempenho substancial, se comparada à estratégia de divisão da imagem sem o processor farm.

Pela Tabela 5.23 é possível observar os melhores resultados obtidos pela estratégia de divisão da imagem em conjunto com a estratégia processor farm operando sobre retas mistas.

Tabela 5.23 Melhores resultados obtidos pela estratégia processor farm em uniăo com a estratégia de divisão da imagem processando sobre retas mistas.

\begin{tabular}{|c|c|c|c|}
\hline Tamanho da imagem & Quantidade de processadores & Tempo & Desvio padrå \\
\hline $512 \times 512$ & 1 & 0,0988 & 0,0005 \\
\hline $1024 \times 1024$ & 3 & 0,2709 & 0.0015 \\
\hline $2048 \times 2048$ & 4 & 0,8180 & 0.0016 \\
\hline
\end{tabular}


Na Figura 5.31, são demonstrados os resultados obtidos pela estratégia processor farm, em união com a divisão da imagem, para as imagens que possuem retas em todos os sentidos de orientação.

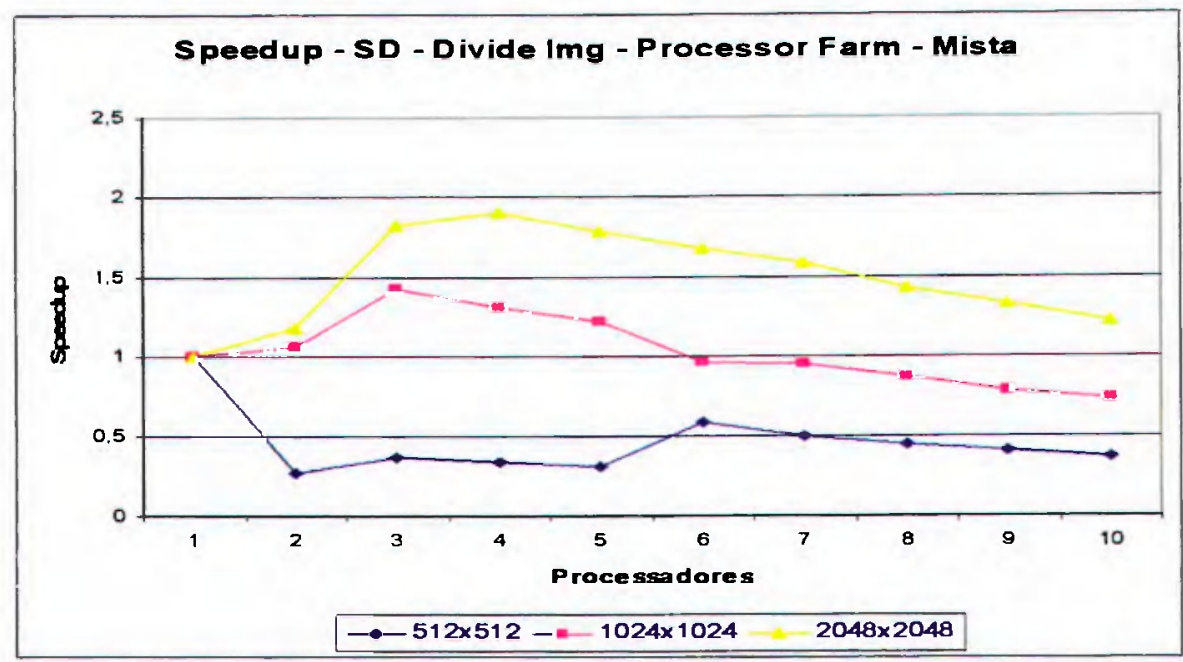

Figura 5.31 Speedup obtido em cluster da implementação da TH com processor farm e divisão da imagem para as imagens com retas mistas.

A Figura 5.31 e a Tabela 5.23, também apresentam um dos melhore resultados obtidos pelo cluster, mas sobre a imagem que possui retas em todos os sentidos de orientação. Para a imagem maior o speedup alcançado foi muito próximo a 1,9 , para a imagem de tamanho maior. Este resultando, também, se explica pelas melhorias implementadas de divisão da imagem e do envio do arranjo acumulador, somente que não houver mais porções para serem processadas.

Pela Tabela 5.24 é possível observar os melhores resultados obtidos pela estratégia de divisão da imagem em conjunto com a estratégia processor farm operando sobre as imagens reais.

Tabela 5.24 Melhores resultados obtidos pela estratégia processor farm em união com a estratégia de divisão da imagem processando sobre as imagens reais.

\begin{tabular}{|c|c|c|c|}
\hline Tamanho da imagem & Quantidade de processadores & Tempo & Desvio padrão \\
\hline $512 \times 512$ & 3 & 0.1173 & 0,0014 \\
\hline $1024 \times 1024$ & 4 & 0,3139 & 0,0085 \\
\hline $2048 \times 2048$ & 4 & 0,9493 & 0,0040 \\
\hline
\end{tabular}

Os resultados obtidos pela estratégia processor farm, com divisão da imagem, para as imagens reais, são apresentados na Figura 5.32. 


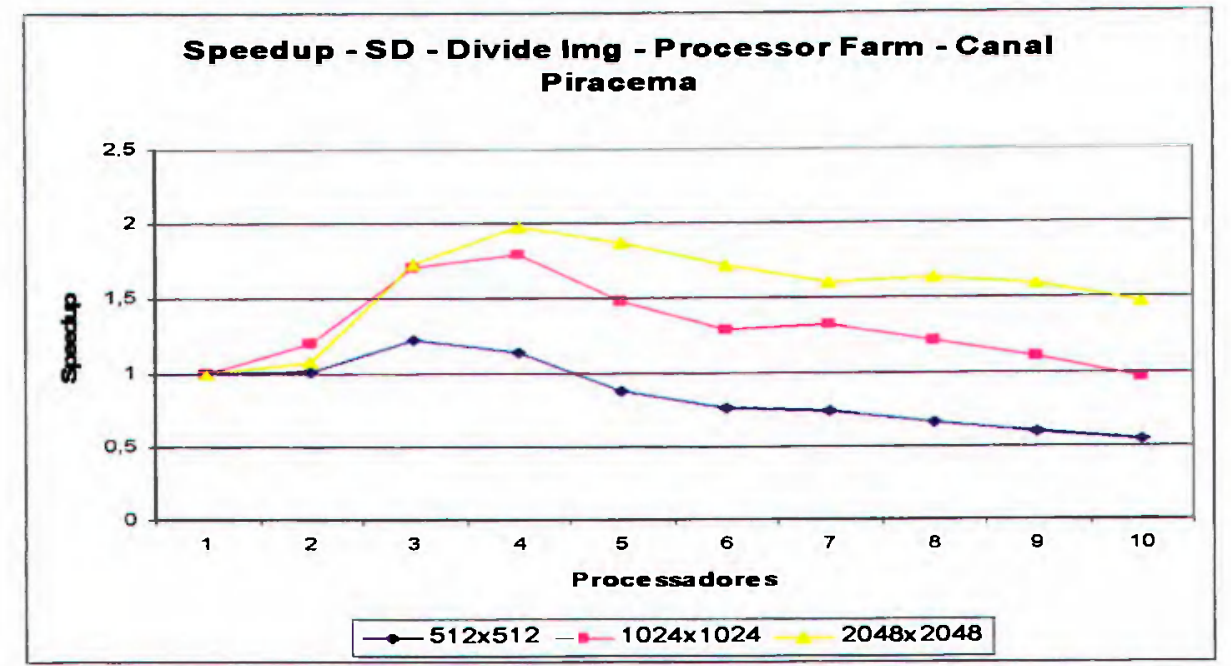

Figura 5.32 Speedup obtido em cluster da implementação da TH com processor farm e divisão da imagem para as imagens reais.

A Figura 5.32 e a Tabela 5.24, também, demonstram o melhor resultado, dentre todas as estratégias avaliadas, obtido em cluster ocorrido para a imagem real. Foi o melhor resultado, tanto para a imagem de tamanho maior, quanto para a imagem de tamanho intermediário

\subsubsection{Considerações sobre os resultados MIMD com memória distribuída}

Para os sistemas distribuídos, tem-se que analisar, principalmente, a quantidade de comunicação envolvida entre os processadores. Pois, é a partir da comunicação, que será definido o desempenho que uma aplicação obtém. E, para atingir um bom desempenho, devem-se procurar mecanismos de minimizar a comunicação e realizá-la somente quando necessário.

Através das Figuras 5.17 a Figura 5.32, observou-se que os melhores desempenhos, foram obtidos utilizando-se a estratégia de divisão da imagem com a estratégia processor farm, atingindo um speedup próximo a 2,2, para a imagem maior. Já para as estratégias de divisão da imagem, sem processor farm, e backmapping o speedup obtido esteve sempre próximo a um e meio na maioria dos experimentos, para a imagem maior. Já para a imagem menor, essas duas últimas estratégias obtiveram um desempenho negativo em alguns casos e em determinadas quantidades de processadores. A Figura 5.33 demonstra o comparativo dos resultados, alcançados sobre a imagem real de tamanho maior, para todas as estratégias implementadas para a arquitetura MIMD distribuída. 


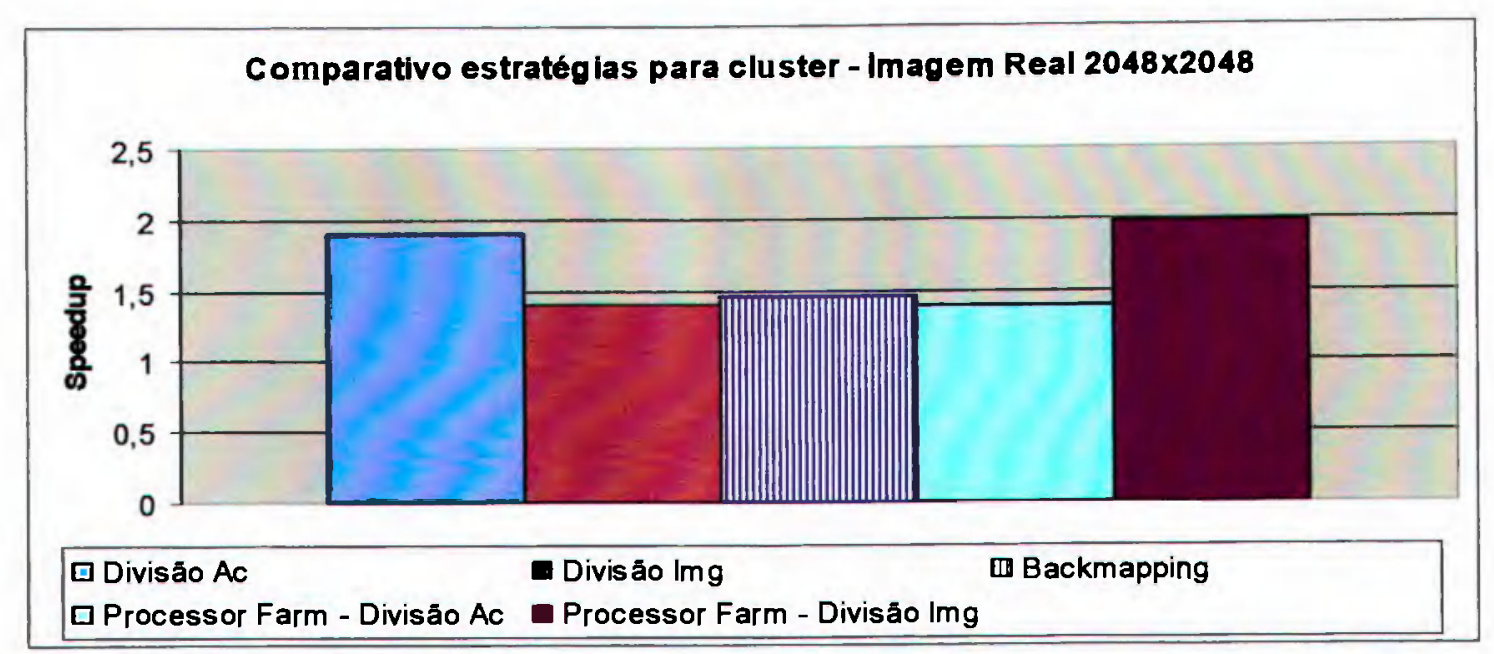

Figura 5.33 comparativo dos resultados, alcançados sobre a imagem real de tamanho maior, para todas as estratégias implementadas para a arquitetura MIMD distribuída.

Pela Figura 5.33, nota-se que o melhor desempenho foi obtido pela estratégia processor farm com a estratégia de divisão da imagem. Já o segundo melhor resultado foi obtido pela estratégia de divisão do arranjo acumulador.

A Figura 5.34 demonstra o comparativo dos resultados, alcançados sobre a imagem real de tamanho intermediário, para todas as estratégias implementadas na arquitetura MIMD distribuída.

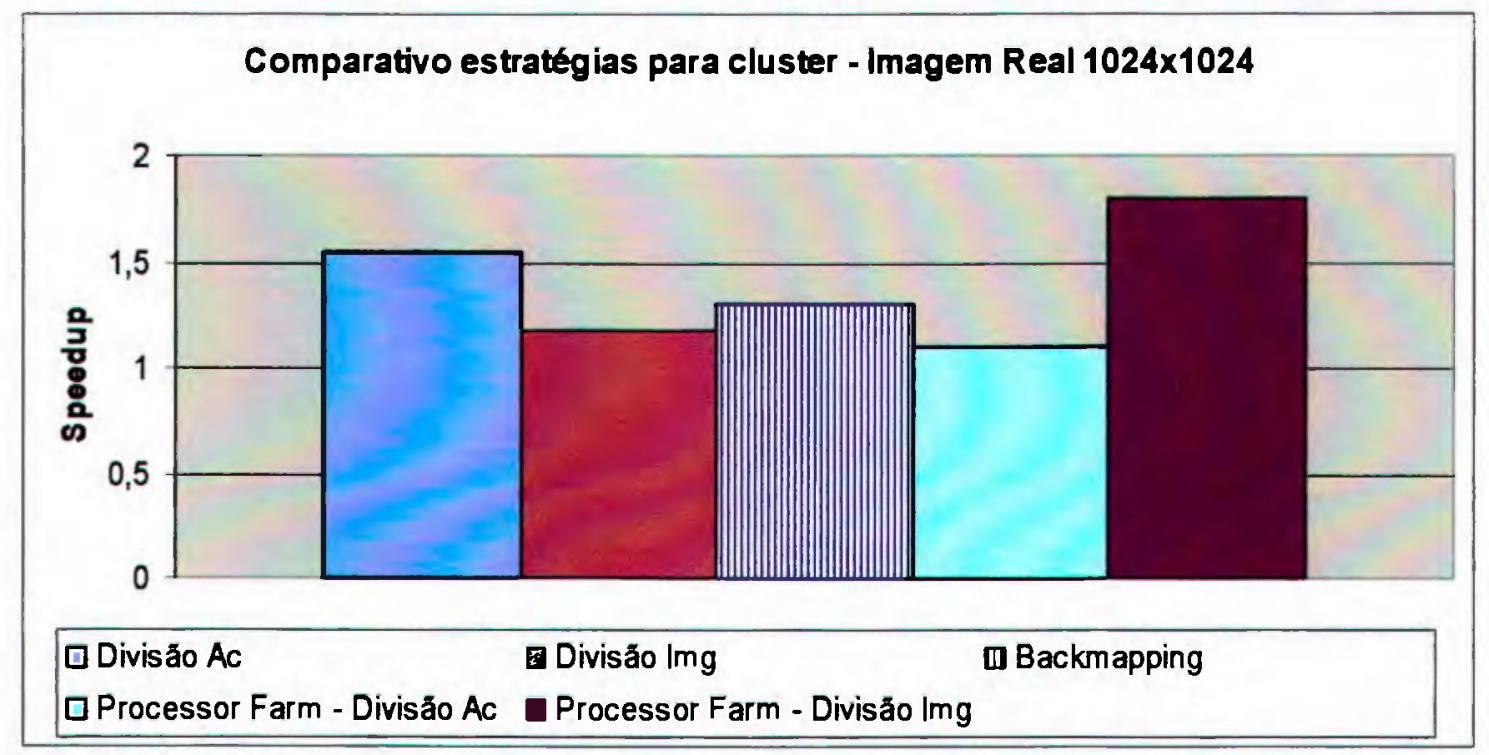

Figura 5.34 comparativo dos resultados, alcançados sobre a imagem real de tamanho maior, para todas as estratégias implementadas para a arquitetura MIMD distribuida.

Conforme mostra a Figura 5.34, a estratégia, para a arquitetura MIMD de memória distribuída, que obteve o melhor desempenho, foi a estratégia processor farm em conjunto com a estratégia de divisão da imagem.

A Figura 5.35, demonstra o comparativo, entre as estratégias, para a imagem real 
e de tamanho menor

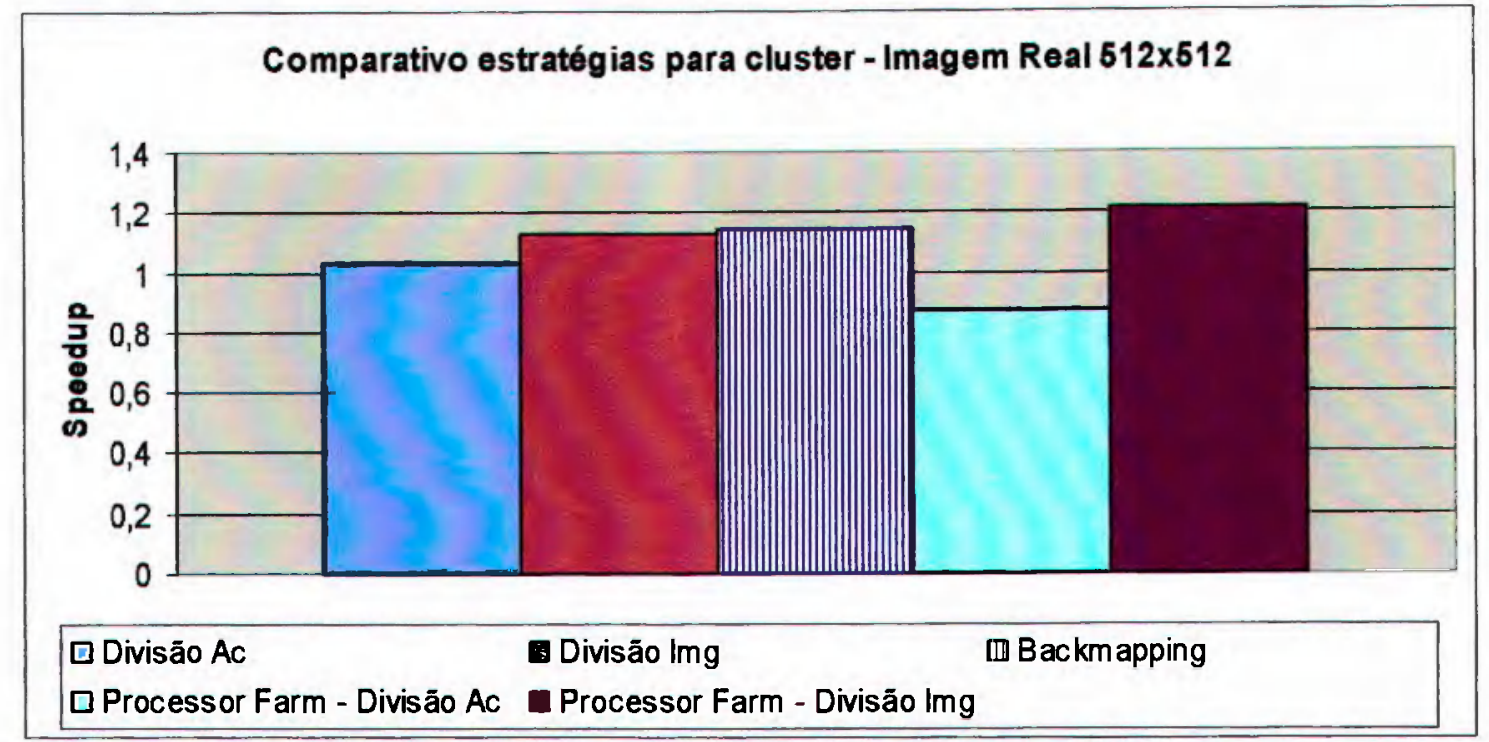

Figura 5.35 comparativo dos resultados, alcançados sobre a imagem real de tamanho maior, para todas as estratégias implementadas para a arquitetura MIMD distribuída.

É possível observar pela Figura 5.35, que o melhor desempenho foi novamente obtido pela estratégia processor farm em conjunto com a estratégia de divisão da imagem.

Outra observação importante, é em relação a quantidade de processadores, realizando o processamento das tarefas no cluster. Pelas Figuras, nota-se que o aumento de processadores, nem sempre foi motivo de aumento do desempenho, pelo contrário, em alguns casos a adição de processadores contribuiu para degradar o resultado. Esses resultados ocorreram devido ao aumento de troca de mensagens, entre os processadores escravos e o servidor, ter demandado mais tempo de execução que o cálculo do arranjo acumulador em si.

\subsection{Considerações gerais}

Como foi possivel observar, através dos resultados obtidos, a escolha de qual estratégia a ser utilizada, para paralelizar a transformada de Hough, não é uma tarefa trivial e depende da arquitetura que será utilizada, além do tipo e do tamanho da imagem que será processada. Para os casos em que o volume de dados a ser processado for pequeno, a paralelização da transformada de Hough pode não ser necessária, pois pode ocorrer que o desempenho obtido seja inferior ao desempenho da versão 
seqüencial, devido à necessidade de realizar o controle e a comunicação com os processadores escravos

Outro fator que deve ser analisando diz respeito à estratégia a ser utilizada, para a paralelização. Pois como observado, na estratégia de divisão da imagem, dependendo da imagem que será processada, alguns processadores podem ficar ociosos o que prejudicará o desempenho. Em contra partida, a estratégia de divisão do acumulador, permite que os escravos recebam uma porção igual de dados para serem processados, já que a imagem é enviada para todos os escravos e o que muda é o intervalo theta que cada escravo irá processar, permitindo dessa forma um balanceamento de carga automático, definindo-se o uso dessa estratégia como a melhor opção, dentre as avaliadas, para a implementação da transformada de Hough, nas arquiteturas apreciadas.

Outra importante observação é a de que a utilização de um cluster, não atinge os mesmos desempenhos que a utilização de uma máquina com memória compartilhada, isso ocorre, devido a necessidade de realizar as trocas de mensagens entre o servidor $\mathrm{e}$ os escravos, o que prejudica o desempenho da aplicação no cluster. Pois, a troca de mensagens se dá pela rede, que é muito mais lenta que a comunicação através da memória compartilhada. Tornando, desse modo, a comparação entre a arquitetura de memória distribuída versus a arquitetura de memória compartilhada injusta, pois, além, da troca de mensagens ocorrer de maneira diferente nas duas arquiteturas, os mecanismos para controle das aplicações requer um pouco mais de atenção nas arquiteturas de memória distribuida. Outro ponto a favor das máquinas com memória compartilhada é a sua popularização e o seu baixo custo, para até quatro processadores, diante de um cluster com, por exemplo, 10 elementos de processamento. Diante desses fatos, mesmo a arquitetura MIMD distribuída possuindo atrativos como a escalabilidade e um menor custo por nó, a arquitetura MIMD de memória compartilhada se torna a opção mais atrativa e vantajosa, possibilitando um ganho de desempenho maior. Permitindo, inclusive, que aplicaçães, como a transformada de Hough, tornem-se viáveis para a utilização em sistemas de tempo real. Entretanto, se não for possível utilizar uma máquina com memória compartilhada, a melhor opção, de paralelização da transformada de Hough, para as máquinas do tipo cluster, é a utilização da estratégia de divisão da imagem com a estratégia processor farm. Pois, além de um desempenho maior em alguns casos, foi, também, a estratégia que obteve o melhor desempenho geral (dentre todas as imagens) para cluster.

Como a junção da melhor estratégia, com a melhor arquitetura, chega-se a 
conclusão, de que quando for necessário realizar a paralelização da transformada de Hough, a melhor arquitetura a ser utilizada é a MIMD com memória compartilhada junto com a estratégia de divisão do arranjo acumulador. 


\section{Conclusões e Trabalhos Futuros}

\subsection{Considerações finais}

Este trabalho de pesquisa teve como objetivo principal o estudo e a implementação da transformada de Hough paralela, buscando diminuir o tempo de processamento no reconhecimento de retas em imagens e identificar qual estratégia de paralelismo é a melhor opção para um determinado tipo de arquitetura. Com este trabalho, foi possível, também, avaliar o desempenho entre arquiteturas MIMD de memória compartilhada versus memória distribuída.

Para tanto, fez-se necessário conhecer as arquiteturas paralelas existentes e os mecanismos que podem ser utilizados, em cada arquitetura, para o desenvolvimento de programas paralelos (Capítulo 2), além de conhecer o algoritmo sequiencial da transformada de Hough (Capítulo 3), bem como as versões paralelas, para a transformada de Hough, encontradas na literatura (Capítulo 4).

Através da implementação dos algoritmos paralelos em máquinas MIMD com memória distribuída e máquinas MIMD com memória compartilhada, foi realizado um estudo identificando as vantagens e desvantagens de cada estratégia, implementada em cada uma das arquiteturas. Com isso, foi possível determinar a melhor implementação para uma dada arquitetura (MIMD distribuída ou MIMD compartilhada), identificando também, os gargalos de comunicação e de processamento em cada uma das estratégias, assim, como acrescentar melhorias ou adaptações à transformada de Hough paralela (Capítulo 5).

Foi possível, também, identificar qual a ferramenta de apoio à programação paralela, obteve um resultado mais expressivo, na execução da transformada de Hough. Sendo possivel, ainda, avaliar os compiladores e seus desempenhos, para cada estratégia de paralelismo. Através dessas avaliações, foi possível identificar que, tanto as estratégias que utilizam a ferramenta OpenMP, quanto as que utilizam o Pthreads, obtiveram um desempenho similar e satisfatório, quando compilados com o compilador do OpenMP, o icpc (Capitulo 5). Já entre as estratégias, da transformada de Hough, 
avaliadas, a que obteve os melhores resultados, foi a estratégia de divisão do arranjo acumulador. Pois, cada processador escravo, recebe toda a imagem para ser processada, sobre a faixa do ângulo theta que lhe couber. Permitindo, dessa maneira, um balanceamento de carga automático, o que não ocorre com a estratégia de divisão da imagem, onde cada processador escravo recebe um pedaço da imagem, que em alguns casos pode não conter dados para serem processados (Capítulo 5), prejudicando, desse modo, o desempenho geral, já que alguns processadores ficam sobrecarregados enquanto outros ficam ociosos.

\subsection{Contribuições}

A implementação e a avaliação da transformada de Hough paralela, em algumas de suas diversas estratégias, para arquiteturas MIMD de memória compartilhada e MIMD de memória distribuída, identificando quais os gargalos de processamento existentes e quais as melhores estratégias para cada tipo de arquitetura, são as principais contribuições que este trabalho apresentou. Deixando claro, que as estratégias que possuem um balanceamento de carga implícito, obtém um melhor desempenho em relação as que não possuem tal mecanismo, independente do tipo de arquitetura que está sendo utilizado. A essas contribuições, somam-se também, o comparativo entre as ferramentas de apoio a programação paralela e à análise da transformada de Hough para cluster.

No comparativo realizado entre as ferramentas, de apoio à programação paralela, para sistemas com múltiplos processadores e memória compartilhada, permitiu-se a identificação de qual ferramenta proporciona uma melhor performance, além da avaliação dos compiladores existentes. Pois, como foi mencionado, o desempenho de cada uma das ferramentas está atrelada ao compilador utilizado, sendo que compiladores específicos, como o icpc, permitem um ganho de performance em relação a outros compiladores.

$\mathrm{Na}$ análise da transformada de Hough para cluster, foi identificando o que inviabiliza a sua implementação pura nesse tipo de sistema, além da adição, neste tipo de arquitetura, das estratégias de envio da imagem por broadcast e a compactação da imagem e do arranjo acumulador antes de seu envio, possibilitando um ganho de performance e tornando a transformada de Hough viável nesse tipo de sistema. Outra contribuição para cluster, foi à implementação e viabilização da estratégia processor 
farm com divisão da imagem. Permitindo-os um ganho de desempenho maior. Sem mencionar a estratégia de envio do arranjo acumulador ao computador mestre, pelos escravos, somente ao final do processamento, quando não existem mais porções de imagem para ser processada.

\subsection{Trabalhos futuros}

De acordo com o apresentado no decorrer dessa dissertação, a paralelização de algoritmos, assim como da transformada de Hough, não é uma tarefa trivial. E a busca por melhores resultados, permite que outros trabalhos sejam desenvolvidos no mesmo escopo.

Algumas das sugestões para trabalho futuro incluem:

- A conversão do método da transformada de Hough para arquiteturas que possuem um único fluxo de instruções, operando sobre múltiplos dados, ou seja, converter a transformada de Hough para a arquitetura SIMD;

- Buscar um ganho de desempenho, na devolução do arranjo acumulador. Em vez dos processadores clientes enviarem os seus arranjos acumuladores para o servidor, estes, enviam para o seu vizinho mais próximo, que irá receber o arranjo acumulador e adicioná-lo ao seu arranjo acumulador, que posteriormente será enviado para seu vizinho. Descentralizando, dessa maneira, o recebimento do arranjo acumulador;

- Pesquisar outros métodos de processamento de imagens, que possuem formas de processamento similar à transformada de Hough e adaptá-los para as estratégias de paralelismo utilizadas pela transformada de Hough nesta dissertação. Não necessitando, dessa maneira, começar a elaboração paralela desses métodos do começo. 


\section{Referências Bibliografias}

ALMASI, G. S., GOTTLIEB A. High Parallel Computing. 2.ed. Redwood City:The Benjamin Communing Publishing Company, Inc., 1994. 519p. ANNARATONE, M. MPPs, Amdahl's law, and comparing computers. Frontiers of Massively Parallel Computation (1992). Disponível em: < http://ieeexplore.ieee.org/iel2/407/6051/00234879.pdf?tp $=$ \&arnumber $=234879 \&$ isn umber $=6051 \&$ arSt $=465 \&$ ared $=470 \&$ arAuthor $=$ Annaratone $\% 2 \mathrm{C}+\mathrm{M} . \% 3 \mathrm{~B}>$. Acesso em: 13 de set.2004.

BASTOS, V.P. Técnicas de segmentação de imagens para recuperação de informaçōes visuais. Disponível em $<$ http://atlas.ucpel.tche. br/ vbastos $>$. Acesso em: 12 Maio 2003.

BALLARD, D. H. Generalized the Hough transform to detect arbitrary shapes. Pattern Recognition Ezmsford, v. 13, n. 2, p.111-122, 1981.

BENTES, Paulo Cesar Lucena. Deteç̧ão de formas circulares utilizando a transformada de Hough, desenvolvida no ambiente windows. São Carlos, 1997. 183f. Dissertação (Mestrado) - Escola de Engenharia de São Carlos, Universidade de São Paulo, São Carlos, 1997.

BRUNO, Odemir Martinez. Paralelismo em Visão Natural e Artificial. São Carlos, 2000. 391f. Tese(Doutorado) - Instituto de Física de São Carlos, Universidade de São Paulo, São Carlos, 2000.

BRUNO, O. M., COSTA, L. F. Effective Image Segmentation with Flexible ICMBased Markov Random Fields in Distributed Systems of Personal Computers. Real-Time Imaging. , v.6, n.4, p.283 - 295, 2000a.

BRUNO, O. M., COSTA, L. F. CVMP - An easy-to-use tool for parallel computer vision algorithms In: THE IBERO-AMERICAN ARTIFICIAL INTELLIGENCE CONFERENCE - IBERAMIA ;. - WORKSHOP ON ARTIFICIAL INTELLIGENCE AND COMPUTER VISION, Atibaia,2000b. Proceedings. Atibaia, UFRJ,200b. p.116-119. 
BRUNO, O. M.; COSTA, L. F. A. Programming Tool for the Development of Parallel Computer Vision and Image Processing Algorithms and Applications. In: SYMPOSIUM ON COMPUTER ARCHITETURE AND HIGH PERFORMANCE COMPUTING, 13., Pirenópolis-GO, 2001a. Proceedings Pirenopolis, Braziliam Computer Society, 2001. p.222-229.

BRUNO, O. M.; CESAR JR, R. M.; CONSULARO, L. A.; COSTA, L. F. Synergos Synergetic Vision Research. Real-Time Systems, v. 21, p.7-42, 2001 a.

CAMPOS JUNIOR, Arion de. Interface gráfica para um ambiente de escalonamento flexível e dinâmico. São Carlos, 2001. 128f. Dissertação (Mestrado) - Instituto de Ciências Matemáticas e de Computação, Universidade de São Paulo, São Carlos, 2001.

CARLING, A. Parallel processing - the transputer and Occam. Wilmslow: Sigma Press, 1988. 180p.

CASTANÓN, Cesar Armando Beltran. Recuperação de imagens por conteúdo através de análise multiresolução por wavelets. São Carlos, 2003. $95 \mathrm{f}$. Dissertação (Mestrado) - Instituto de Ciências Matemáticas e de Computação, Universidade de São Paulo, São Carlos, 2003.

CHUTATAPE, O.; GUO, L. A modified Hough transform for line detection and its performance. Pattern Recognition, p.181-192, 1999.

COULOURIS, G.; DOLlimORE, J.; KINDBERG, T. Distributed systems concepts and design. 3.ed. Harlow: Addison Wesley, 2001. 772p.

CRIVELLI S., JESSUP, E. R. The PMESC Programming Library for DistributedMemory MIMD Computers. Journal of Parallel and Distributed Computing, v.57, n.3, p. 295-321, 1999.

DI GREGORIO, S.; RONGO, R.; SPATARO, W.; SPEZZANO, G.; TALIA, D. High performance scientific computing by a parallel cellular environment. future generation computer Systems. Future Generation computer systems, v.12, n.5, p.357-369, 1997.

DUDA, R. O.; HART, P. E. Use of the Hough transformation to detect lines and curves in pictures. Communications of the ACM, v 15, p.11-15, 1972.

DUNCAN, R. A survey of parallel computer, architectures. Computer, v.23, n.2, p.05-16, 1990. 
FALCÃO, A. X. Fundamentos de processamento de imagem digital. Disponível em $<$ http://www.dcc.unicamp.br/ cpg/material-

didatico/mo815/9802/curso/curso.html> Acesso em: 04 Abr.2003.

FLYNN, M. J. Some Computer Organization and Their Effectiveness .IEEE

Transactions on Computers, v.21, p.948-960, 1972.

GEIST, A.; BEGUELIN, A.; DONGARRA, J.; JIANG, W.; MANCHEK, R.;

SUNDEREAM, V. PVM: Parallel Virtual Machine: a User's guide and tutorial for networked Parallel Computing. Londres: The MIT Press, 1994. Iv.

GERIG, G.; KLEIN, F. Fast contour identification though efficient Hough transform and simplified interpretation strategy. In: INTERNATIONAL CONFERENCE ON PATTERN RECOGNITION, 8., Paris, 1986. Proceedings. Paris, IEEE,1986. p. 498-500.

GONZALEZ, R. C.; WOODS, R. E. Digital Image Processing. 2.ed. Upper Saddle River: Prentice Hall, 2001. 793p.

GROPP, W.; LUSK, E. Installation and user's guide to mpich: a portable implementation of MPIVersion 1.2.5 Disponível em: $<\mathrm{http} / /$ wwwunix.mcs.anl.gov/mpi/mpich/docs/mpichman-chp $/$ mpichman-chp4.htm>. Acesso em: 10 Mar. 2004.

GUIL, N.; VILLALBA, J.; ZAPATA, E.L. A fast Hough transform for segment detection. Image Processing. IEEE Transactions on Image Processing , v.4, n.11 ,p.1541-1548, 1995.

HOPWOOD, L.; MILLER, W.; GEORGE, A. Parallel implementation of the Hough transform of rectangular objects (1996). Disponível em:

$<$ http://ieeexplore.ieee.org/iel3/3684/10833/00510069.pdf?tp $=$ \&arnumber $=510069$ \&isn umber $=10833 \&$ arSt $=261 \&$ ared $=264 \&$ arAuthor $=$ Hopwood $\% 2 \mathrm{C}+\mathrm{L} . \% 3 \mathrm{~B}+$ Miller $\% 2 \mathrm{C}+$ W.\%3B+George\%2C+A.\%3B>. Acesso em: 13 set.2004.

HOUGH, P. V. C. Method and means for recognizing complex patter. /Patente Industrial U.S. Patent 3.069.654, 1812.62/

HUECKEL, M. A local operator which recognizes edges and lines. Journal of Association Computer, v. 20, p.634-646, 1973.

IEEE Computer Society. A Backgrounder on IEEE Std 1003.1. Disponível em: $<$ http://www.opengroup.org/austin/papers/backgrounder.html>. Acesso em: 08 Abr.2004 
ILLINGWORTH, J.; KITTLER, J. The adaptative Hough transform. IEEE Trans.

Pattern Anal. Machine Intel., v.9, n.5, p.690-695, 1987.

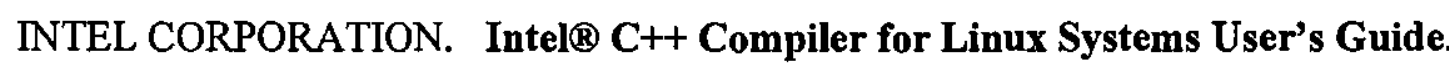

Disponível em:

<ftp://download.intel.com/support/performancetools/c/linux/v8/c_ug_lnx.pdf $>$.

Acesso em: 21 Abr. 2004.

JIN, L. ; YANG, L. Parallel solution of Hough transform and convolution problems - a novel multimodal approach In:SYMPOSIUM ON APPLIED COMPUTING TECHNOLOGICAL CHALLENGES OF THE 1990's-ACM/SIGAPP., Kansas City, 1992. Proceedings. Kansas City, ACM, 1992. p.775-781.

JAQUIE, Kalinka Regina Lucas. Extensão da Ferramenta de Apoio à Programação Paralela (F. A. P. P.) para Ambientes Paralelos Virtuais. São Carlos, 1999.

152f. Dissertação (Mestrado) - Instituto de Ciências Matemáticas e de Computação, Universidade de São Paulo, São Carlos, 1999.

KESIDIS, A. L.; PAPAMARKOS, N. On the inverse Hough transform. IEEE

Transactions on Pattern Analysis and Machine Intelligence, v.21, n.12, p.1-15, 1999.

KRAHE, J. L.; POUSSET, P. The detection of parallel straight lines with the application of the Hough transform (1988). Disponível em:<

http://ieeexplore.ieee.org/iel2/220/1 164/00028407.pdf?tp=\&arnumber $=28407 \&$ isnu mber $=1164 \&$ arSt $=939 \&$ ared $=941$ vol. $2 \&$ arAuthor $=$ Krahe $\% 2 C+$ J.L. $\% 3 B+$ Pousset $\%$ 2C+P.\%3B >. Acesso em: 13 de set.2004.

KRISHNASWAMY, D.; BANERJEE, P. Exploiting task and data parallelism in parallel Hough and Random transforms (1997). Disponível em:< http://ieeexplore.ieee.org/iel3/4895/13499/00622678.pdf?tp=\&arnumber=622678\&i snumber $=13499 \&$ arSt $=441 \&$ ared $=444 \&$ arAuthor $=$ Krishnaswamy $\% 2 C+D . \% 3 \mathrm{~B}+\mathrm{Ba}$ nerjeer $\% 2 \mathrm{C}+\mathrm{P} . \% 3 \mathrm{~B}>$. Acesso em: 13 set.2004.

QUINN, M. J. Designing Efficient Algorithms for Parallel Computers. New York: McGraw Hill, 1987. 288p.

LAWRENCE LIVERMORE NATIONAL LABORATORY. POSIX Thread programming. Disponível em <http://www.llnl.gov/computing/tutorials/pthreads $>$. Acesso em: 05 abr. 2003.

LAWRENCE LIVERMORE NATIONAL LABORATORY. OpenM. Disponível em $<$ http://www.llnl.gov/computing/tutorials/openMP>. Acesso em: 05 Abr.2003b. 
LAWRENCE LIVERMORE NATIONAL LABORATORY. Introduction to parallel computing. Disponível em $<$ http://www.llnl.gov/computing/tutorials/parallel_comp>. Acesso em: 05 abr.2003c.

LAWRENCE LIVERMORE NATIONAL LABORATORY. Massage Passing Interface. Disponível em $<$ http://www.llnl.gov/computing/tutorials/mpi $>$. Acesso em: 05 Abr.2003d.

\section{LAWRENCE LIVERMORE NATIONAL LABORATORY. MPI performance} topics. Disponivel em <http://www.llnl.gov/computing/tutorials/mpi_performance>. Acesso em: 05 abr.2003e.

LI, H.; LAVIN, M. A.; MASTER, R. J. L. Fast Hough transform: a hierarquical approach. Computer Vision Graphics and Image Processing, v.36, p.139-161, 1986.

LI, Z. N.; YAO, B. G.; TONG, F. A linear generalized Hough transform and its parallel implementation. In: INTERNATIONAL CONFERENCE ON COMPUTER VISION AND PATTERN RECOGNITION, CVPR'91., Lahaina-HI, 1991. Proceedings. IEEE, 1991. p 672-673, 1991.

MARQUES FILHO, O., VIEIRA NETO, $\mathrm{H}$. Processamento de imagens Digital. São Paulo: Ed Brasport, 1999. 406p.

MARTINEZ, Ana Claudia. Um novo método para medidas de gotas de chuva com técnicas do processamento digital de imagem. São Carlos, 2002. $194 f$.

Dissertação (Mestrado) - Escola de Engenharia de São Carlos, Universidade de São Paulo, São Carlos, 2002.

MOREIRA, D.A. Operating systems. Disponível $\mathrm{em}:<$ http://java.icmc. usp.br/training/course.jsp?idcurso $=0 \mathrm{~s}>$. Acesso em:18 jan.2004

MOREIRA, Edmilson Moreira. Projeto de uma ferramenta de auxílio na depuração de programas paralelos. São Carlos, 2000. 87f. Dissertação (Mestrado) - Instituto de Ciências Matemáticas e de Computação, Universidade de São Paulo, São Carlos, 2000.

MPI FÓRUM. MPI 2.0. Disponivel em: $<$ http://www.mpi-forum.org/docs/mpi-20.os $>$. Acesso em: 13 Jun.2003. 
NATIONAL CENTER FOR SUPERCOMPUTING APPLICATIONS. Intermediate MPI tutorial. Disponível em: $<$ http://webct.ncsa.uiuc.edu:8900>. Acesso em: 10 junho 2003 .

NATIONAL CENTER FOR SUPERCOMPUTING APPLICATIONS Introduction to

OpenMP. Disponível em: <http://webct.ncsa.uiuc.edu:8900>. Acesso em: 18 Jan.2004

OPEN MP Architecture Review Board. OpenMP $\mathrm{C}$ and $\mathrm{C}++$ application program interface. Disponível em: $<\mathrm{http} / / \mathrm{www}$.openmp.org/specs/mpdocuments/cspec20.pdf.> Acesso em: 08 abr.2004.

PACHECO, P. Parallel programming with MPI. San Francisco: Morgan Kaufmann, 1997. 418p.

PACS TRAINING GROUP. Introduction to MPI. Disponível em: $<$ http://webct.ncsa.uiuc.edu:8900>. Acesso em: 08 abr.2004.

PEREIRA, Aledir Silveira. Processamento de imagens médicas utilizando a transformada de hough. São Carlos, 1995. 263f. Tese (Doutorado) - Instituto de Física de São Carlos, Universidade de São Paulo, São Carlos, 1995.

PRINCEN, J.; ILLINGWORTH, J.; KITLER, J. A hierarchical approach to line extraction (1989). Disponível em: $<$ http://ieeexplore.ieee.org/iel2/247/1531/00037833.pdf?tp=\&arnumber=37833 \&isnumber $=1531 \&$ arSt $=92 \&$ ared $=97 \&$ arAuthor $=$ Princen $\% 2 \mathrm{C}+\mathrm{J} . \% 3 \mathrm{~B}+\mathrm{Illingworth}$ $\% 2 \mathrm{C}+\mathrm{J} . \% 3 \mathrm{~B}+\mathrm{Kittler} \% 2 \mathrm{C}+\mathrm{J} . \% 3 \mathrm{~B}>$. Acesso em: 13 set.2004.

SANTANA, R. H. C., et al. Computação Paralela (1998). Disponível em: $<$ http://lasdpc.icmc.usp.br/disciplinas/2003-1/pcg/Seminarios/arq_paralela_doc.zip >. Acesso em: 06 Fev.2003.

SATO, L. M., MIDORIKAWA, E. T., SENGER, H. Introdução a Programação Paralela e Distribuída. Disponível em $<$ http://www.lsi.usp.br/ liria/jai96.html $>$. Acesso em: 02 Out.2002. (Monografia EP/USP)

SILVA, G. P. Programação paralela com OpenMP. Disponível em: <http://equipe.nce.ufrj.br/gabriel/procpar/OpenMP.pdf> .Acesso em: 15 Jan.2004. SILVA, Ernani Paranagua. Aplicação da transformada de Hough em inspeção visual automática. São Carlos, 1996. 199f. Dissertação (Mestrado) - Escola de Engenharia de São Carlos, Universidade de São Paulo, São Carlos, 1996. 
SOUZA, Paulo Sergio Lopes. Máquina Paralela Virtual em Ambiente Windows.

São Carlos, 1996. 145f. Dissertação (Mestrado) - Instituto de Ciências

Matemáticas e de Computação, Universidade de São Paulo, São Carlos, 1996.

TORELLI, J; MALARA, R. Programação paralela com POSIX Threads.

Disponível em $<$ http://rasputin.if.sc.usp.br/users/rodrigo/pthreadsdoc.pdf $>$. Acesso em: 10 jul.2003. (Monografia IFSC/USP)

TRAINA, A. J. Processamento de Imagens. Disponível em

$<$ http://gbdi.icmc.usp.br/documentacao/apostilas/cg/Ap_pi.pdf>. Acesso: em 02

maio 2003. (Monografia ICMC/USP)

TSUJI, S.; MATSUMOTO, F. Detection of ellipses by a modified Hough transform.

IEEE Transactions of computers, v.c-27, n. 8, p. 777-781, 1978.

VUILLEMIN, J. E. Fast linear Hough transform (1994). Disponível em: $<$ http://ieeexplore.ieee.org/iel2/1001/7844/00331821.pdf?tp=\&arnumber=331821\&isnum ber $=7844 \&$ arSt $=1$ \&ared=9\&arAuthor=Vuillemin $\% 2 C+$ J.E.\%3B $>$. Acesso em: 13 set.2004. 


\section{APÊNDICE A - Desenvolvendo com OpenMP}

Neste apêndice serão demonstrados algumas formas e diretivas para o desenvolvimento com OpenMP. No desenvolvimento com OpenMP, é necessário que seja incluso no cabeçalho do programa a biblioteca omp.h. Esta biblioteca possui as diretivas e funções utilizadas pelo OpenMP. A Figura A.l a seguir mostra um programa exemplo utilizando algumas das diretivas e funções que serão descritas nos itens seguintes.

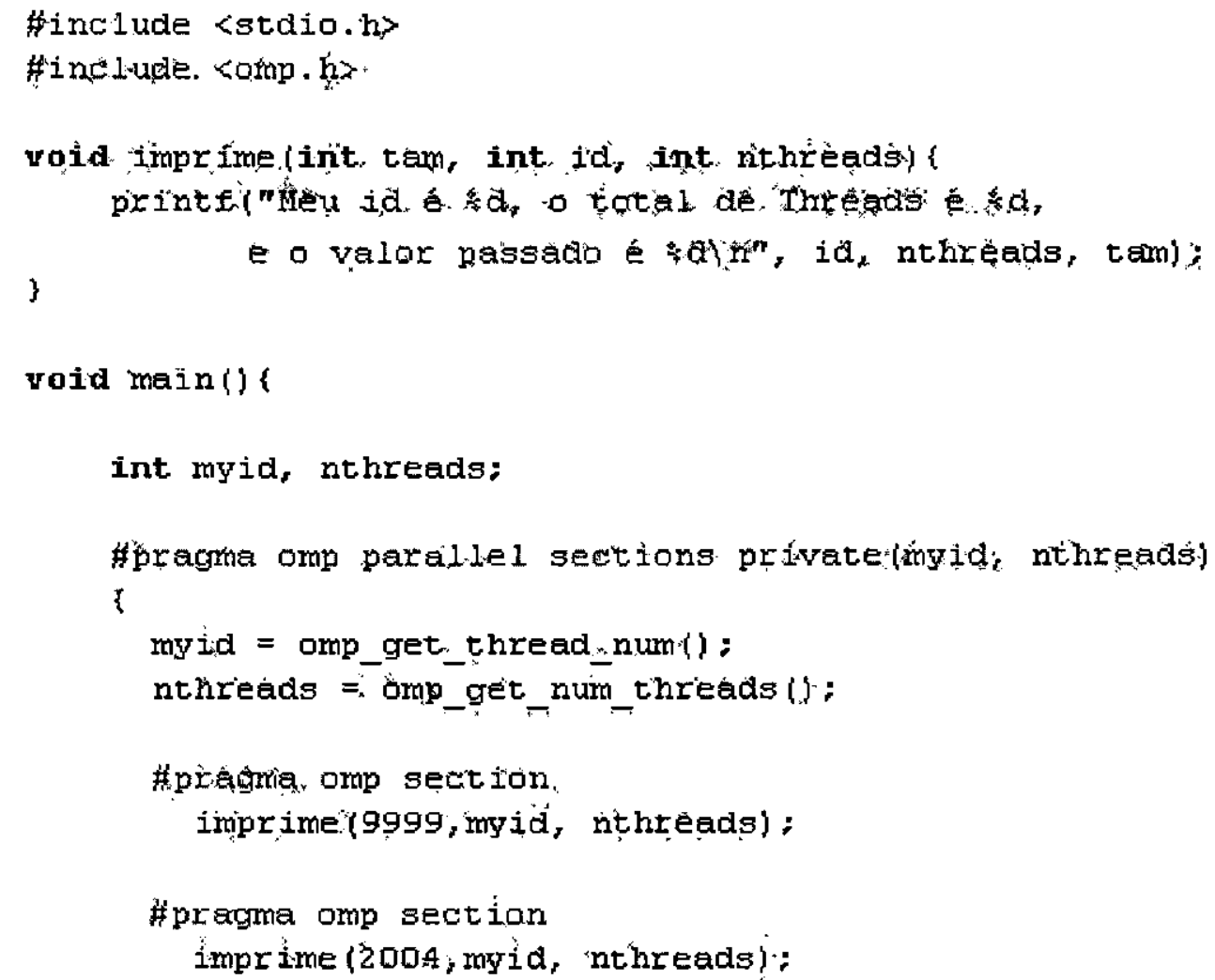

Figura A.1 Programa exemplo do OpenMP

a) Formato das diretivas 
As diretivas são baseadas na diretiva \#pragma, definida no padrão $\mathrm{C}$ e $\mathrm{C}++$. Compiladores que suportam a API OpenMP para $\mathrm{C}$ e $\mathrm{C}++$ devem incluir na linha de comando opções que ativam e permitem a interpretação das diretivas OpenMP.

A sintaxe básica das diretivas do OpenMP é a seguinte:

\#pragma omp nome_diretiva [cláusula [ [,] clausula] [...]] nova linha

Cada diretiva do OpenMP inicia com \#pragma omp, para que não exista conflitos com outras diretivas (de outros desenvolvedores) de mesmo nome. As diretivas do OpenMP são case sensitive e a ordem em que as cláusulas aparecem, nas diretivas, não é significante. $\mathrm{E}$, apenas, um nome de diretiva pode aparecer por cláusula. A diretiva, a seguir, não é permitida por possuir múltiplos nomes de diretivas.

/*Erro - múltiplos nomes de diretivas. */

\#pragma omp parallel barrier

\section{b) Construção paralela}

A diretiva seguinte define uma região paralela, esta será a região do programa que será executada por múltiplas threads em paralelo. Esta é a construção fundamental que inicia a execução paralela de um programa.

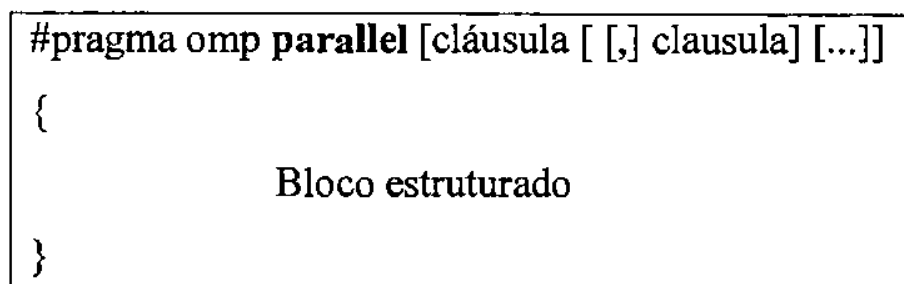

if(expressão escalar) - esta cláusula permite fazer com que a diretiva de região paralela passe a ser condicional. Esta cláusula pode ser útil se não houver trabalho suficiente para tornar o paralelismo compensador.

private(lista de variáveis) - esta cláusula define as variáveis em "lista de variáveis" que serão de uso privativo de cada thread no time de threads criados.

firstprivate(lista de variáveis) - esta cláusula é utilizada para permitir que uma variável tenha um valor inicial quando começar a região paralela.

shared(lista de variáveis) - dentro da região paralela todas as threads poderão enxergar o conteúdo das variáveis que estão indicadas na "lista de variáveis" 
compartilhadas. As alterações dessas variáveis são vistas pelas outras threads do time de threads.

copyin(lista de variáveis) - Promove mecanismos para associar o mesmo valor das variáveis pertencentes a threadprivate para cada thread do time de execução da região paralela.

reduction(operador: lista de variáveis) - Redução produz um único valor a partir de operações de associativas como adição, multiplicação, máximo, mínimo, entre outras.

num_threads(integer) - Define o número de threads que haverá na região paralela. Ou seja, define o time de threads.

\section{c) Diretivas de trabalho compartilhado}

As diretivas de trabalho compartilhado aparecem dentro de uma região paralela e indicam como o trabalho deve ser compartilhado entre as threads. As diretivas de trabalho compartilhado não criam novas threads, elas apenas usam as já criadas. As diretivas de trabalho compartilhado são:

-for;

- sections;

- single.

Essas diretivas, podem ser combinadas com o construtor paralelo, como por exemplo, \#pragma omp parallel for.

\section{- For}

Os laços são uma grande fonte de paralelismo na maioria dos códigos. A diretiva de trabalho compartilhado for, divide as interações do laço entre as threads. A sintaxe da diretiva é a seguinte:

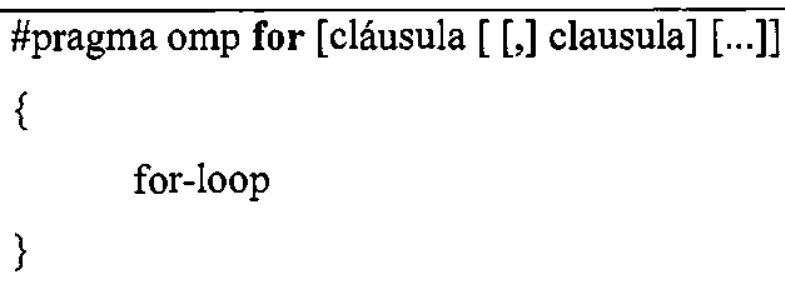


Nessa diretiva, além das citadas na diretiva \#pragma omp parallel, pode haver também uma cláusula chamada schedule, em que o programador poderá indicar como deve ser feita a distribuição das interações entre as threads. A sintaxe é:

schedule(kind[, chunk_size])

Sem colocar cláusulas adicionais a diretiva for irá dividir as interações o mais igualmente possivel entre as threads.

\section{- Sections}

A diretiva de seção paralela permite que blocos separados de códigos sejam executados em paralelo. Podendo, por exemplo, executar diversas sub-rotinas independentes. Esta diretiva não é escalável, pois cada diretiva utiliza uma thread do time, cabendo ao programador especificar a quantidade de diretivas a serem utilizadas. A sintaxe dessa diretiva é:

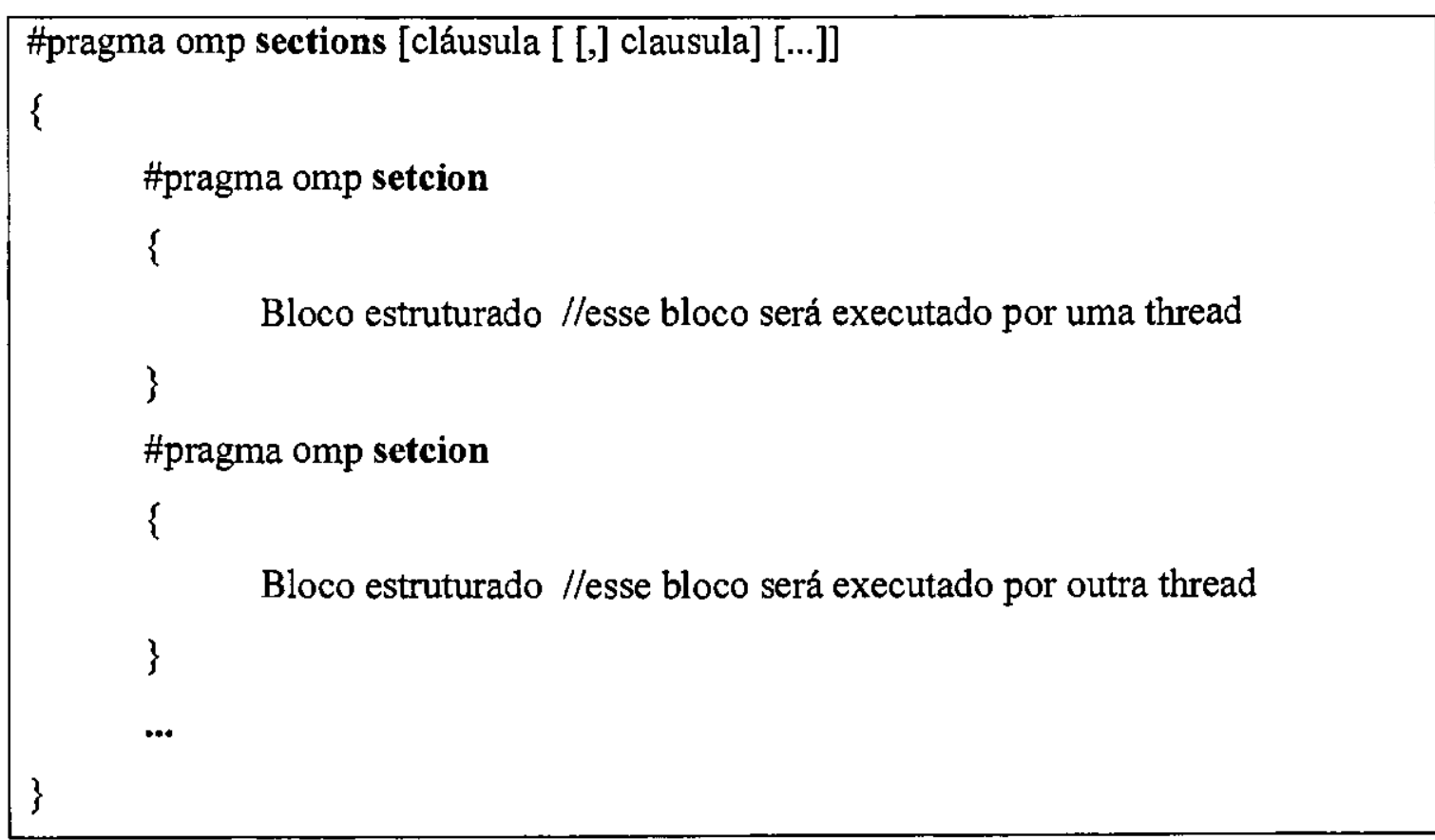

- Single

Esta diretiva, indica que apenas uma thread poderá executar um bloco, sendo essa thread a primeira que alcançar esse bloco será a thread que irá executá-lo. As outras 
threađs que alcançarem esse bloco após o início de sua execução, deverão aguardar, até que a thread que está executando o bloco, conclua a execução. A sintaxe é:

\#pragma omp single [cláusula [ [,] clausula] [...]]

\section{d) Diretivas de sincronização e controle}

As diretivas de sincronização e controle, permitem que as threads sejam sincronizadas para executar uma tarefa, ou que, apenas uma thread por vez poderá executar uma tarefa, ou ainda determina qual thread poderá executar uma determinada tarefa. As diretivas mais comumente utilizadas que pertencem a essa categoria são:

- critical;

- atomic; e

- barrier.

\section{- Critical}

Essa diretiva, indica as threads que o bloco a ser executado é uma região crítica e deverá ser executado por uma única thread por vez. A sintaxe é:

\#pragma omp critical [nome]

\{

Bloco estruturado

\}

O nome dado à seção critica é para que nenhuma outra thread entre em uma região critica com o mesmo nome.

- Atomic

A diretiva atomic, é utilizada para que variáveis que são compartilhadas pelas threads sejam atualizadas atomicamente. Esta diretiva, é aplicada a somente uma sentença e não há um bloco, como pode ocorrer em outras diretivas. Sua sintaxe é:

\#pragma omp atomic

sentença

\section{- Barrier}


Esta diretiva determina que nenhuma thread poderá prosseguir até que todas as outras threads tenham alcançado a barreira. Para que não ocorra um deadlock é necessário que todas ou nenhuma thread alcance a barreira. A sintaxe é:

\#pragma omp barrier

e) Funções de ambiente de execução

As funções de ambiente de execução permitem configurar e verificar atributos de execução do OpenMP. Algumas das funções de ambiente de execução são:

- void omp_set_num_thread(int numero_thread) - esta função define o número padrão de threads que será criado na região paralela;

- int omp_get_num_thread0 - esta função retorna o número de threads que estão sendo executadas por uma região paralela;

- int omp_get_thread_num0 - a função retorna o identificador da thread dentro do time, por exemplo, se esta função foi chamada pela thread master o numero retornado por ela será zero;

- int omp_get_num_procs0 - esta função retorna o número de processadores disponíveis no momento da chamada. 


\section{APÊNDICE B - Desenvolvendo com Pthreads}

Neste apêndice, assim como no apêndice A, são apresentadas algumas formas e funções que auxiliam e facilitam o desenvolvimento de programas paralelos utilizando a API Phtreads.

a) Introdução

O Pthreads é uma API que possui um conjunto de mais de 60 funções, estas funções são divididas em 3 grupos (LAWRENCE, 2003) (TORELLI \& MALARA, 2003), de acordo com sua finalidade. Os grupos são:

- Gerenciamento de threads: neste grupo se enquadram as funções utilizadas para a manipulação das threads. Algumas funções que pertencem a este grupo são as funções de criação, finalização, definição de atributos, entre outras.

- Mutexes: este grupo possui as funções de exclusão mutua. Estas funções são responsáveis pela sincronização das threads. Algumas funções existentes são de criação, destruição, bloquear e desbloquear mutexes.

- Variáveis de condição: assim como nos mutexes, as variáveis de condição são utilizadas para a sincronização de threads. O que difere os mutexes das variáveis de condição é que, esta última, bloqueia um thread dependendo do valor existente em uma variável. Neste grupo, existem funções de criação, destruição, espera e sinal.

Por convenção, todos os nomes de funções existentes do POSIX Threads iniciam como Pthreads.

b) Iniciando e criando um thread 
Para programar, utilizando o POSIX Threads, é necessário que esteja incluso no cabeçalho do programa à biblioteca Pthreads.h.

Tipicamente, todo o programa inicia com uma única thread executando, é a chamada thread principal, que tem seu início com o início da execução do programa. A partir dessa thread é necessário criar explicitamente todas as outras threads, essas threads podem criar outras threads e assim sucessivamente.

Para criar uma nova thread, o programador deve fazê-lo explicitamente, utilizando a função Pthreads_create. Esta função possui a seguinte nomenclatura:

\begin{tabular}{l} 
int Pthreads_create(Pthreads *threadid, const Pthreads_attr_t ${ }^{*}$ threadattr, void \\
${ }^{*}\left({ }^{*}\right.$ start_routine) $\left(\right.$ void $\left.{ }^{*}\right)$, void ${ }^{*}$ arg); \\
threadid - se a thread foi criada corretamente o threadid irá conter o identificador da \\
thread. \\
threadattr - este parâmetro configura os atributos da thread. Se o programador quiser \\
utilizar os atributos padrões, basta colocar NULL neste atributo. \\
\hline start_routine - neste parâmetro o programador deve definir qual será a primeira rotina \\
C que a thread irá executar após ter sido criada. \\
\hline arg - a passagem de parâmetros para a rotina constante em start_routine, será feita \\
através desse parâmetro. E, somente um argumento poderá ser passado. Se nenhum \\
argumento for necessário, basta colocar NULL.
\end{tabular}

\section{c) Terminando um thread}

O término de uma thread, pode ocorrer de diversas maneiras. As mais frequientemente utilizadas são: o término explícito da thread, através da função Pthreads_exit, ou implicitamente, quando a start_routine encerra sua execução.

Caso a thread principal, ou seja, a função main 0 , tenha terminado a sua execução implicitamente, sem realizar a chamada a função Pthreads_exit), as threads secundárias, que foram criadas a partir da função main), serão igualmente terminadas, mesmo que não tenham chegado ao final de sua execução. Para garantir que as threads secundárias continuem a sua execução, mesmo após o término da thread principal, a thread principal deve ser encerrada explicitamente utilizando a função Pthreads_exit().

A função Pthreads_exit() possui a seguinte nomenclatura: void Pthreads_exit(void *status); 
Status - esse parâmetro pode ser utilizado pelo programador para determinar um código de término.

Na Figura B.l, é ilustrado um exemplo de utilização dos conceitos básicos do Pthreads (LAWRENCE, 2003). Na linha 15, os threads são criados e cada um chama a função da linha quatro, PrintHello, passando para a função o id da thread.

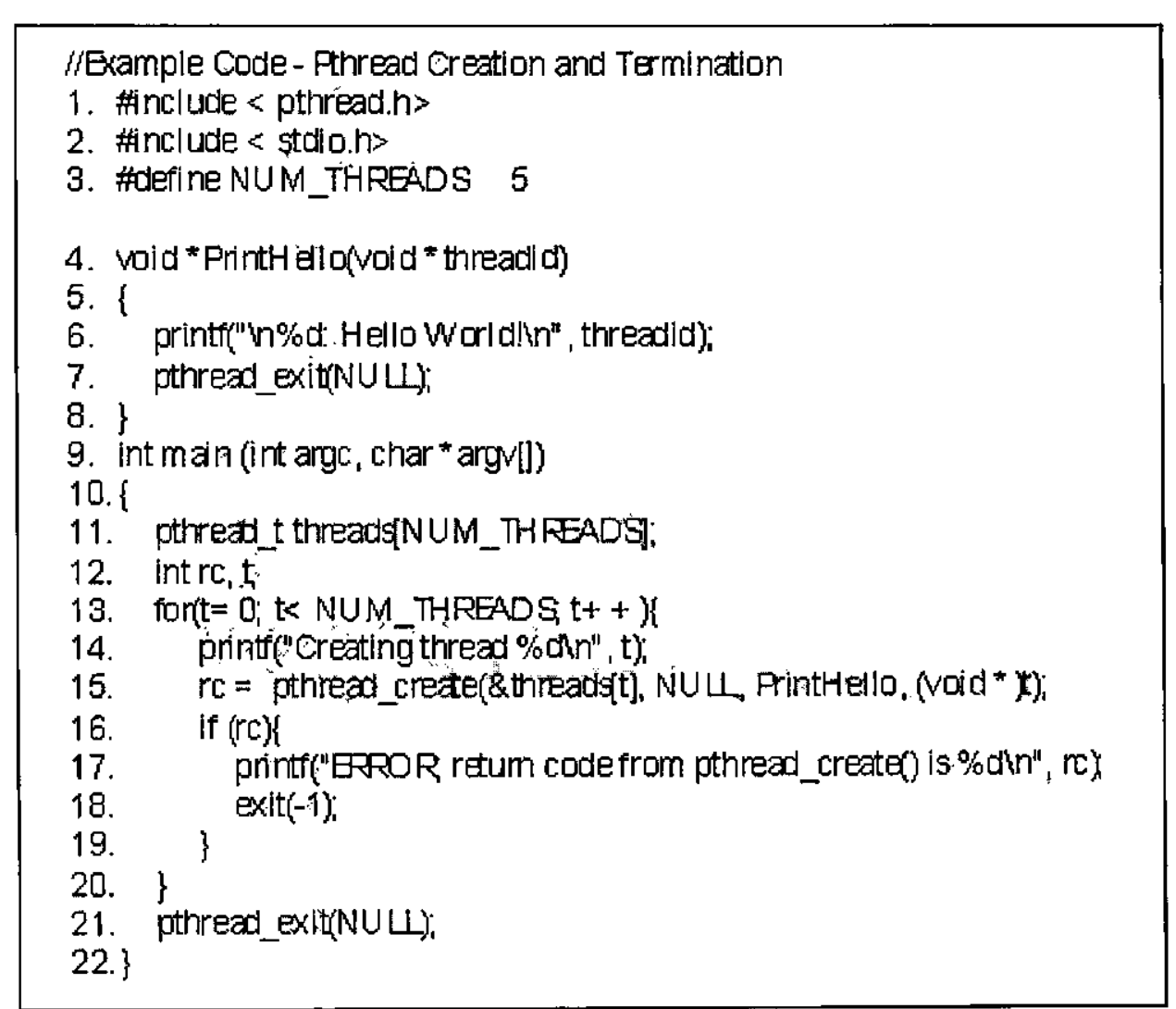

Figura B.1 Exemplo de programa utilizando as funções básicas do Pthreads

\section{d) Passando parâmetros para o thread}

A passagem de parâmetros requer uma atenção especial, pois o Pthreads aceita somente o envio de um parâmetro para a rotina. Dessa forma, faz necessário criar uma estrutura para que mais de um parâmetro seja passado como parâmetro para a função inicial da thread. Para a passagem de parâmetro, é necessário que este seja passado por referência e que se realize um casting para o tipo void: (void *). O exemplo apresentado na Figura B.2, ilustra a passagem de parâmetros utilizando uma estrutura. 


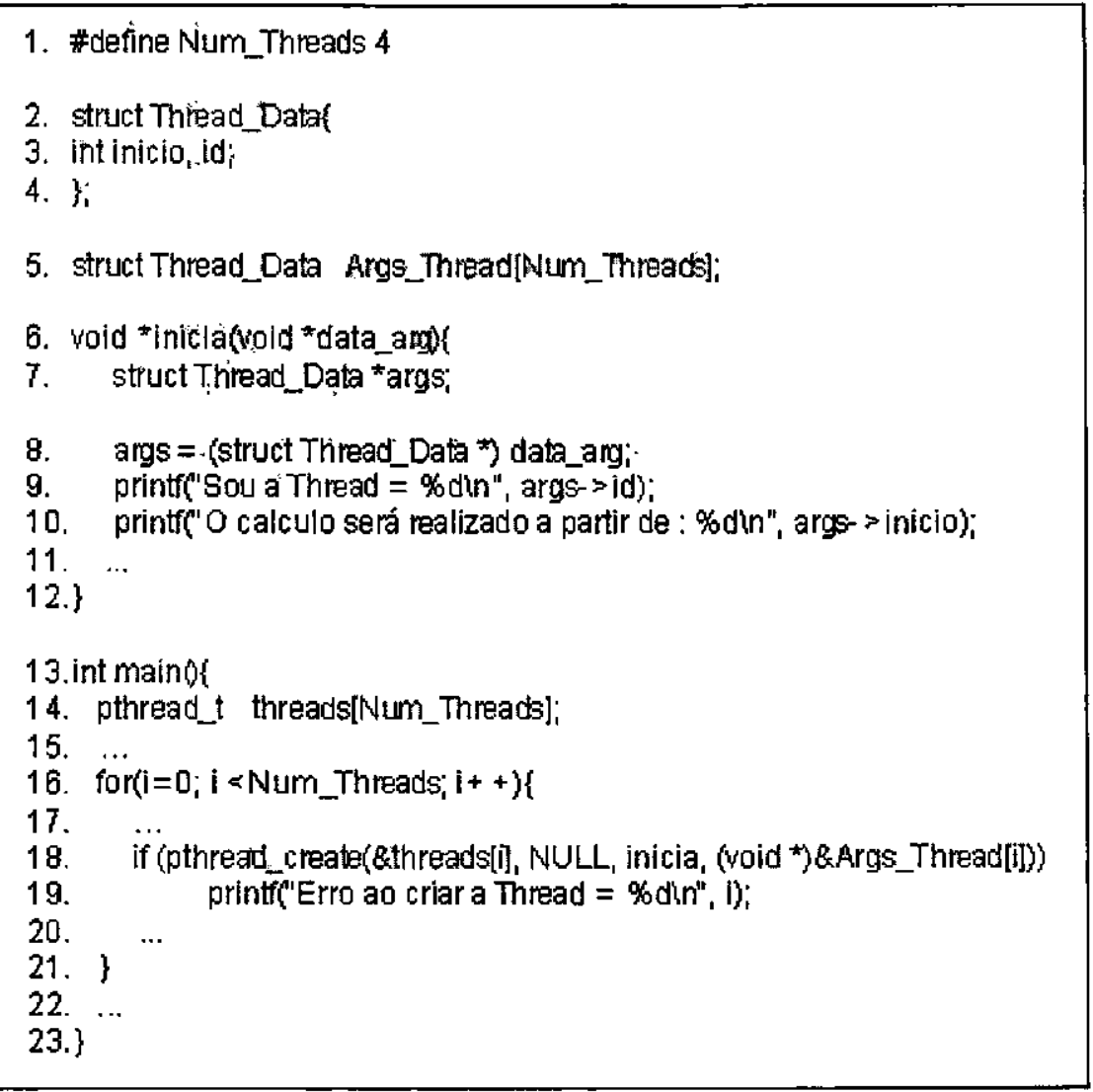

Figura B.2 Exemplo de passagem de parâmetros

\section{e) Aguardando o término de um thread}

Para aguardar a conclusão de um thread o Pthreads possui a rotina join. Esta função permite ao programador bloquear a execução de uma thread até que outra thread, definida como parâmetro da função, termine. A nomenclatura da função é: int Pthreads_join(Pthreads_t threadid, void **status); threadid - Indica de qual thread que se deve aguardar a conclusão, para que a thread que chamou o Pthreads join continue a execução. status - Ao finalizar a execução da thread definida pelo threadid, esta pode fornecer um código de término através da função Pthreads_exit(void *status) e esse código é retornado no parâmetro status da função Pthreads join. 


\section{APÊNDICE C - Desenvolvendo com MPI}

O MPI usa objetos chamados comunicadores e grupos (communicators and group) para definir quais coleções de processos podem se comunicar entre si. Muitas rotinas do MPI utilizam esse comunicador com argumento, para poder realizar a comunicação. Um comunicador simples já é definido pelo MPI para realizar diversas tarefas é o MPI_COMM_WORLD, que pode ser usado na maioria dos casos.

Dentro do comunicador, cada processo tem um identificador único. Para identificar um único processo nessa coleção de processos o comunicador associa um valor inteiro para cada um dos processos no momento de sua criação. Esse identificador único é chamado de rank. Este rank, o programador utiliza para especificar o processo de origem e o de destino para enviar as mensagens.

As funções e rotinas do MPI para o $\mathrm{C}$ e $\circ \mathrm{C}++$ seguem o padrão MPI_Xxxx_xxxx 0 . Nos itens a seguir serão vistos algumas das principais funções do MPI.

\section{a) Rotinas de gerenciamento de ambiente}

Serão descritas algumas das rotinas utilizadas para o controle e a identificação dos processos no MPI.

- MPI_Init(\&argc, \&argv) - Esta função inicializa o ambiente de execução do MPI. Esta função deve ser chamada em todos os programas MPI e antes que qualquer outra função do MPI seja chamada.

- MPI_Comm_size(comm, \&size) - Determina o número de processos no grupo associados ao mesmo comunicador.

- MPI_Comm_rank(comm, \&rank) - Retorna o identificador do processo no grupo. Esta função, é freqüentemente utilizada para determinar quais processos poderão executar um determinado bloco 
de instruções.

- MPI_Finalize0 - Termina o ambiente de execução do MPI. Esta função deve ser a última função MPI que deve ser chamada.

\section{b) Rotinas de comunicação}

As rotinas de comunicação, se dividem em dois grupos: as rotinas de comunicação ponto a ponto e as rotinas de comunicação coletiva. Nas rotinas de comunicação ponto a ponto, a comunicação é realizada entre pares, ou seja, a comunicação é feita única e exclusivamente entre dois processos. Essas rotinas podem ser de dois tipos, as bloqueantes e as não-bloqueantes. Já as rotinas de comunicação coletiva, permitem a comunicação entre dois ou mais processos, podendo, por exemplo, realizar a comunicação de um processo para todos, ou de todos para um.

As duas rotinas de comunicação ponto a ponto mais importantes são:

- MPI_Send(buffer, count, type, dest, tag, comm) - envia dados, contido no buffer, para o processo destino especificado no argumento dest. O argumento count é a quantidade de dados do tipo type que será enviado. $O$ argumento tag é utilizado pelo programador para identificar uma mensagem. E o argumento comm indica qual é o grupo de comunicação do processo.

- MPI_Recv(buffer, count, type, source, tag, comm, status) - recebe a quantidade, count, de dados do tipo type do emissor especificado em source e armazena os dados no buffer. $\mathrm{O}$ argumento tag indica qual mensagem que o receptor deverá receber e o argumento status irá conter o emissor da mensagem e o identificador (tag) da mensagem.

As rotinas de comunicação em grupo podem ser definidas em três tipos: as rotinas de sincronização, de troca de mensagem e as de computação coletiva. Exemplos de algumas dessas rotinas são observados na Figura C.1 e na Figura C.2 é demonstrado um programa exemplo utilizando algumas das rotinas MPI apresentadas. Algumas dessas rotinas são:

- MPI_Bcast(\&buffer, count, type, root, comm) - Envia dados do processo com rank "root", que é o processo 0 , para todos os outros 
processos pertencentes ao grupo de comunicação. Esse tipo de comunicação de um para todos é denominada broadcast. Na Figura C.1 (a) é demonstrado um exemplo de broadcast.

- MPI_Scatter(\&buffer, count, type, \&recvbuf, recvcount, recvtype, root, comm) - envia mensagens distintas do destinatário para cada processo do grupo. Um exemplo pode ser observado na Figura C.1 (b).

- MPI_Gather(\&sendbuf, sendent, sendtype, \& recvbuf, recvcount, recvtype, root, comm) - Um destinatário recebe mensagens distintas de cada um dos processos do grupo. Um exemplo pode ser observado na Figura C.1 (c).

- MPI_Reduce(\&sendbuf, \&recvbuf, count, datatype, op, root,comm) - Aplica a operação de redução para todos os processos e armazena o resultado em um dos processos. Algumas das operações de redução, são a adição, o produto, o valor máximo, o valor mínimo, dentre diversas outras. Um exemplo da operação de adição pode ser observada na Figura C.1 (d).

- MPI_Barrier (comm) - cria uma barreira para sincronizar todos os processos de um mesmo grupo. Os processos do grupo quando alcançarem a barreira deverão aguardar até que todos os outros processos do grupo tenham alcançado a barreira para depois prosseguirem a sua execução. 


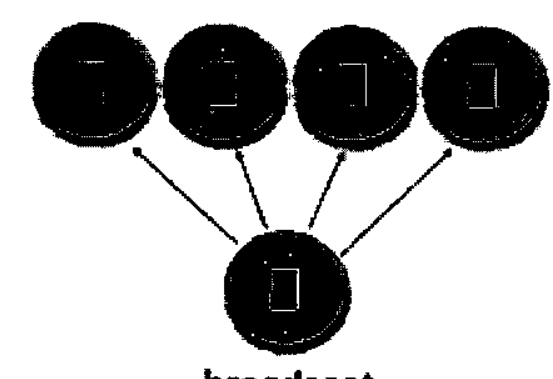

broadcast

(a)

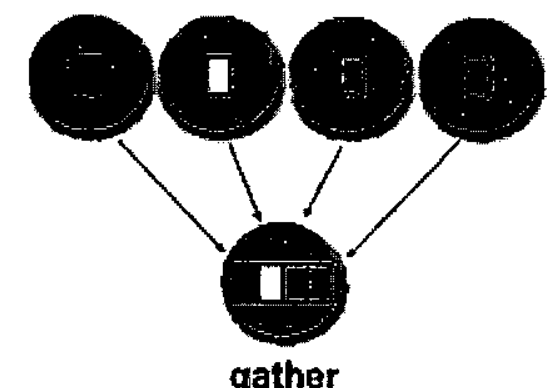

(c)

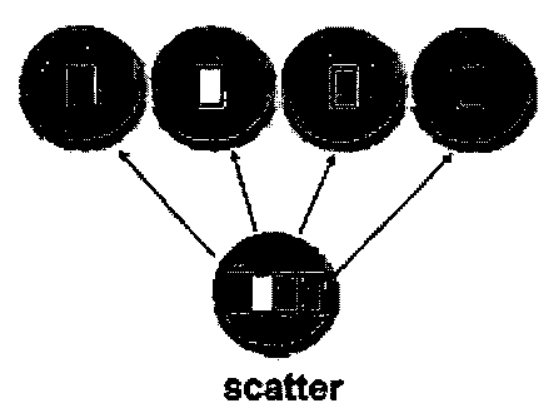

(b)

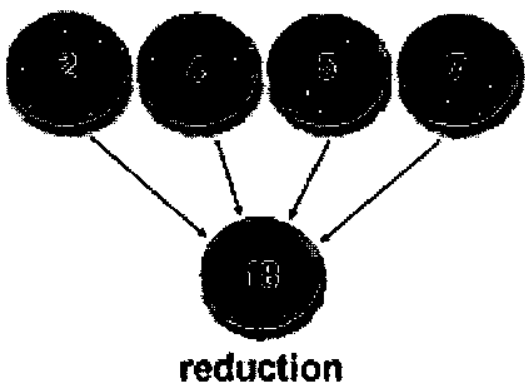

(d)

Figura C.1 Exemplos de comunicação coletiva. (a) broadcast, (b) scatter, (c) gather, (d) redução.

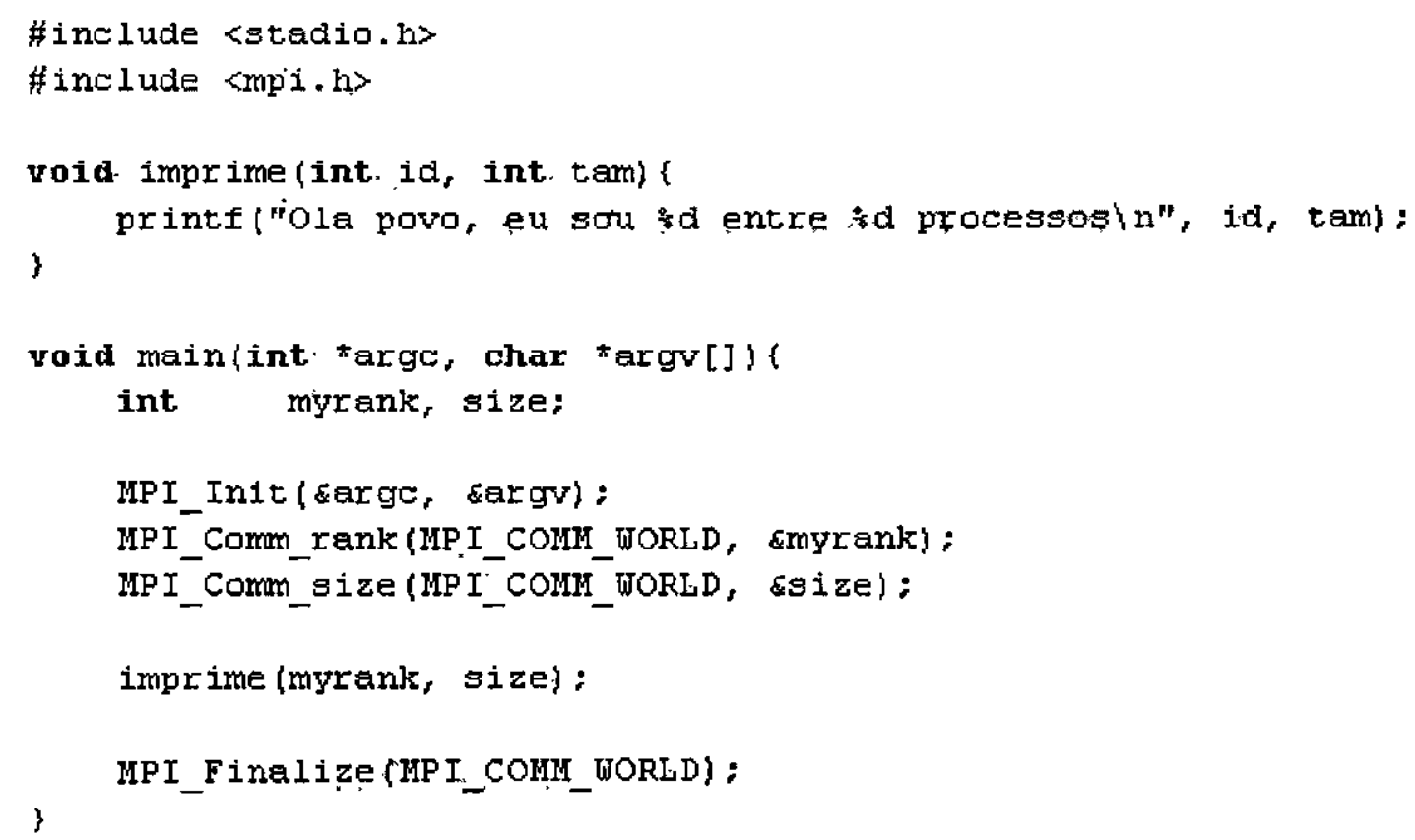

Figura C.2 Exemplo de programa MPI 